SAND84-7109

Unlimited Release

UC-66c

\title{
Evaluation of Borehole Electromagnetic and Seismic Detection of Fractures
}

Hsi-Tien Chang Geothermal Technology Development Division 6241 Sandia National Laboratories Albuquerque, NM 87185

S. A. Suhler, T. E. Owen Department of Geosciences Southwest Research Institute San Antonio, TX 78284

Prepared by Sandia National Laboratories Albuquerque. New Mexico 87185 and Livermore, California 94550 for the United States Department of Energy under Contract DE-AC04-76DP00789

Printed February 1984

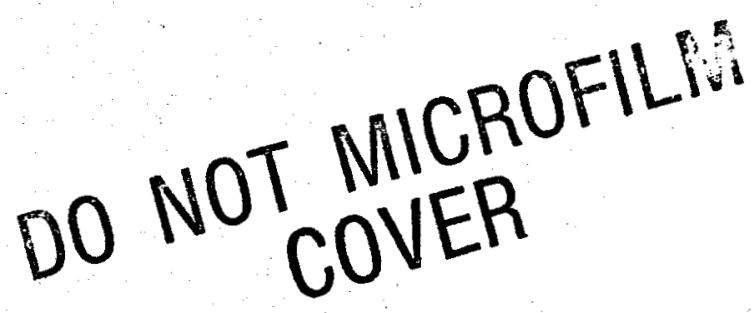




\section{DISCLAIMER}

This report was prepared as an account of work sponsored by an agency of the United States Government. Neither the United States Government nor any agency Thereof, nor any of their employees, makes any warranty, express or implied, or assumes any legal liability or responsibility for the accuracy, completeness, or usefulness of any information, apparatus, product, or process disclosed, or represents that its use would not infringe privately owned rights. Reference herein to any specific commercial product, process, or service by trade name, trademark, manufacturer, or otherwise does not necessarily constitute or imply its endorsement, recommendation, or favoring by the United States Government or any agency thereof. The views and opinions of authors expressed herein do not necessarily state or reflect those of the United States Government or any agency thereof. 


\section{DISCLAIMER}

Portions of this document may be illegible in electronic image products. Images are produced from the best available original document. 


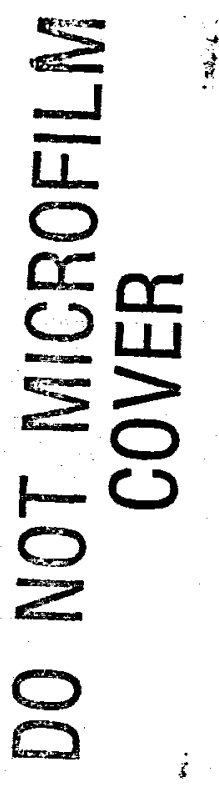

Issued by Sandia National Laboratories, operated for the United States Department of Energy by Sandis Corporation.

NOTICE: This report was prepared es an account of work aponsored by an agency of the United States Government. Neither the United States Government nor any agency thereof, nor any of their employees, nor any of their contractors, mubcontractors, or their employees, makes eny warranty, express or implied, or essumes any legal liability or responsibility for the accuracy, completeness, or usefulness of any information, apparatus, product, or process disclosed, or represents that its use would not infringe privately owned rights. Reference herein to eny specific commercial product, process, or ervice by trade name, trademark, manufacturer, or otherwise, does not necessarily constitute or imply its endorsement, recommendation, or favoring necessarify constitute or imply its endorsement, recommendation, or favoring contractors or ubcontractors. The views and opinions expressed herein do not necessarily atate or reflect those of the United States Government, any ezency thereof or any of their cantractors or eubcontractors.

Printed in the United States of America Available from

National Technical Information Service

U.S. Department of Commerce

5285 Port Royal Road

Springfield, VA 22161

NTIS price codes

Printed copy: $\mathbf{A 0 5}$

Microfiche copy: $\mathbf{A 0 1}$ 


\section{EVALUATION OF BOREHOLE ELECTROMAGNETIC AND SEISMIC} DETECTION OF FRACTURES

$$
\text { SAND 84-7109 }
$$

Hsi-Tien Chang

Geothermal Technology Development Division, 6241 Sandia National Laboratories

Albuquerque, New Mexico 87185

SAND $-84-7109$

DE84 009507

\author{
S. A. Suhler \\ T. E. Owen \\ Department of Geosciences \\ Southwest Research Institute \\ San Antonio, Texas 78284
}

\section{ABSTRACT}

Experiments were conducted to establish the feasibility of downhole high-frequency techniques for location of fractures in the vicinity of boreholes. An existing flame-cut slot in granite was filled with salt water to simulate a brine-filled fracture. The first method used an electromagnetic wave at 30 to $300 \mathrm{MHz}$, VHF frequencies. A transmitter consisting of a phased dual-dipole array arranged to provide a directional signal toward the fracture was installed in a borehole opposite the fracture. A receiver was also located in the same borehole. The radar returns from the simulated fracture were detectable in boreholes located at distances of up to 12 meters from the fracture. These results indicate for the first time the feasibility of a downhole VHF radar for use in a single borehole for detection of fractures located away from the borehole.

Similar experiments were also conducted using seismic waves at 4.5 to $6 \mathrm{KHz}$. The transmitter and the receiver in this case were located in separate boreholes. During this experiment, reflections from the slot were obtained only with the transducers orlented for shear wave lllumination and detection. These results suggest that a high-frequency shear wave can also be used to detect fractures away from a borehole.

\section{DISCLAIMER}

This report was prepared as an account of work sponsored by an agency of the United States Government. Neither the United States Government nor any agency thereof, nor any of their employees, makes any warranty, express or implied, or assumes any legal liability or responsibility for the accuracy, completeness, or usefulness of any information, apparatus, product, or process disclosed, or represents that its use would not infringe privately owned rights. Reference herein to any specific commercial product, process, or service by trade name, trademark, manufacturer, or otherwise does not necessarily constitute or imply its endorsement, recommendation, or favoring by the United States Government or any agency thereof. The views and opinions of authors expressed herein do not necessarily state or reflect those of the United States Government or any agency thereof. 
TABLE OF CONTENTS

$\begin{array}{lc}\text { ABSTRACT } & \frac{\text { Page }}{\text { i }} \\ \text { LIST OF ILLUSTRATIONS } & \text { iv } \\ \text { LIST OF TABLES } & \text { vii }\end{array}$

I. INTRODUCTION 1

II. INSTRUMENTATION

A. Directional Borehole Radar Probe 2

1. Technical Specifications 2

2. Operating Functions 4

B. Hole-to-Hole Electromagnetic Probe 4

1. Basic System 7

2. Technical specifications 8

C. Borehole Seismic Equipment 9

D. Probe Handling and Data Recording Equipment 10

III. TEST SITE 12

A. Location and Description. 12

B. Site Preparation 12

$\begin{array}{ll}\text { IV. EXPERIMENTAL PROCEDURES } & 18\end{array}$

A. Auxiliary Experiments 18

1. Preliminary Site Evaluation Tests 18

2. Radar Antenna Directivity Experiments 21

B. Fracture Detection Experiments-Summary 28

1. Echo-Ranging Experiment Plan 28

2. Radar Data Acquired 28

3. Hole-to-Hole Electromagnetic Data 28

4. Seismic Reflection Data 31 
TABLE OF CONTENTS (cont'd)

Page

V. TEST RESULTS

A. Directional Radar Experiments 33

1. Air-Filled Target Slot Tests 33

2. Metal Reflector Tests 34

3. Conductive Fluid Tests 40

B. Hole-to-Hole Electromagnetic Reflection Tests $\quad 47$

1. Dry Target Slot Experiments 47

2. Target Slot Filled with Conductive Fluid 47

C. Seismic Experiments 53

1. Probe Orientation Experiments 53

2. Reflection Tests Without Water in Target slot 59

3. Reflection Test with Water in the Target Slot 62

VI. CONCLUSIONS AND RECOMMENDATIONS 69

VII. BIBLIOGRAPHY

VIII.DISTRIBUTION 


\section{LIST OF ILLUSTRATIONS}

1gure No:

1

2

3

4

5

6

7

8

9

10

11

12

13

System Block Diagram of Borehole Directional Radar Probe

Page

Surface Contro1 Unit

115 VDC Probe Power Supply 6

Simpiffed Illustration of the Hole-to-Hole Electromagnet1c System

SwR Logging Van on Site

Texas Pearl Granite Quarry, Texas Granite

Corporation, Marbie Falls, Texas

Layout Pian of Test Site at Texas Pearl Quarry $\quad 14$

Test Site at Texas Pearl Quarry $\quad 16$

Liquid Handifig Operations at Test site $\quad 17$

Layout of Transmiter and Recelver Probes for

Electromagnetic parameter Experiments

Borehole Radar Directional Antenna Test Results

Radar In 4.75 Inch Diameter Borehole, Eight Meters from Recelver in siot in Granite (230 Magnetic Heading from Radar to Recelver)

Borehole Radar Directional Antenna Test Results

Radar in 4.75 Inch Diameter Borehole, 12 Meters from Receiver in SIot in Granite (230' Magnetic Heading from Radar to Receiver)

Borehole Radar Directional Antenna Test Results

Radár in 4.75 Inch Diameter Borehole, 4.0 meters from Recelver In 4.75 Inch Diameter Borehole In Grante ( $50^{\circ}$ Magnetic Heading from Radar to Recelver)

Borehole Radar Directional Antenna Test Results

Radar In 4.75 Inch Dlameter Borehole 8.0 Meters from Recelver In 4.75 Inch Diameter Borehole In Granite ( $50^{\circ}$ Magnetic Heading from Radar to Recelver) 


\section{LIST OF ILLUSTRATIONS (cont'd)}

Figure No.

$\underline{\text { Page }}$

15

16

17

18

19

$45^{\circ}\left(225^{\circ}\right)$ Antenna Position Radar Response From Borehole

No. 1, Air Filled Target slot

Radar Signal with Probe in Borehole 2, Target S1ot Dry

Radar Signals with Probe in Borehole 3, Target Slot Dry

Raw Data Waveforms with Probe in Borehole 1, Metal Reflector in Target slot

Radar Signals with Probe in Borehole 1, Metal Reflector in Target Slot

Radar Signals with Probe in Borehole 1, Metal

Reflector in Target Slot

Constant Angle Scans of Borehole 1 with 10.1 Ohm Centimeter Brine in Target slot

Constant Depth Scan
Brine in Target Slot

Radar Probe in Borehole 2, Constant Angle Scan, 10.1 Ohm Centimeter Resistivity Brine in Target Slot

Radar Probe in Borehole 2, Constant Depth Scan, 10.1 Ohm Centimeter Resistivity Brine in Target Slot

Radar Probe in Borehole 1, $16.0 \mathrm{Ohm}$ Centimeter

Resistivity Brine in Target slot

Radar Probe in Borehole 2, 16.0 Ohm Centimeter

Resistivity Brine in Target Slot

Radar Probe In Borehole 3, 16.0 Ohm Centimeter

Resistivity Brine in Target Slot

Hole to Hole Electromagnetic Tests, Receiver in Borehole 2 Transmitter in Borehole 3, Target Slot Dry

Hole to Hole Electromagnetic Tests, Receiver in Borehole 1 Transmitter in Borehole 3, Target slot Dry

Hole to Hole Electromagnetic Tests, Receiver in Borehole 4 
Borehole 2, Transmitter in Borehole 1, 260 Ohm Centimeter Brine in Target slot

Hole to Hole Electromagnetic Tests, Transmitter Fixed in

Borehole Seismic Common Depth Scan, Receiver in Borehole 1

Transmitter in Borehole 2, Transducer Orientation - $R / 180^{\circ}$, $\mathrm{T} / 0^{\circ}$, Target Slot Dry

Borehole Seismic offset Scan, Receiver Fixed at 6 Meters in Borehole 1, Transmitter in Borehole 2, Transducer Orientation $\mathrm{R} / 180^{\circ}, \mathrm{T} / 0^{\circ}$, Target Slot Dry

Borehole Seismic Common Depth Scan, Receiver in Borehole 2, Transmitter in Borehole 3 , Transducer Orientation - $R / 180^{\circ}$, $\mathrm{T} / 0^{\circ}$, Target Slot Dry $\mathrm{T} / 0^{\circ}$, Target slot Dry $\mathrm{T} / 0^{\circ}$, Target Slot Dry

Transmitter in Borehole 2, Transducer Orientation - $R / 180^{\circ}$, $\mathrm{T} / 0^{\circ}$, Target slot Water Filled $\mathrm{T} / 0^{\circ}$, Target slot Water Filled $\mathrm{T} / 270^{\circ}$, Target Slot Water Filled 


\section{LIST OF TABLES}

Table No.

Page

I

Preliminary Electromagnetic Parameter Tests

19

II

Preliminary Seismic Parameter Tests

22

III

Effects of Borehole Fluid Resistivity on Directional

23

IV Antenna Performance

v

Summary of Radar Data

VI

Summary of Hole-to-Hole Electromagnetic Data

Summary of Seismic Data

32 


\section{INTRODUCTION}

The conduction of hot fluids into geothermal wells is, at least, partially dependent upon the presence of natural or artifically induced fractures in the geothermaily active rock matrix. Because of the very high cost of driliing and fracturing in geothermal areas, it is economically critical that technigues for detecting natural or induced fractures be developed. A very desirable technique for detecting and locating such fractures is one which employs a borehole probe operating from a single hole. In this report, two candidate fracture detection techniques were evaluated. Both techniques employ propagating wave energy and rely on reflections from the fractures for detection purposes.

One of the methods is a pulsed-echo electromagnetic technique in which an electromagnetic pulse is launched into the drilled formation from a borehole probe by means of a directional transmitting antenna at the depth of interest in the hole. Reflections from fractures or other geologic structures which exhibit a contrast in electromagnetic properties are detected by a receiving antenna in the same probe. The second method evaluated is a borehole seismic reflection technique in which a seismic Impulse is launched into the formation and reflections from reglons of contrasting elastic wave impedance are detected. With either technique, distance to the reflecting anomaly from the probe is determined from the two-way pulse travel time between the probe and the target and the known propagation velocity of the host medium. The reflection signal waveforms provide unique information regarding the size, shape, and character of the reflector.

The reported evaluation tests were performed using probe systems developed by Southwest Research Institute for the U.S. Bureau of Mines and for the U.S. Army. These systems, described in detail later, are basically geotechnical probes intended for use in shallow (1000 feet or less) vertical or horizontal boreholes.

To exhibit the use of these avaliable probe systems in a minimumcost preliminary evaluation experiment, a test site was sought that would provide an ldealized target simulating a vertical planar fracture. The test site selected for this purpose was a grante quarry near Marble Fa116. Texas. After preliminary measurements of the seismic and electromagnetic properties of the granite were performed, five vertical test boreholes were drilled into the granite. Probe system output signals were recorded during the field tests in which various combinations of probe configurations and target conditions were evaluated. 
Electromagnetic and seismic probing techniques were evaluated as methods for detecting fractures in granite. The VHF electromagnetic system is capable of operating either in single boreholes as a directional radar probe or as a holeto-hole probe. The seismic system is experimental equipment that employs piezoelectric source and receiver transducers to launch and detect seismic impulses in the drilled formations. These systems were developed for the U.S. Bureau of Mines, Denver Research Center, under Mining Safety and Health programs. The radar probe was developed for detecting hazards in advance of coal mining from vertical boreholes. The seismic system. Is a prototype borehole seismic velocity probe developed to measure seismic velocity in coal and coal measure rocks from dry horizontal or vertical boreholes. The equipment was provided by the Bureau of Mines on loan to Southwest Research Institute.

\section{A. Directional Borehole Radar Probe}

The electromagnetic probe is a VHF video-pulse radar consisting of a Borehole Probe and a Surface Control Unit. The following description pertains to the basic functions of these two assemblies and gives a concise listing of the electrical and mechanical specifications of each component.

1. Technical Specifications

a. Borehole Probe

(1) Radar Transmitter

Pulse Repetition Frequency:

Power Output:

Pulse Width:

Temporature range:

(2) Radar Receiver

Noise Figure:

Bandwidth:

RF Gain:

Time Domain Sampler Window:

Sample Pulse Width:

Sampler Output Time Base:

Temperature range:

(3) Antennas

Transmitter:

Receiver:
Phased Dual-Dipole Array: $18 \mathrm{~dB}$ front-to-back ratio directivity. Mechanical positioning at elght preset azimuthal rotational positions around probe axis:

Electrically short monopole, omnidirectiona1. 
(4) Mechanical

$\begin{array}{ll}\text { Length (w/o centralizers): } & 13.3 \text { feet } \\ \text { Diameter: } & 3.0 \text { inches } \\ \text { Centralizers Length-upper: } & 20.75 \text { inches } \\ \text { Borehole Diameter Range: } & 19.5 \text { inches } \\ \text { Total Probe Weight: } & 4-6 \text { inches } \\ \text { Cable Head: } & 108 \text { pounds } \\ & 4-\text { conductor, } 1.0 \text { inch } \\ \text { Pressure Limit: } & \text { Gearhart-Owen }\end{array}$

\section{b. Surface Control Unit}

\section{(1) Electrical}

Power: $115 \mathrm{VAC}, 60 \mathrm{~Hz}$

Receiver: Antenna position (adjustable in 45-degree segments);

Antenna control (Auto-Manual)

Borehole Orentation (Horizontal/Vertical);

Receiver Gain:

RF: High ( $30 \mathrm{~dB})$; Low ( $0 \mathrm{~dB})$

Early TVG: $0,20,40$, or $60 \mathrm{~dB}$;

Display Rate: $0.2 \mathrm{~Hz}$ or. $20 \mathrm{~Hz}$;

TVG Range: $\quad 0,0.1,0.2$ or $0.5 \mathrm{~dB} / \mathrm{ns}$. *TVG: Time Varying Gain

Outputs: Video Out (Analog Signal)

Sync Out (Analog Signa1)

Antenna Position (Digital)

Display Rate (Digital)

Antenna Control (Digital)

RF Gain (Digital)

Borehole Orientation (Digital)

Early Gain (Digital)

Gain Slope (Digital)

(2) Mechanical

Control Module: Size: Standard NIN Module (4" wide) Weight: 4.75 pounds

Power Supply:

Size: Standard NIM Module (4" wide) Weight: 18.25 pounds

Cabinet:

Size: Standard 19-inch rack mountable NIM bin with power supplies

Welght: 33 pounds

**NIM: Nuclear Instrument Module

(3) Wireline Cable

Type: Conventional 4-conductor armored logging cable.

Length: 2,000 feet (maximum) 


\section{Operating Functions}

The Block Diagram of Figure 1 shows the downhole and surface elements of the Borehole Direction Radar Probe. The Surface Control Unit contains the command and control circuits for the probe. The Surface Control Unit also receives status and receiver output signals from the Borehole Probe and provides adjustable signal conditioning for the received signals.

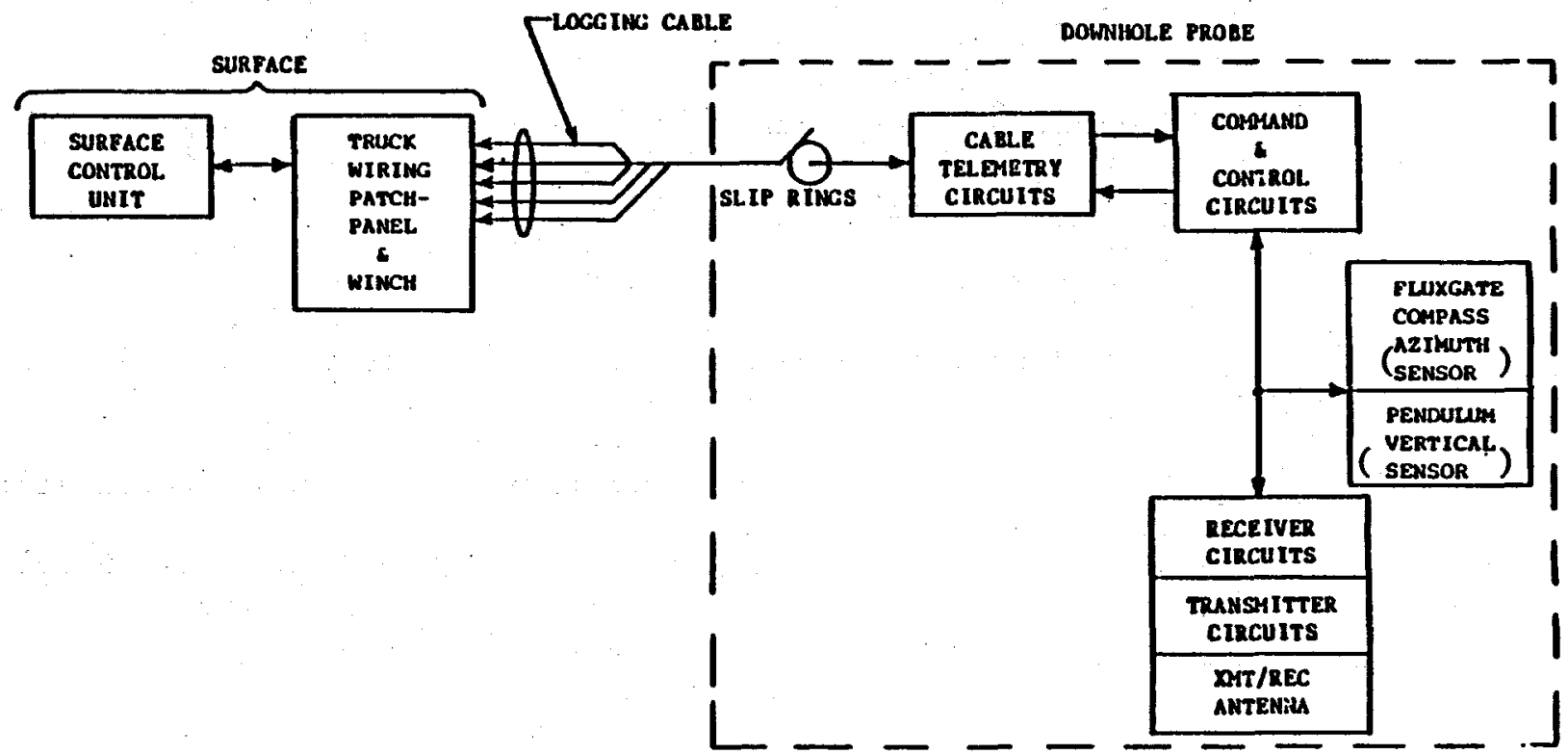

FIGURE 1. SYSTEM BLOCK DIAGRAM OF BOREHOLE DIRECTIONAL RADAR PROBE .

In addition to the radar transmitter and receiver, the Borehole Probe contains a digital communication system which receives and decodes commands downhole and encodes and transmits probe status and video signals to the surface. Antenna position commands from the surface are directed to an antenna rotation circuit which contains position sensors for either vertical or horizontal borehole operation. The antenna section of the probe consists of a directional transmitter antenna and an omnidirectional receiver antenna. Probe functions controlled from the surface include antenna rotation, receiver gain, and receiver video display rate.

The modules which comprise the basic surface equipment are shown in Figures 2 and 3 . Support equipment required to operate the system includes a wireline logging winch with up to 2,000 feet of four-conductor armored cable and a suitable data recording system. The data recording system and the wireline winch system used in the fracture detection tests were furnished by Southwest Research Institute.

B. Hole-to-Hole Electromagnetic Probe

A pulsed VHF electromagnetic system which operates in a completely bistatic mode was employed in several experiments. Hole-to-hole tests were performed to obtain measurements of the electromagnetic propagation velocity and losses in the granite. The system consists of separate borehole transmitter 


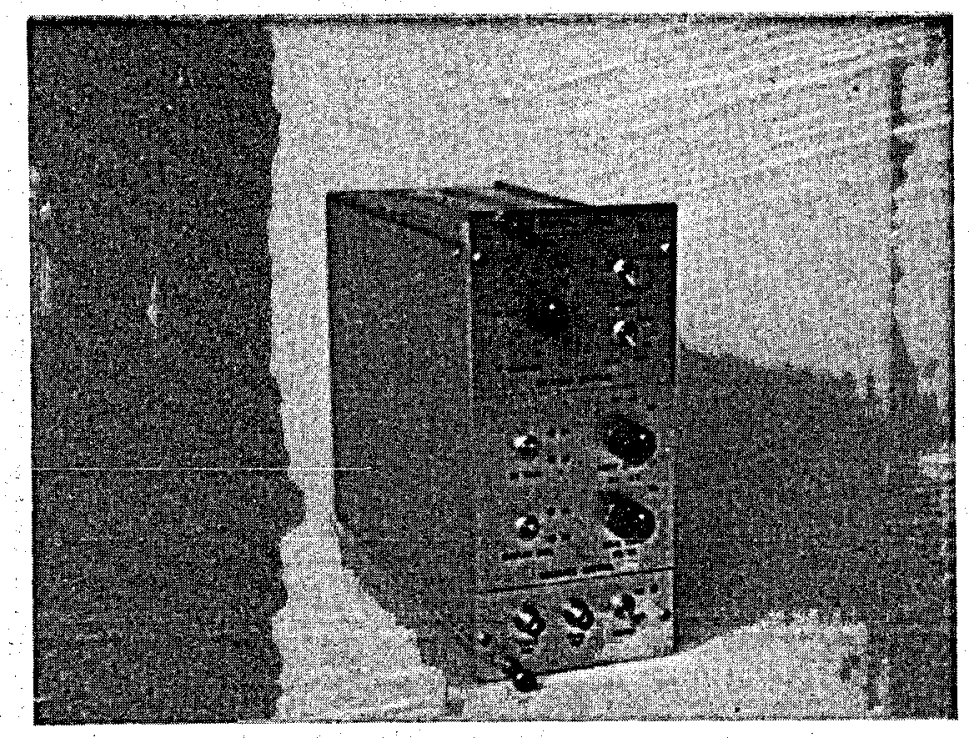

(a) Front Panel

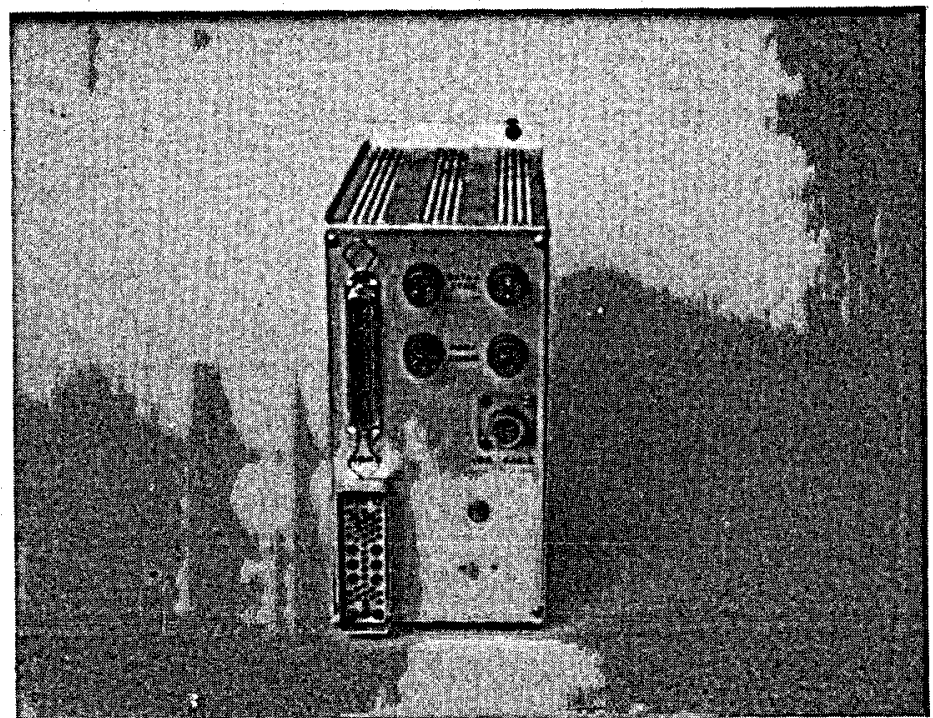

(b) Rear Panel

FIGURE 2. SURFACE CONTROL UNIT 


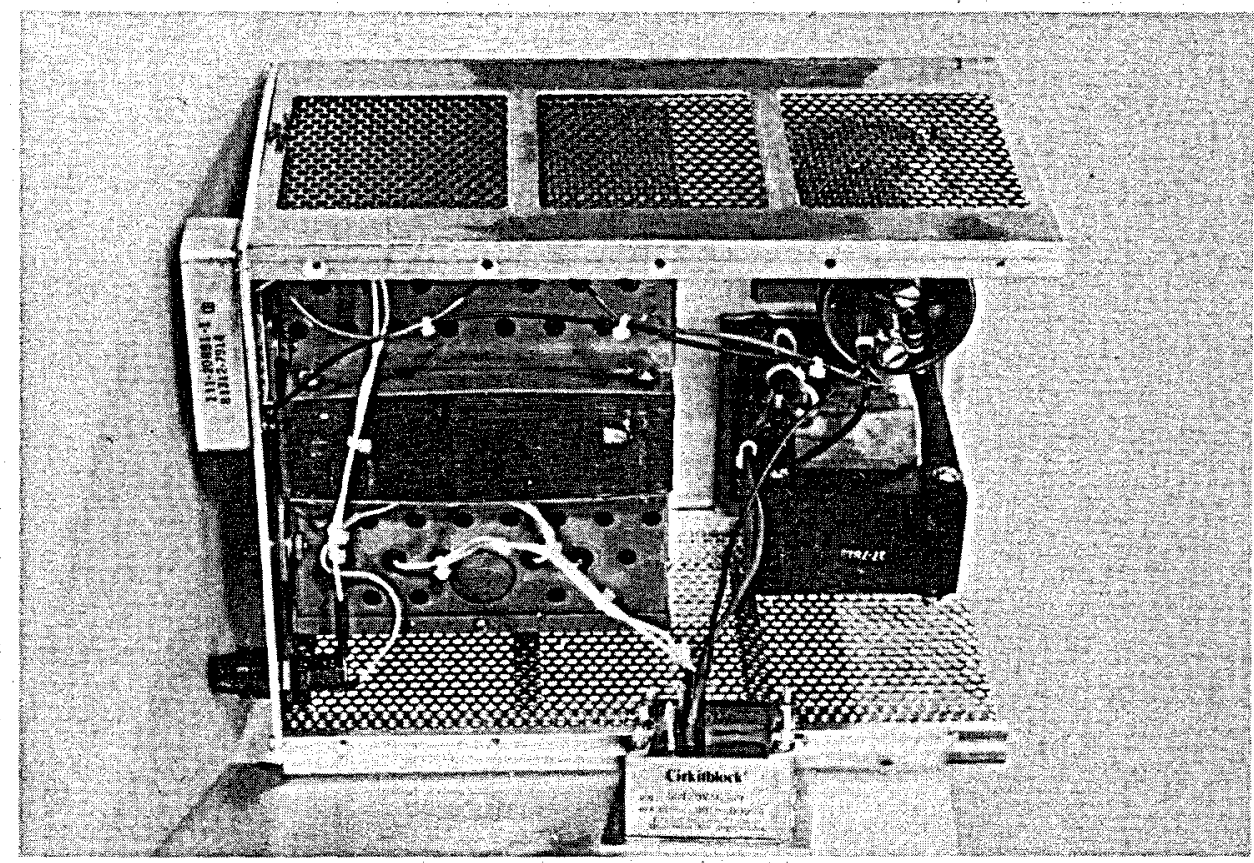

(a) Interior View

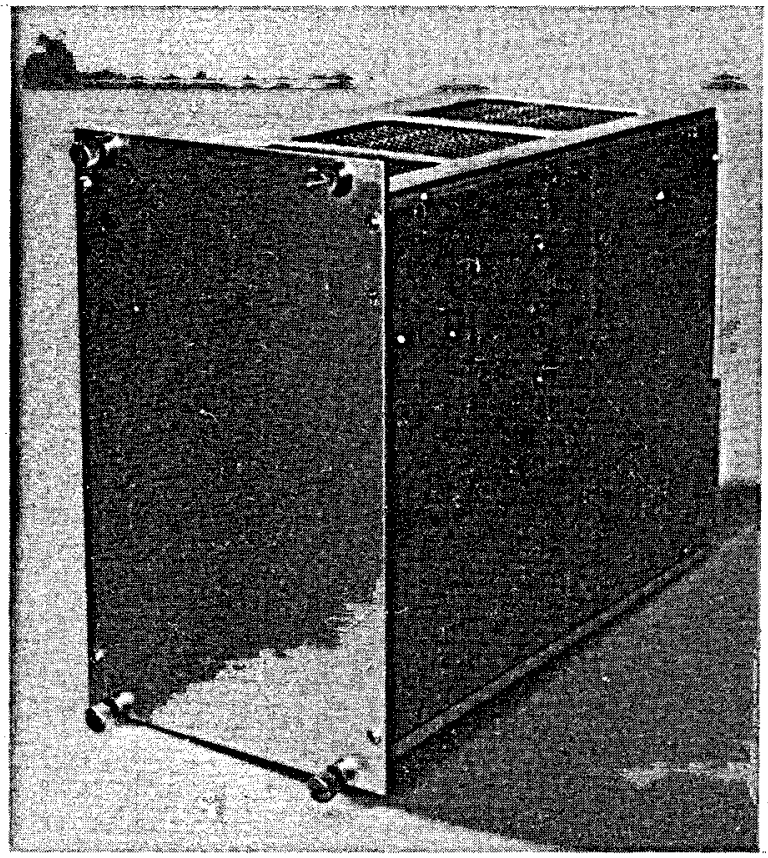

(b) Front Panel

FIGURE 3. 115 VDC PROBE POWER SUPPLY 
and receiver probes and a surface control unit. The transmitter and the synchronized time domain sampling receiver operate in separate boreholes thereby permitting the direct measurement of propagation time over known path lengths. Operating the transmitter or recelver in a third borehole over a distance different from the first path length permits the attenuation in the intervening rock to be determined.

\section{Basic System}

The hole-to-hole ground penetrating electromagnetic system consists of a transmitter probe and a receiver probe and three surface modules as shown in Figure 4. The surface elements of the system consist of the Surface Control Unit, the Digital Recorder Control Unit, the Digital Magnetic Tape Recorder, and the Dual Wireline Winch. These units control and manipulate the borehole probes in the hole-to-hole mode of operation. The digital recording system is employed to provide magnetic tape records for later computer processing.

In operation, short-duration electromagnetic pulses are launched from the transmitter located in one of a pair of boreholes on either side of the region of interest. The receiver is positioned in the adjacent hole to detect

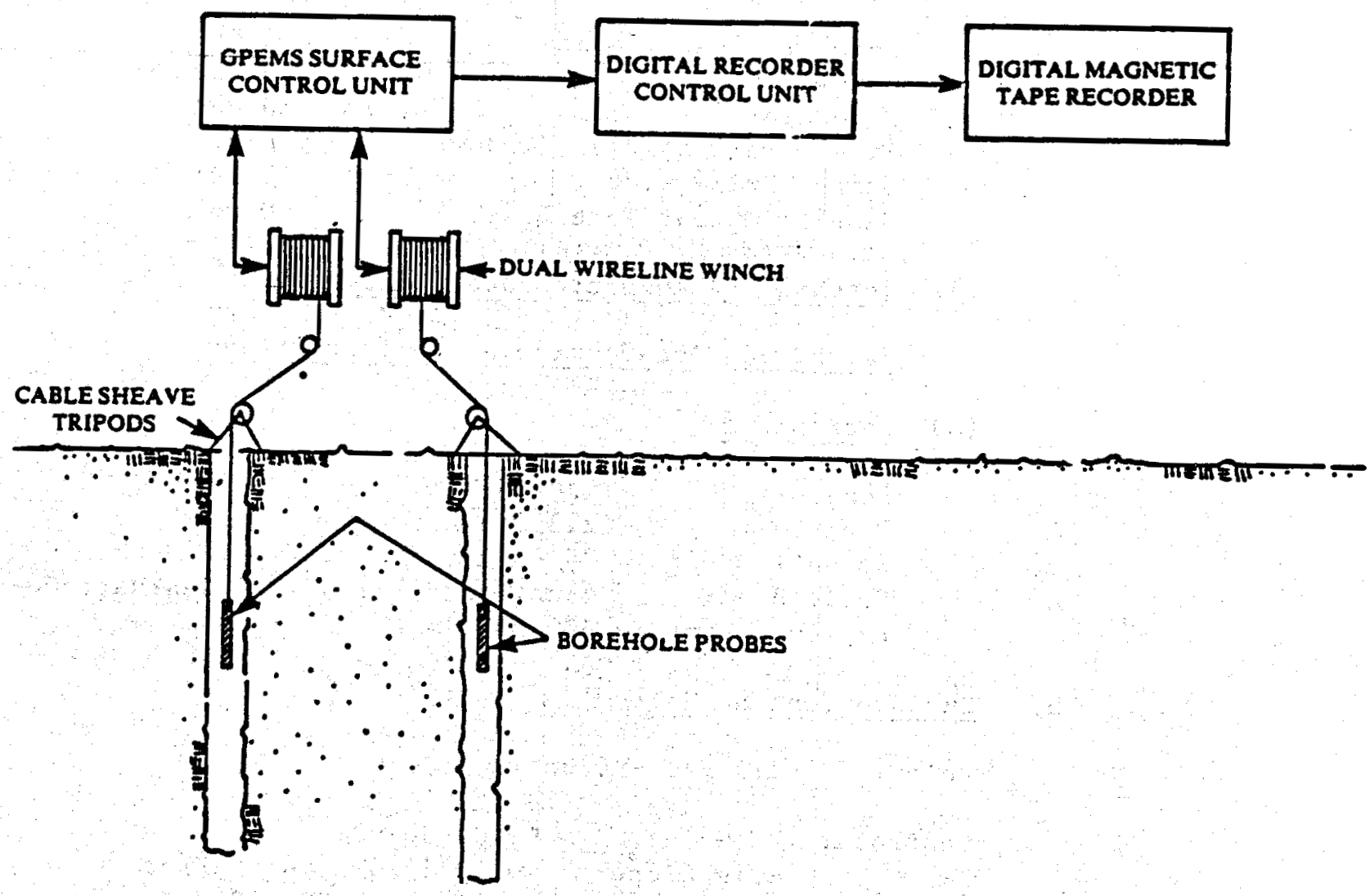

FIGURE 4. SIMPLIFIED ILLUSTRATION OF THE HOLE-TO-HOLE ELECTROMAGNETIC SYSTEM 
the transmitted pulse. The received waveform of the electromagnetic pulse is converted to a low-frequency replica of the real-time pulse by a timedomain sampler and is transmitted to the surface for display on an oscilloscope and for digital recording. In operation, the transmitter and receiver are first located at the same depth below the subsurface region of interest. The two probes are then hoisted together maintaining a common depth while the horizontally transmitted pulse waveforms are continuously recorded as a function of depth along the boreholes. Probe depth is measured by cable odometers on the wireline winches. The recorded signals are processed later by computer.

\section{Technical Specifications}

\section{a. Borehole Probes}

(1) Transmitter

$$
\begin{array}{lc}
\text { Pulse Repetition Frequency: } & 40 \mathrm{kHz} \\
\text { Power Output: } & 6 \mathrm{~kW} \text { (peak) } \\
\text { Pulse Width: } & 10 \mathrm{~ns} \\
\text { Temperature Range: } & 0^{\circ}-85^{\circ} \mathrm{C}
\end{array}
$$

(2) Receiver
Noise Figure:

Bandwidth:

RF. Gain:

Time Domain Sampler Window:

Sample Pulse Width:

Sampler Output Time Base:

Temperature Range:

$$
\begin{aligned}
2.5 \mathrm{~dB} \\
30-300 \mathrm{MHz} \\
0 \text { or } 30 \mathrm{~dB} \\
500 \mathrm{~ns} \\
1 \mathrm{~ns} \\
60 \mathrm{~ms} \\
0^{\mathrm{gS}}-85^{\circ} \mathrm{C}
\end{aligned}
$$

(3) Antennas (transmitter and receiver)

Resistance loaded dipole, omnidirectioanl

(4) Mechanical

$\begin{array}{ll}\text { Length: } & 120 \text { inches } \\ \text { Diameter: } & 2.25 \text { inches } \\ \text { Weight: } & 35 \text { pounds } \\ \text { Cable Head: } & 4-\text { conductor, } 1.0 \text { inch Gearhart-Owen } \\ \text { Pressure Limit: } \quad 500 \text { psi }\end{array}$

b. Surface Control Unit 
c. Recorder Control Unit

\begin{tabular}{|c|c|}
\hline ontrols: & $\begin{array}{l}\text { Borehole Scan Switch } \\
\text { Recording Internal (Thumbwheel) } \\
\text { Odometer Preset (Thumbwhee1) } \\
\text { Odometer Preset (Display) } \\
\text { Odometer Zero } \\
\text { Probe Offset (Thumbwhee 1) } \\
\text { Data ID (Thumbwhee 1) } \\
\text { Recorder Reverse } \\
\text { Recorder Write } \\
\text { Recorder Stop } \\
\text { Recorder Run } \\
\text { Recorder Forward } \\
\text { Recorder Track Advance } \\
\text { AC Power }\end{array}$ \\
\hline
\end{tabular}

d. Dua1-Drum Winch

(1) Cable

Capacity: $\quad 1000$ feet

Type: 7/32" diameter, double armored, 4-conductor

Cable Head: One inch diameter, Gearhart-Owen

(2) Controls

Type: Servo controlled in fixed offset mode;

Speed: Manually adjustable 0 to 60 feet per minute;

Modes: Left drum only; right drum only; both.

\section{c. Borehole Seismic Equipment}

The pulse-echo selsmic probes employed in the tests are prototype components of a borehole seismic velocity probe. This equipment consists of: (1) a borehole transmitter probe; (2) a borehole receiver probe; (3) separate hydraulic pumps, lines, and electrical cables for operating the probes in shallow boreholes; and (4) surface electronic equipment to power and operate the probes.

The sesimic transmitter probe contains a piezoelectric pulse transducer consisting of a multi-element stack of piezoceramic elements. This cylindrical stack of crystals is installed in a hydraulically actuated piston within the probe. Activating the hydraulic pump causes the piston to extend radially from the probe body clamping the probe in the borehole and bringing the transducer into contact with the borehole wall. The probe also contains a high-voltage power supply and a pulse discharge network. To develop a highenergy-rate seismic pulse, the transducer stack is charged to approximately 1000 volts causing it to contract in length. The stored energy is then abruptly discharged causing the rapidly expanding piezoelectric transducers to generate a broad bandwidth seismic impulse in the drilled formation. This highly repeatable pulse can be generated at repetition rates up to ten pulses per second. 
The seismic receiver probe is similar to the transmitter probe with the exception that the receiver transducer piezoceramic elements are configured for maximum sensitivity for converting the detected seismic pulses to electrical signals. Separate piezoceramic elements are employed in this receiver probe to provide preferential detection of compressional and shear waves traveling parallel to the borehole axis.

The transmitter and receiver probes are connected to the surface via electrical cables and hydraulic lines. The surface unit controls the hydraulic pump and the transmitter synchronization. A receiver selector switch and seismic preamplifier in the Surface Unit is connected to the receiver probe to amplify the signal to the appropriate level for display and recording.

\section{Probe Handling and Data Recording Equipment}

Both electromagnetic probe systems operate from four-conductor armored logging cables; the radar probe requiring a single cable and the hole-to-hole system requiring two such cables. Southwest Research Institute maintains a logging van equipped with a dual-drum winch system having an automatic servo control for positioning the probes in two boreholes. Each of the wireline drums are fitted with 1000 feet of cable. The cable conductors are connected through slip-rings on each drum to an equipment rack in the van. Power for all systems is provided by a $6.3 \mathrm{kw}$ gasoline powered motor-generator. Data from the two EM probe systems were recorded on DC-300 digital magnetic tape cartridges. Depth of the probe(s) and all control settings were recorded with each full waveform at preset intervals along the borehole(s).

Seismic data were recorded on DC-100 digital magnetic cassettes. Recording and formatting of the tapes was performed by a Hewlett Packard 9825 desktop computer and a Phoenix Data Systems A/D converter. A Nicolet signal averager was employed to improve the signal-to-noise ratio of the seismic and radar signals under high noise conditions. The analog output of the averager was taken directly to the $A / D$ converter for digit'izing and recording.

Figure 5 shows the logging van on site with the telescoping boom elevated and a probe lowered into one of the boreholes. The simulated fracture slot in the granite is visible in the foreground. 


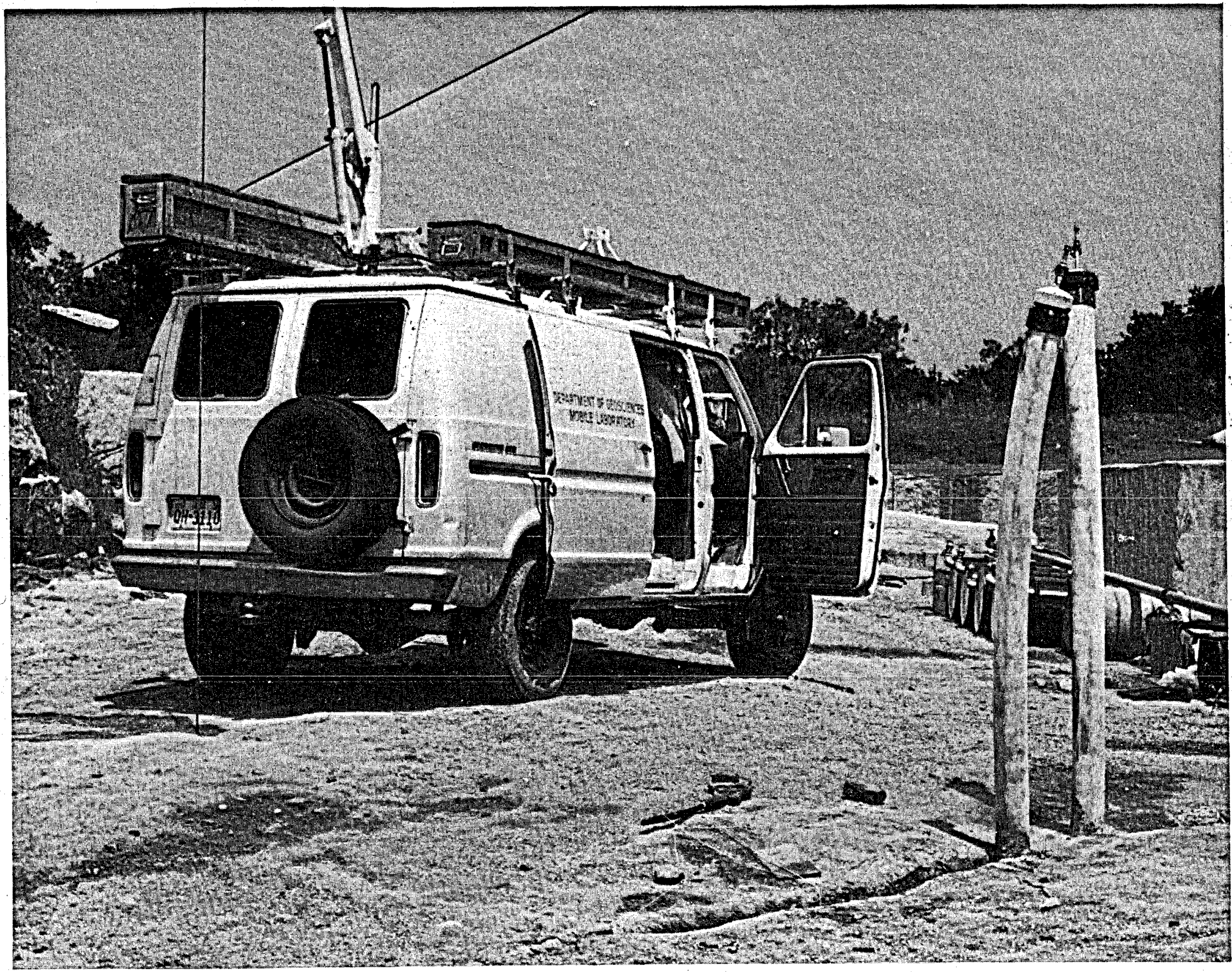

FIGURE 5. SWRI LOGGING VAN ON SITE 
III. TEST SITE

A. Location and Description

The test site is a granite quarry operated by the Texas Granite Corporation of Marble Falls, Texas, a division of the Cold Spring Granite Company. The company operates three quarries in the area; the one used in the tests described here is located in the town of Granite Shoals, Texas approximately 12 miles west of the main office and processing plant at Marble Falls. The quarry is in an extensive outcropping of principally red granite beginning at the western edge of the town of Marble Falls and extending over an area of several hundred square miles. The granite is visible from the surface as low mounds seldom rising more than about 100 feet above the surrounding terrain. The domes are typically less than one quarter mile in diameter.

Figure 6 shows two views of the quarry test site. In operation, rectangular blocks of granite are removed by flame cutting or drill and blast techniques in sizes and shapes determined by finished block requirements. This type of quarrying accounts for the steplike appearance of the high wall.

In the flame cutting operation, blocks of granite are cleared from the wall on two faces by narrow cuts made with an oxygen-gas cutting torch. The process does not melt the rock, but instead the heat causes a continuous spalling effect. The cutting process produces a planar slot in the granite two to four inches wide to the full depth of the block. The final step in removing the block of granite is to drill shot holes under the block, charge the holes with explosive, and blast the block free from the floor of the quarry.

It was hoped that a test site situation would be available where the orthogonal cuts on the back and side of a block had been made but with the block still attached to the quarry floor. These cuts would provide a slot which could be filled with brine to simulate a fluid-filled fracture in a geothermal well. Unfortunately no such quarrying operations were available at the time of the tests. An alternate, target was found at the Texas Pearl (1ight beige to gray granite) quarry which proved to be a more satisfactory test location. A flame-cut slot approximately six meters deep and extending 12.3 meters away from the highwall had been made and then abandoned because of severe stress cracking of the blocks of granite as they were being removed. Figure 7 shows a plan view of the test site including the partially cut block and the test boreholes.

\section{B. Site Preparation}

Five test boreholes were drilled as shown in Figure 7 . Three holes were located broadside to the target slot. The other two boreholes were drilled in line with the plane of the slot. Probes operated in these holes view the slot edge-wise representative of a fracture extending radially from the borehole. The holes were drilled to 9.1 meters depth, approximately three meters deeper than the target slot. 


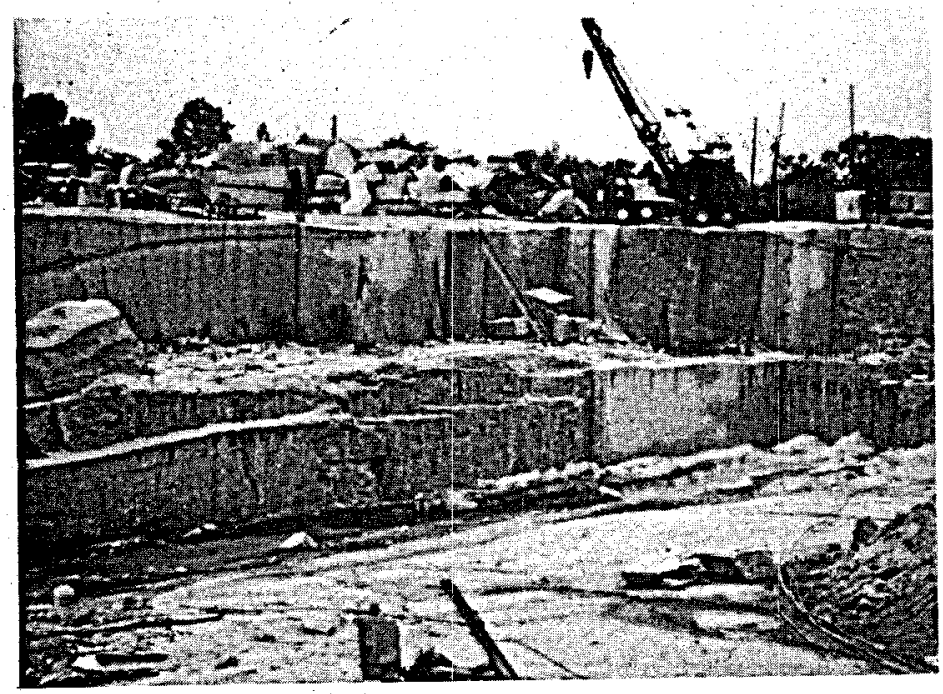

(a) View of Northwestern Rim Across Quarry

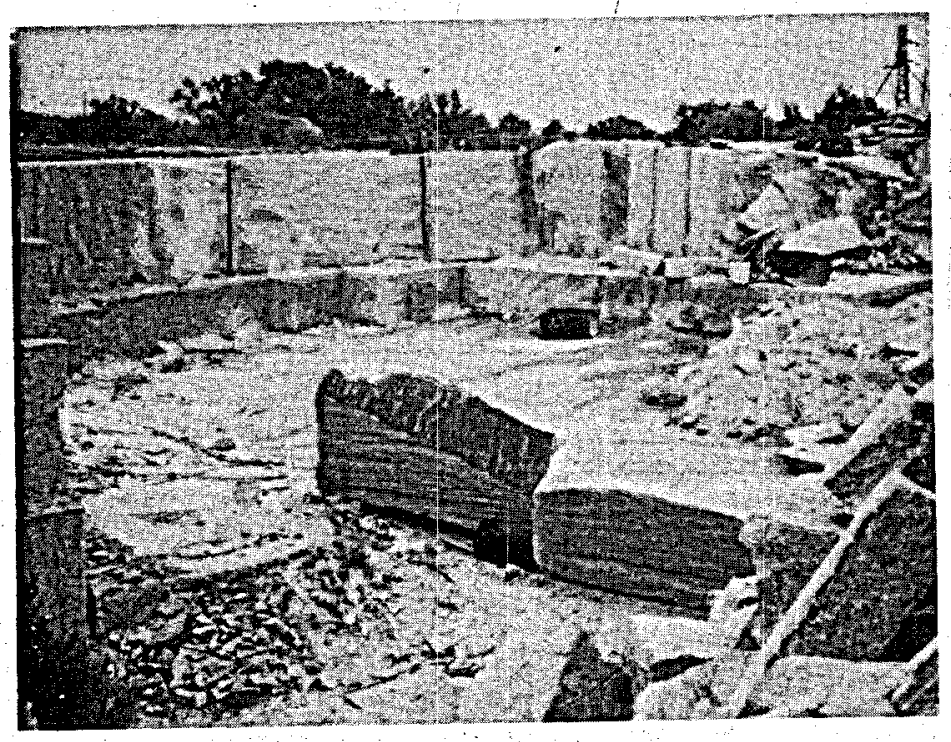

(b) View to Southeast Across Quarry

FIGURE 6. TEXAS PEARL GRANITE QUARRY, TEXAS GRANITE CORPORATION, MARBLE FALLS, TEXAS 


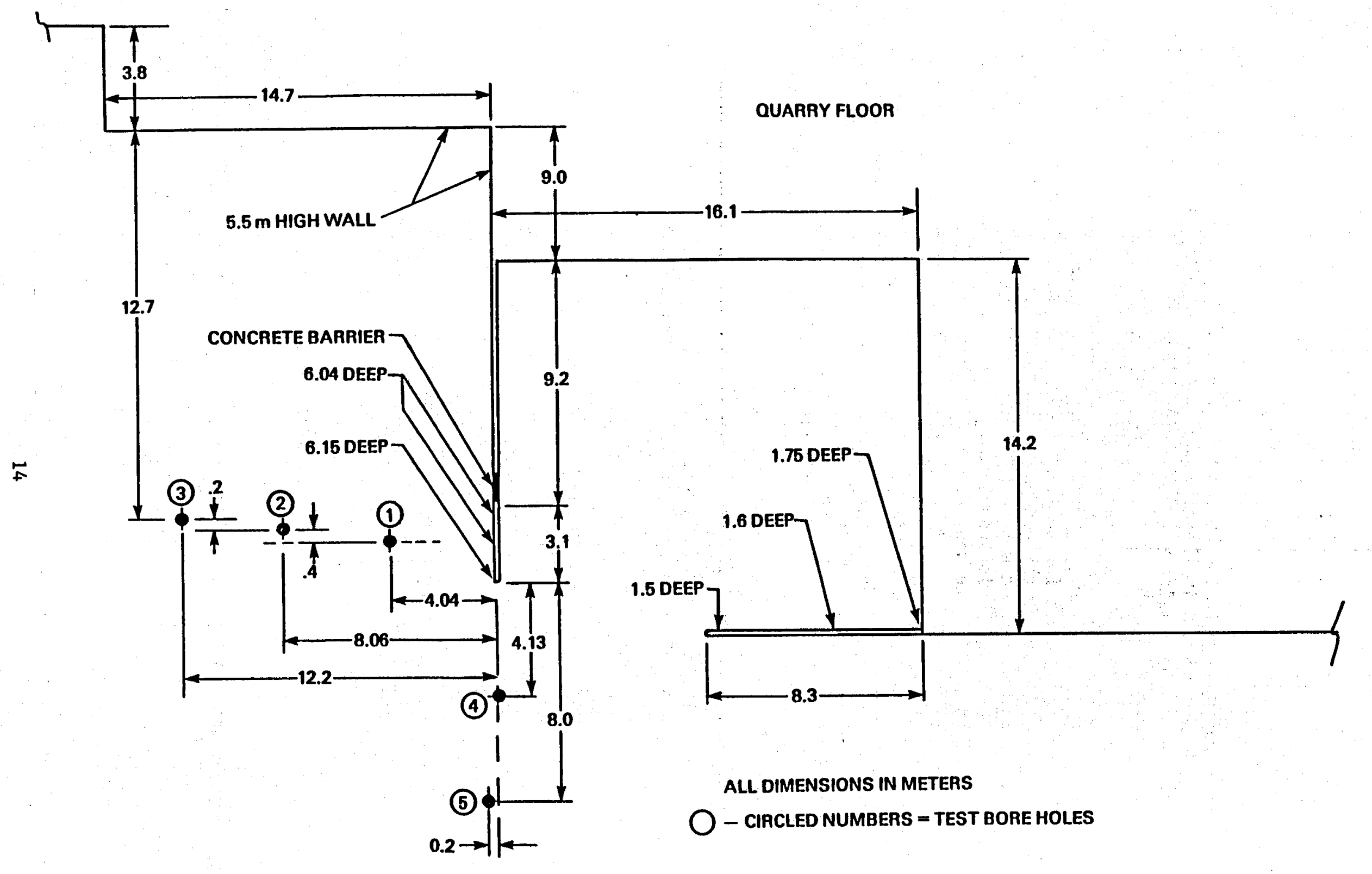

FIGURE 7. LAYOUT PLAN OF TEST SITE AT TEXAS PEARL QUARRY 
A barrier was installed in the slot at 3.1 meters from the closed end extending from the surface to the bottom of the slot. The purpose of the barrier was to contain fluid in the closed end of the slot. This closed off section of the slot, when filled with conductive fluid, provided a rectangular $(3.1 \times 6 \mathrm{~m})$ planar interface which is a reasonable simulation of an open fracture filled with brine.

Figure 8 shows a view of the slot with the open quarry in the background. The original concept for sealing the slot was to place a length of four-inch firehose, folded at the center, into the slot. It was anticipated that when the hose was inflated with air it would effectively seal the slot. The surface roughness of the slot was so excessive that when the slot was filled with water the leak rate was not acceptable.

The barrier was formed by pouring three yards of ready-mixed concrete into the slot on the back side of the firehose barrier. The slot was effectively sealed to permit the experiments to proceed. Minor leakage through fractures at the base and in the walls of the slot were noted throughout the experiments. The leak rate was low and it was possible to maintain an appropriate fluid level by means of a water supply hose.

An important goal of the tests was to determine the effects of fracture-fluid conductivity on the electromagnetic reflection signals. To perform these experiments, the slot was initially filled with fresh water. Later, the slot was filled with salt water having a concentration of approximately 10 parts per 100 which was diluted to lower concentrations by the addition of fresh water. Salt was mixed with fresh water in 55 gallon drums and hauled to the site by truck as shown in Figure 9. Approximately 800 gallons of water was required to fill the slot each time the salt concentration was changed. Radar reflection tests were performed using three different fluid conductivity levels. Samples of the fluid in the slot and in the boreholes were taken for later analysis. 


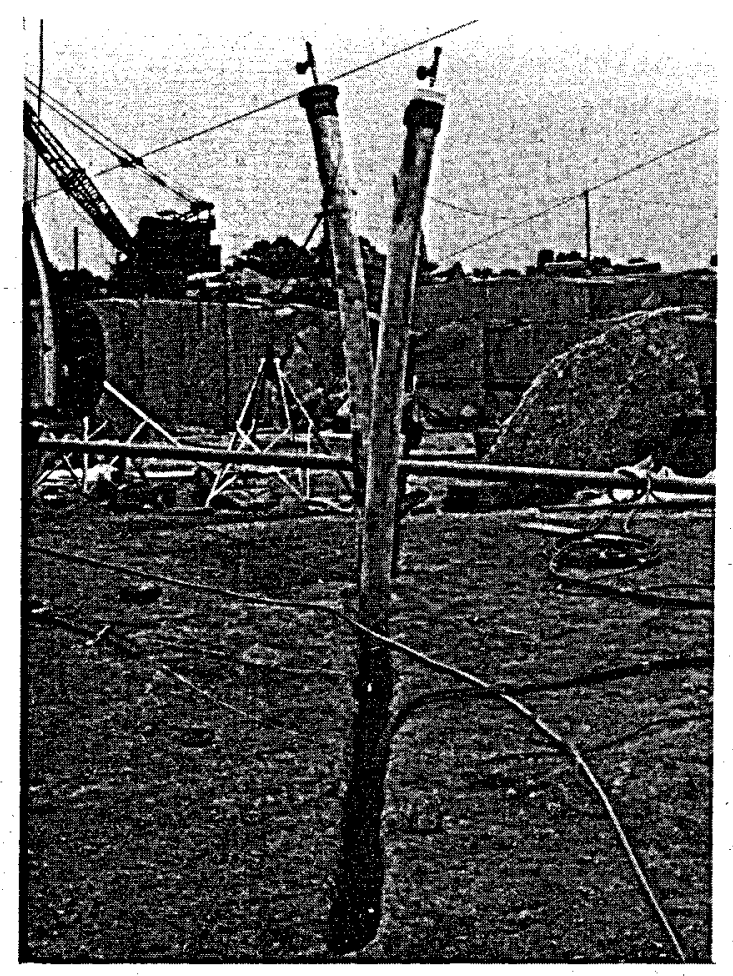

(a) Test slot with Firehole Barrier

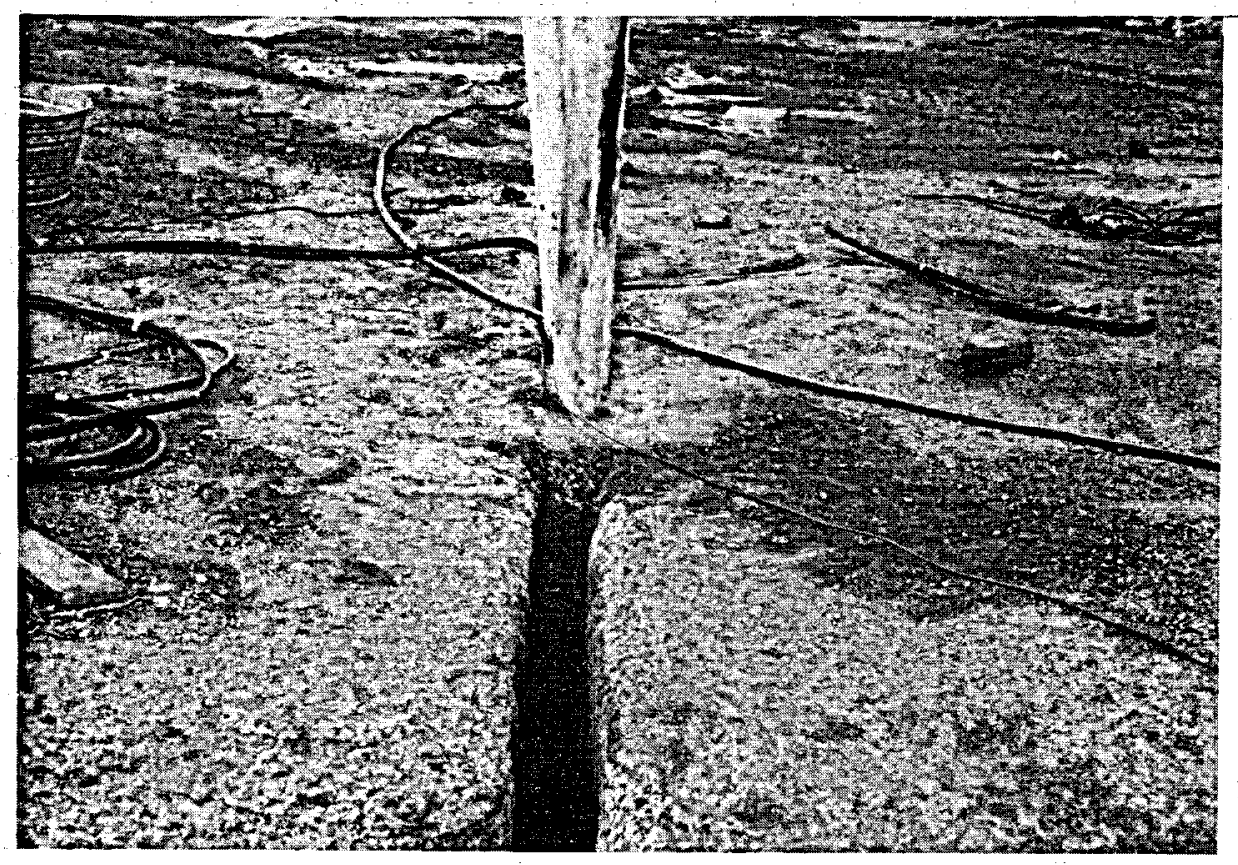

(b) Concrete Barrier in Test Slot

FIGURE 8. TEST SITE AT TEXAS PEARL QUARRY 


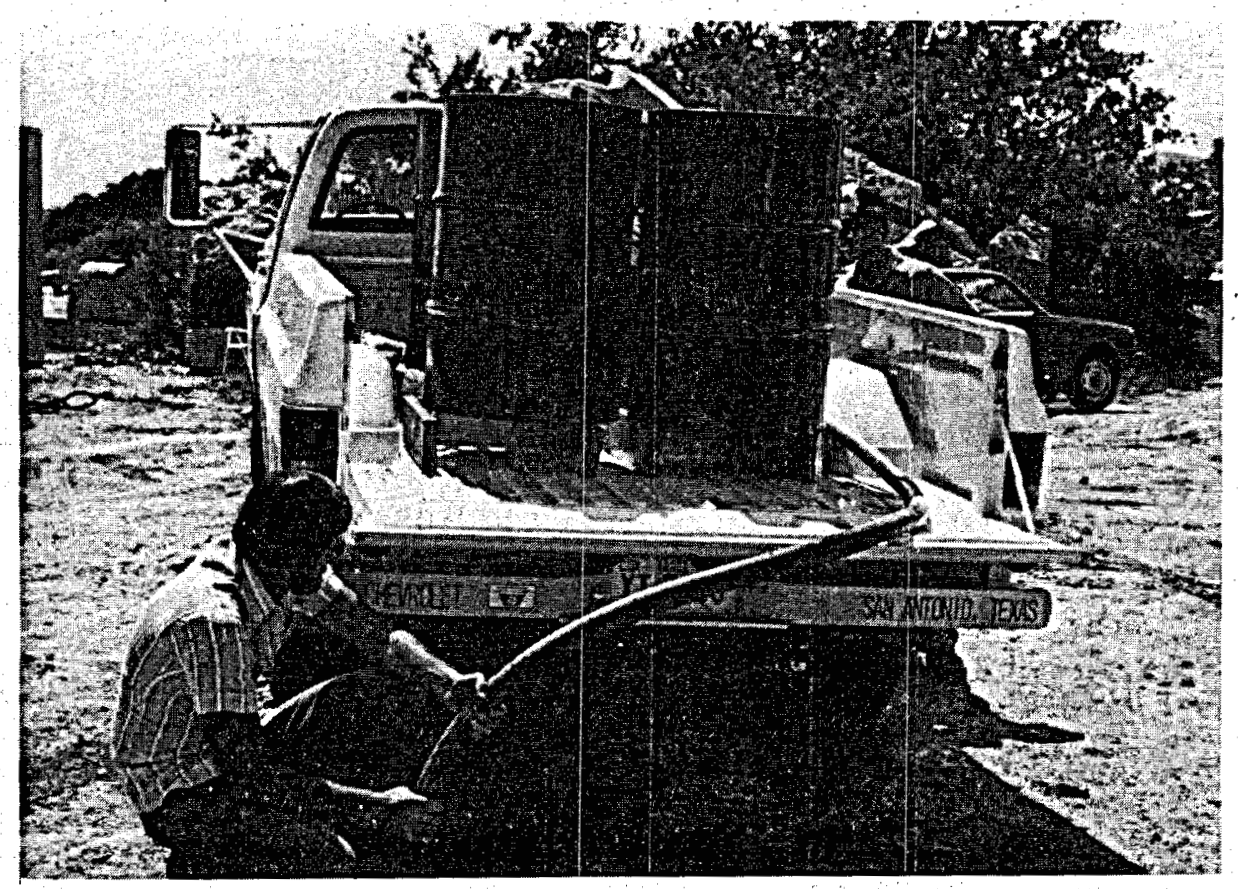

(a) Filling Test slot with Salt Water

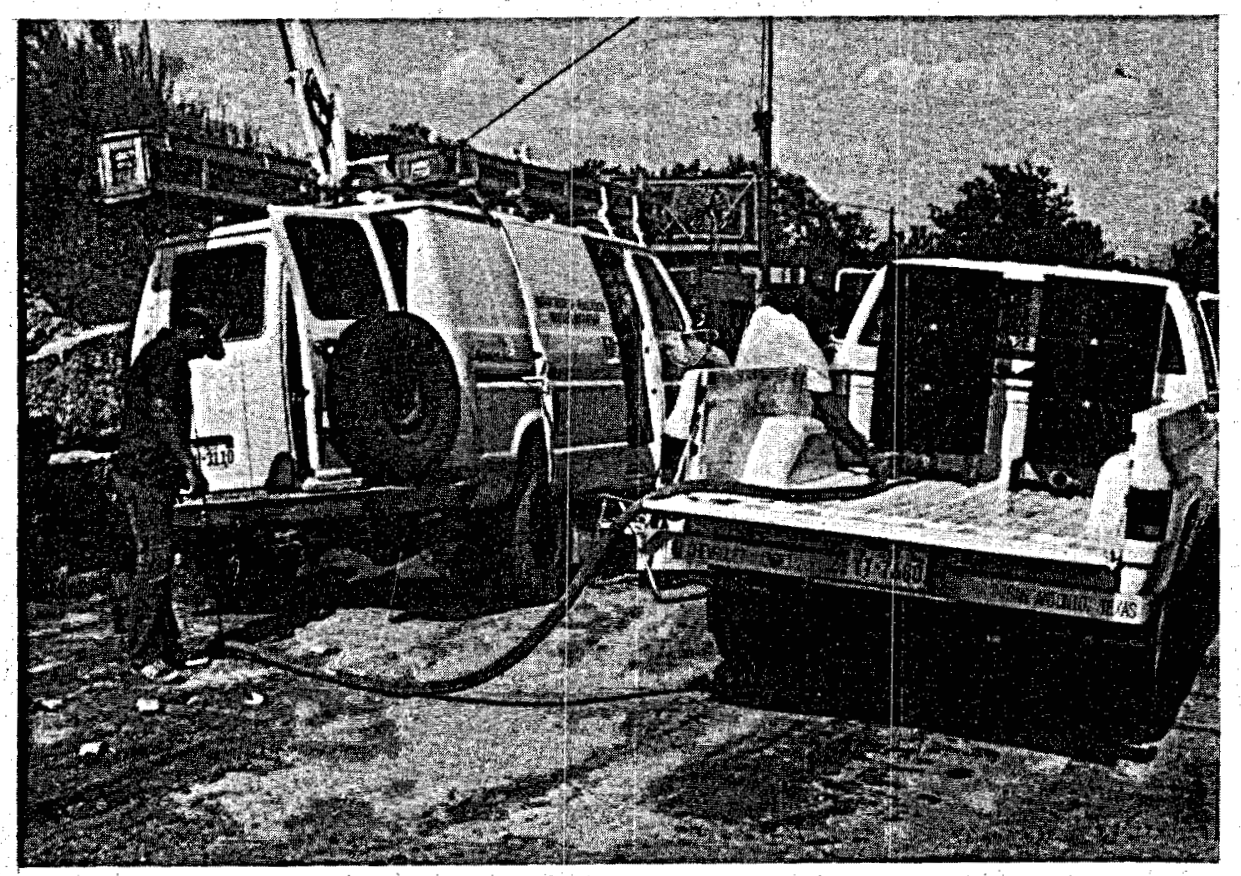

(b) Filling Test Boreholes with Salt Water

FIGURE 9. LIQUID HANDLING OPERATIONS AT TEST SITE 


\section{A. Auxiliary Experiments}

\section{Preliminary Site Evaluation Tests}

Prior to the final site selection, experiments were conducted to measure the electromagnetic and seismic propagation characteristics of the granite at the Texas Pearl Quarry. The purpose of these preliminary tests was to determine the suitability of the site, primarily in terms of the propagation loss characteristics of the rock. The maximum acceptable total two-way propagation loss was established at $120 \mathrm{~dB}$.

\section{a. Electromagnetic Parameter Experiments}

Electromagnetic measurements were performed using the hole-to-hole pulsed electromagnetic system with the borehole antennas replaced with bow-tie dipole antennas made of sheet lead. The antennas were adhered to the surfaces of the granite block using a high dielectric constant grease. Electromagnetic pulse propagation times between the source and receiving antennas separated by a known path length through the rock and the received signal amplitudes were recorded.

The approximate propagation velocity can be obtained by dividing the antenna separation path length by the propagation time. A more accurate determination of the velocity may be obtained from pulse signals observed at two or more receiver stations. If the difference in two path lengths is divided by the difference in travel times over the two paths, a velocity value is obtained which is free of any errors caused by instrumental time delays:

Table I presents the results of the electromagnetic propagation parameter tests. The Figure 10 shows the placement of the antennas. The transmitting antenna was placed in the large slot labeled No 1 . The receiving antenna was placed at four different positions in an adjacent slot labeled No. 2. Path length, apparent travel time, and signal amplitude for each station was recorded. The pulse amplitude attenuation rate in excess of the three dimensional spreading loss was calculated for each of the six possible combinations of the four antenna positions. The average attenuation of the pulse waveform caused by dissipative losses in the granite was $1.36 \mathrm{~dB}$ per meter. This value compares well with published data for three different wet granites. At 100 megahertz, the attenuation rates for charcoal granite, rockville granite, and rainbow granite were reported to be respectively, 1.345 , 1.183 , and $1.354 .(1)$

Six values of propagation velocity were calculated using the differential travel times over the six possible distance combinations. The average propagation velocity was 0.128 meters per nanosecond. The relative dielectric constant of the granite was calculated to be 5.49 which compares favorably with reported values of $6.5,6.25$, and 5.89 for the three granites mentioned above. (I)

(1) Griffin, R.E. and Marovelli, R.L., "Dielectric Constants and Dissipation Factors for Six Rock Types Between 20 and 100 Megahertz;" U.S. Bureau of Mines Report RI 6913, Department of the Interior; 1967: 
TABLE I. PRELIMINARY ELECTROMAGNETIC PARAMETER TESTS

\begin{tabular}{ccccc}
\hline Position & $\begin{array}{c}\text { Spacing } \\
\text { (Meters) }\end{array}$ & $\begin{array}{c}\text { Pulse Trave1 Time } \\
\text { (ns) }\end{array}$ & $\begin{array}{c}\text { Receiver Output } \\
\text { (Volts) }\end{array}$ \\
\hline 1 & 9.14 & 124 & 0.014 \\
2 & 10.66 & 135 & 0.0115 \\
3 & 12.19 & 150 & 0.0075 \\
4 & 13.7 & 159 & 0.0045 \\
\hline
\end{tabular}

\begin{tabular}{|c|c|c|}
\hline $\begin{array}{c}\text { Propagation } \\
\text { Path }\end{array}$ & $\begin{array}{l}\text { Velocity } \\
\text { (M/ns) }\end{array}$ & $\begin{array}{l}\text { Attenuation } \\
(\mathrm{dB} / \mathrm{m})\end{array}$ \\
\hline $1-2$ & 0.137 & 0.24 \\
\hline $2-3$ & 0.100 & 1.6 \\
\hline $3-4$ & 0.16 & 2.2 \\
\hline $1-3$ & 0.116 & 0.95 \\
\hline $2-4$ & 0.125 & 1.9 \\
\hline $1-4$ & 0.128 & 1.3 \\
\hline Average & 0.128 & 1.36 \\
\hline
\end{tabular}




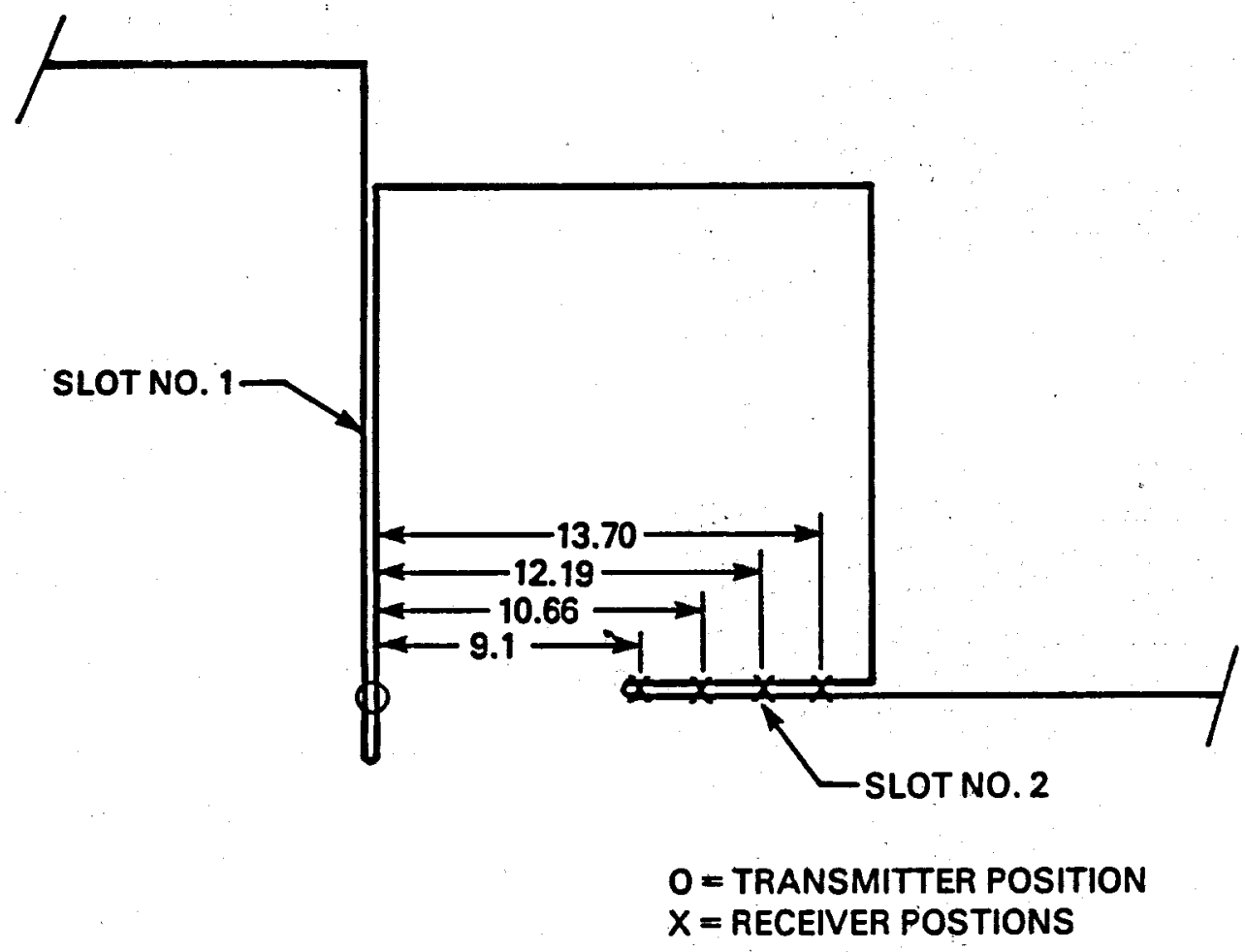

FIGURE 10. LAYOUT OF TRANSMITTER AND RECEIVER PROBES FOR ELECTROMAGNETIC PARAMETER EXPERIMENTS 


\section{b. Seismic Parameter Experiments}

Preliminary seismic tests were performed using the Bureau of Mines prototype seismic velocity measuring probes. The transmitter and receiver probes were position in the two slots used for the electromagnetic parameter tests. The seismic transmitter position was fixed at one location in Slot No. 1. The receiver was then positioned at $1.22,1.83$, and 2.66 meters away from the transmitter in Slot No. 1 and at $8.0,9.22,10.21$, and 12.54 meters away from the transmitter in Slot No. 2. Photographs of the received pulse waveform at each station were recorded and later analyzed to yield the results presented in Table II.

The spacing between source and receiver at each station, the apparent seismic wave travel time for both compressional and shear waves, and the maximum received signal amplitude of each wave type are listed in Table II(a). Table II(b) presents the computed values of compressional and shear wave velocity based on the apparent travel time.

The velocity values indicated for the case where the source and receiver were located in the Slot No. 1 (Stations 1,2 and 3 ) are obviously not compressional wave velocities but appear to be appropriate for surface wave propagation. Higher velocity compressional and shear wave arrivals were not detected.

For measurements using the source and receiver in separate slots, the compresssional and shear wave velocities are consistent with values obtained by others $(2)$ for Texas Gray granite. The average velocity for the six interstation calculations was $5.89 \mathrm{~km}$ per second for compressional waves and $3.05 \mathrm{~km}$ per second for shear waves. In later tests, the compressional wave velocity was again measured between the slot and three boreholes. Two values were obtained, 5.83 and $6.0 \mathrm{~km}$ per second.

It was not possible to obtain an accurate determination of the seismic attenuation rate for the granite. The signal amplitude values were found to be sensitive to clamping position in the slots and insufficient data were available to obtain an acceptable average amplitude from the collected data. The loss is estimated to be approximately $0.3 \mathrm{~dB}$ per meter for compressional waves and approximately one $d B$ per meter for shear waves.

The value of electromagnetic and seismic velocity and attenuation observed at the Texas Pearl Quarry were considered acceptable with no significant deviation from propagation characteristics measured by other investigators. The site was accepted as satisfactory for the planned fracture detection experiments.

\section{Radar Antenna Directivity Experiments}

Several experiments were conducted to measure the incident radar signal illumination of the target slot by the radar and to ascertain the directivity factor of the radar probe antenna. The measurements were made by placing a bowtie antenna in the dry slot at six meters depth. The received signal was

(2) Hughes, D.S. and Purette, C., "Variation of Elastic. Wave Velocities in Granite with Pressure and Temperature", Geophysics, Vol. XXI, No. 2, April, 1956. 
TABLE II. PRELIMINARY SEISMIC PARAMETER TESTS

(a) Seismic Propagation Times and Signal Amplitudes

\begin{tabular}{cccccc}
\hline Station & $\begin{array}{c}\text { Spacing } \\
\text { (Meters) }\end{array}$ & $\begin{array}{c}\text { Pulse Trave1 Time } \\
\text { (ms) }\end{array}$ & S & Receiver Output \\
(mV)
\end{tabular}

(b) Computed Seismic Velocities

\begin{tabular}{|c|c|c|}
\hline \multirow[t]{2}{*}{ Propagation Path } & \multicolumn{2}{|c|}{$\begin{array}{c}\text { Velocity } \\
(\mathrm{km} / \mathrm{sec})\end{array}$} \\
\hline & $\mathbf{P}$ & s \\
\hline $1-2$ & 2.65 & 1.96 \\
\hline $1-3$ & 2.51 & - \\
\hline $2-3$ & 2.76 & - \\
\hline Average (S1ot No. 1 Measurements) & 2.64 & 1.96 \\
\hline $4-5$ & 6.10 & 4.06 \\
\hline 4-6 & 6.31 & 3.68 \\
\hline 4-7 & 5.67 & 2.67 \\
\hline $5-6$ & 6.60 & 3.00 \\
\hline $5-7$ & 5.53 & 2.55 \\
\hline $6-7$ & 5.17 & 2.33 \\
\hline Average (Slot No. 2 Measurements) & 5.89 & 3.05 \\
\hline
\end{tabular}


recorded for various rotational positions of the radar transmitting antenna which was placed in Borehole No. 2 located eight meters from the slot. The bowtie antenna output waveform was recorded on Polaroid film for three positions of the source antenna: maximum signal $\left(225^{\circ}\right)$; minimum signal $\left(45^{\circ}\right)$; and at an intermediate position $\left(135^{\circ}\right)$ relative to Magnetic North.

Figure 11 shows these waveforms which clearly demonstrate the directivity of the radar transmitting antenna. The peak-to-peak amplitude of the signal at $225^{\circ}$ is approximately 0.8 volts and at $45^{\circ}$ the signal amplitude is 0.5 volts. The front-to-back ratio of the antenna is therefore $4.08 \mathrm{~dB}$ for this experiment. The other signals which also exhibit a change in amplitude as the radar antenna rotates are the result of reflections from impedance discontinuities on the receiving antenna cable.

The experiment was repeated with the radar probe positioned in Borheole No. 3 located 12 meters from the bowtie antenna in the slot. Figure 12 shows the receiver output for transmitting antenna headings of $45^{\circ}, 135^{\circ}$, and . $225^{\circ}$. The calculated front-to-back ratio for the antenna at 12 meters range is approximately $5 \mathrm{~dB}$.

In the next experiment, the radar probe was lowered into Borehole No. 1 and the separate bowtie antenna was lowered into Borehole No. 2 four meters distant; both boreholes were dry. The front-to-back ratio of the antenna was measured to be $6.0 \mathrm{~dB}$ with the maximum signal received when the transmitting antenna heading was $45^{\circ}$ as shown in Figure 13.

The receiving antenna was then moved to Borehole No. 3 with the radar probe remaining in Borehole No. 1. The results in Figure 14 show the antenna front-to-back ratio to be approximately $6 \mathrm{~dB}$.

The final experiment in this series was designed to investigate the effects on the directional antenna performance of conductive fluids surrounding the 3.0-inch diameter probe in a 4.75-inch diameter borehole. Table III summarizes the results of this test.

TABLE III. EFFECTS OF BOREHOLE FLUID RESISTIVITY ON DIRECTIONAL ANTENNA PERFORMANCE

\begin{tabular}{|c|c|c|c|c|}
\hline $\begin{array}{c}\text { Fluid } \\
\text { Resistivity } \\
(\text { ohm-cm) }\end{array}$ & & & $\begin{array}{c}\text { Antenna } \\
\text { Directivity } \\
\text { (dB) }\end{array}$ & $\begin{array}{l}\text { Radiation } \\
\text { Loss* } \\
\text { (dB) }\end{array}$ \\
\hline & $45^{\circ}$ & $225^{\circ}$ & & \\
\hline$\infty$ (air) & 16.0 & 8.0 & +6.0 & 0 \\
\hline $600-700$ & 14.5 & 7.3 & +5.9 & 0.85 \\
\hline $40-50$ & 8.0 & 2.0 & +12.0 & 6.0 \\
\hline
\end{tabular}

* Relative to air-filled borehole condition 


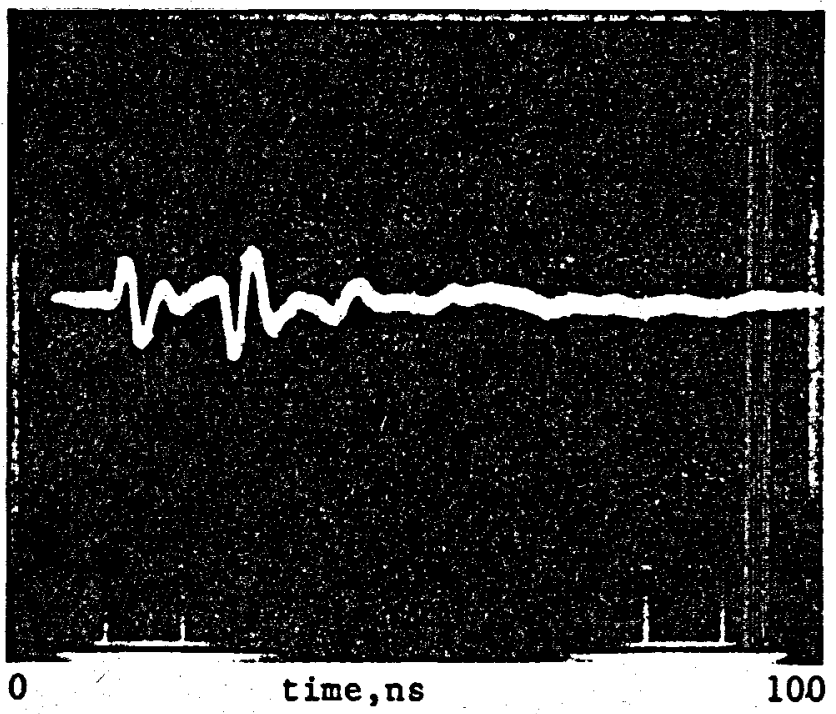

$$
\text { ANTENNA HEADING - } 45^{\circ}
$$

HORIZ. SENS. - 10 NSIDIV

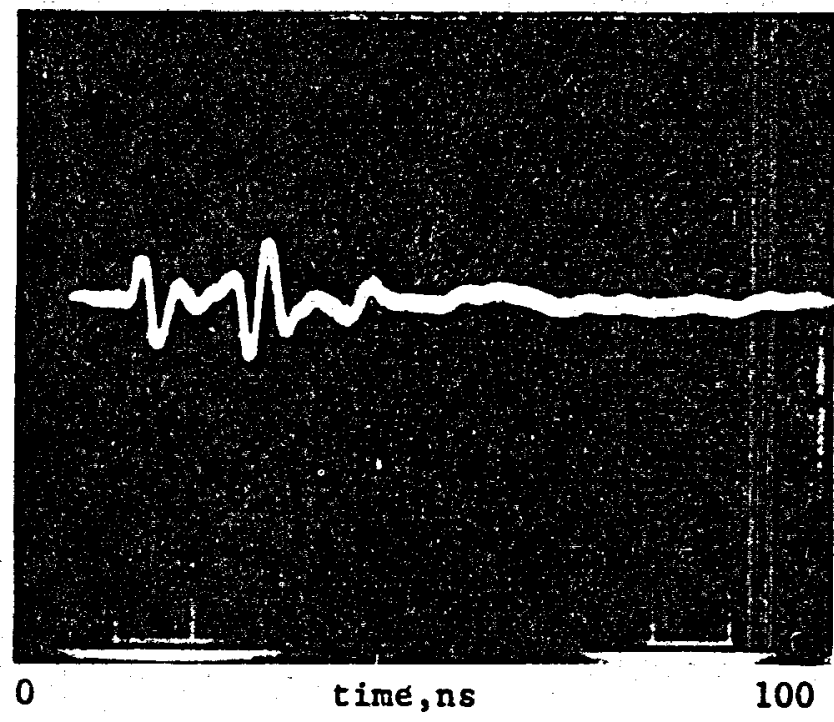

ANTENNA HEADING - $135^{\circ}$

HORIZ. SENS. - 10NS/DIV

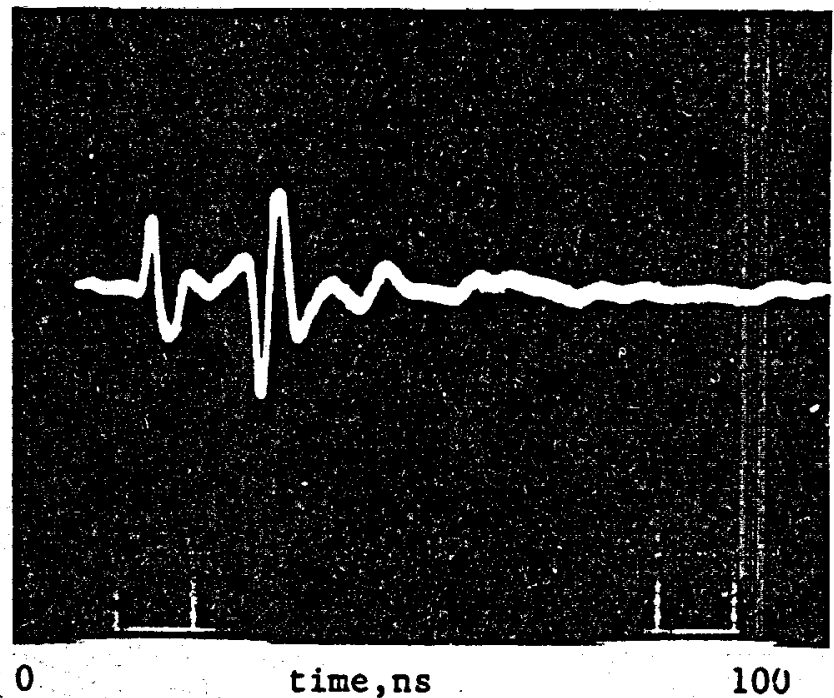

ANTENNA HEADING - 225

HORIZ. SENS. - 10 NS/DIV

Relative Amplitudes in vertical scale

FIGURE 11. BOREHOLE RADAR DIRECTIONAL ANTENNA TEST RESULTS - RADAR IN

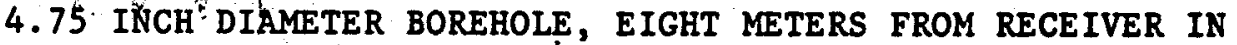
SLOT IN GRANITE (230 $20^{\circ}$ MAGNETIC HEADING FROM RADAR TO RECEIVER) 


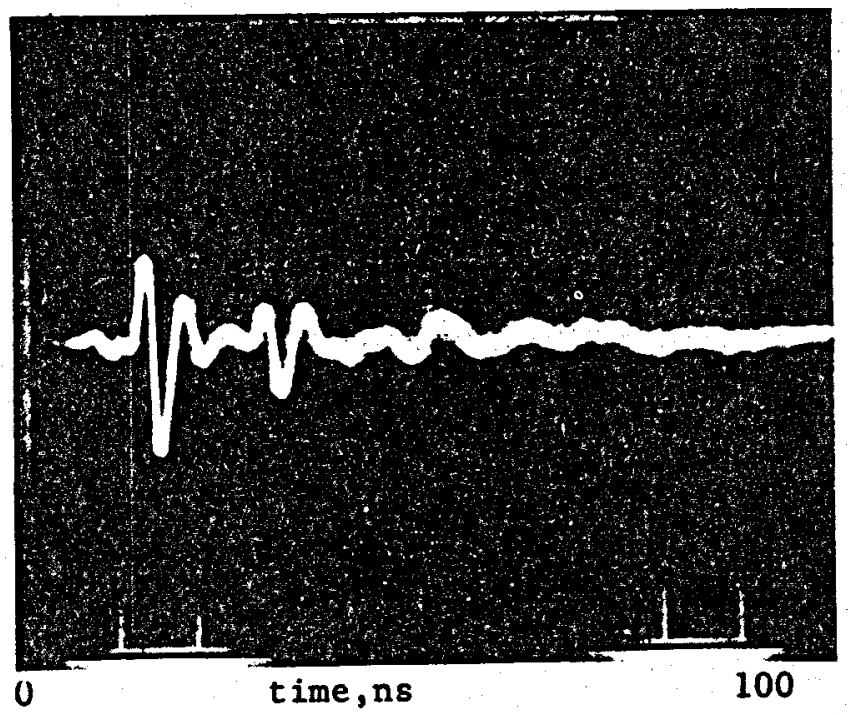

ANTENNA HEADING - $45^{\circ}$

HORIZ. SENS. - 10 NS/DIV

0

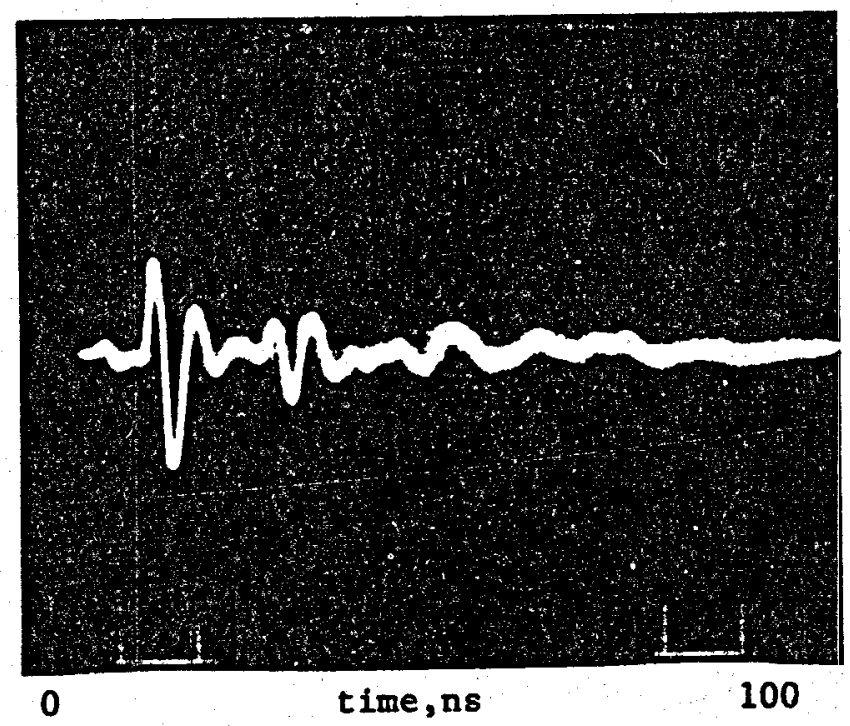

\author{
ANTENNA HEADING - $135^{\circ}$
}

HORIZ. SENS. - 10NS/DIV

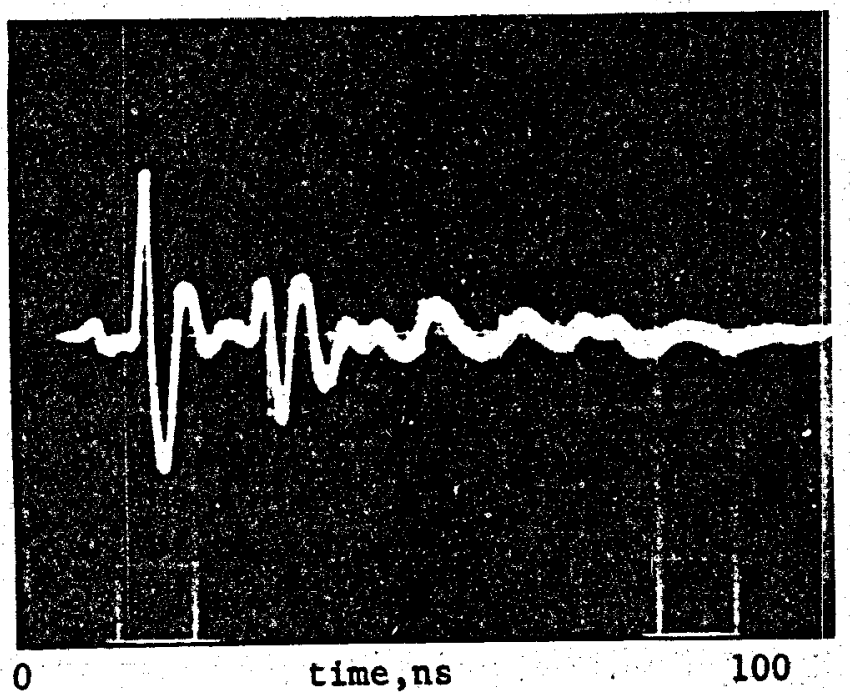

\footnotetext{
ANTENNA HEADING $-225^{\circ}$

HORIZ. SENS. - 1ONSIDIV

Relative Amplitudes

in vertical scale
}

FIGURE 12. BOREHOLE RADAR DIRECTIONAL ANTENNA TEST RESULTS - RADAR IN 4.75 INCH DIAMETER BOREHOLE, 12 METERS FROM RECEIVER IN SLOT IN GRANITE ( $230^{\circ}$ MAGNETIC HEADING FROM RADAR TO RECEIVER) 

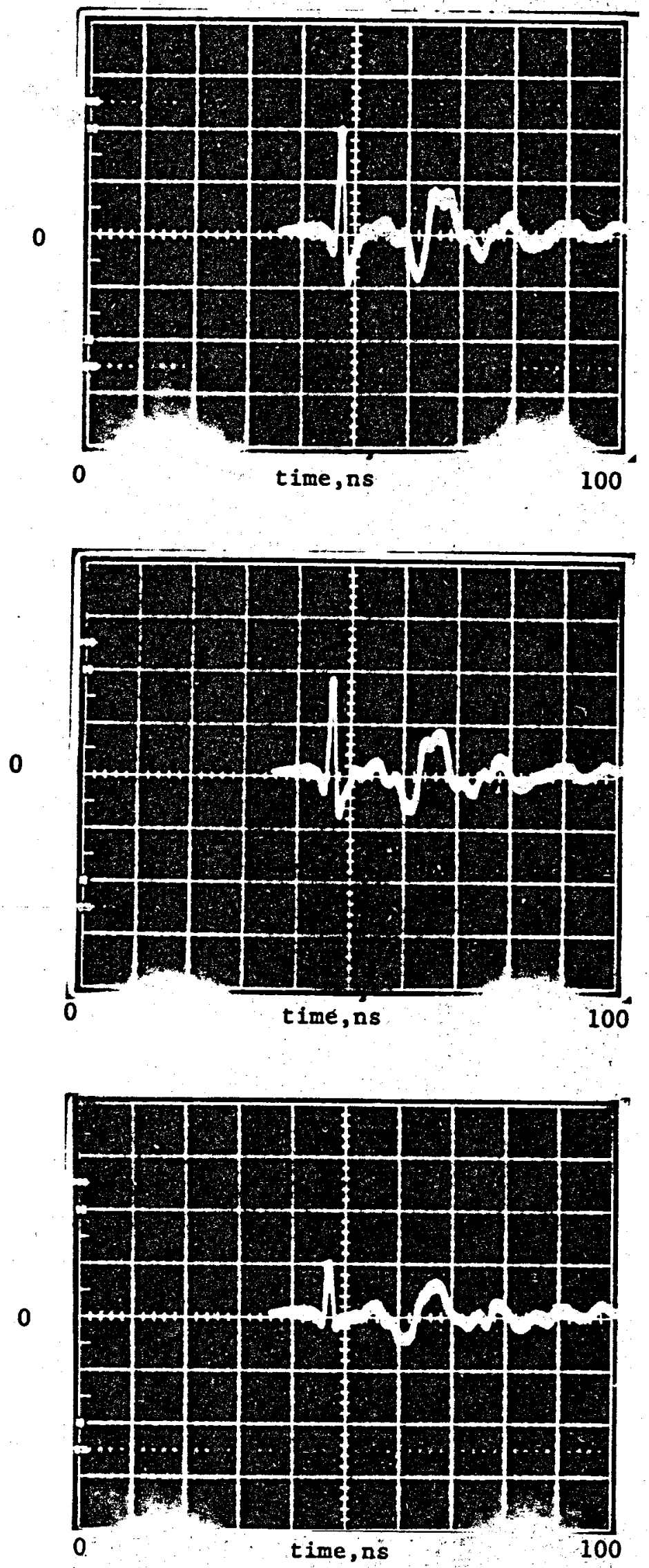

\author{
ANTENNA HEADING - $45^{\circ}$
}

HORIZ. SENS. - 10NS/DIV

ANTENNA HEADING - $135^{\circ}$

HORIZ. SENS. - 10 NS/DIV

ANTENNA HEADING - $225^{\circ}$

HORIZ. SENS. - 10 NS/DIV

Relative Amplitudes in vertical scale

FIGURE 13. BOREHOLE RADAR DIRECTIONAL ANTENNA TEST RESULTS - RADAR IN 4.75 INCH DIAMETER BOREHOLE 4, 80 METERS FROM RECEIVER IN 4.75" DIAMETER BOREHOLE IN GRANITE 5 MAGNETIC HEADING FROM RADAR TO RECEIVER 


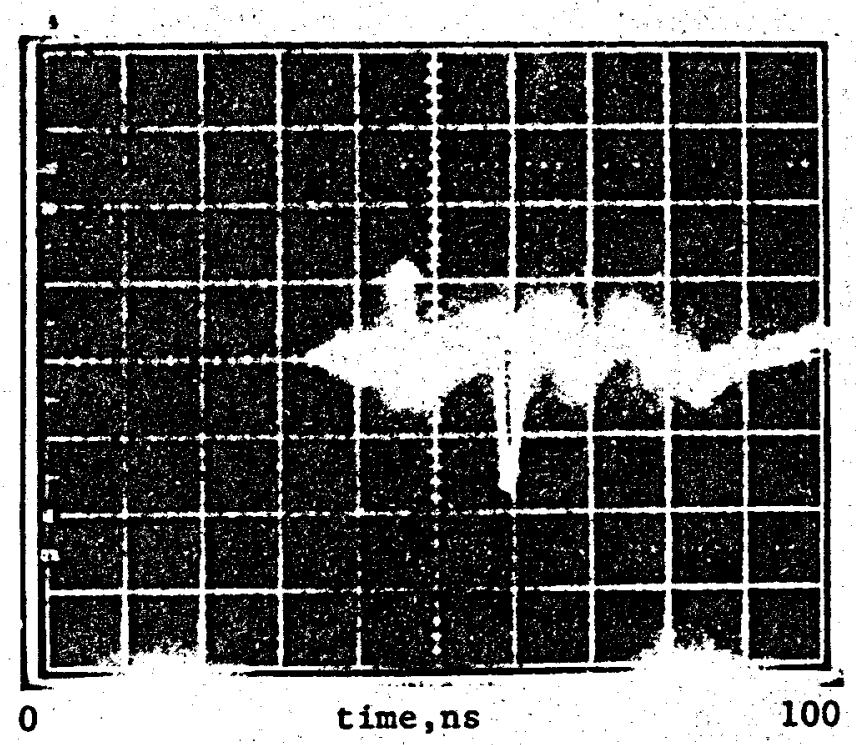

\author{
ANTENNA HEADING - $45^{\circ}$ \\ Shas \\ HORIZ. SENS. - 10NS/DIV
}

\author{
ANTENNA HEADING - $225^{\circ}$ \\ HORIZ. SENS. - 10 NS/DIV \\ Relative Amp1itudes \\ in vertical scale
}

FIGURE 14. BOREHOLE RADAR DIRECTIONAL ANTENNA TEST RESULTS - RADAR IN 4.75 INCH DIAMETER BOREHOLE 8.0 MFTERS FROM RECEIVER IN 4.75" DIAMETER BOREHOLE IN GRANITE ( $50^{\circ}$ M RADAR TO RECEIVER) 
The output of the separate bowtie recelving antenna was recorded while the radar probe was operated in Borehole No. 1 with no liquid in the hole, then with muddy water without added salt, and finally with approximately one pound of salt added to the water in the hole. The resistivity of the muddy water was approxtmately 600 to 700 ohm* centimeter and was 40 to 50 ohm-centimeters when salt was added. The 600 ohm-centimeters water had very little effect on the antenna performance, apparently reducing the directivity by only $0.1 \mathrm{~dB}$ and attenuating the maximum signals by only $0.85 \mathrm{~dB}$. The increased conductivity of the salt water caused a 6-dB decrease in the antenna output but increased the front-to-back ratio to $12 \mathrm{~dB}$. The principal effect was a sharpening of the null in the back direction of the antenna.

B. Eracture Detection Experiments-Summary

1. Echo-Ranging Experiment P1an

The objective of the experiments was to test the feasibility of detecting fractures in the vicinity of boreholes by means of either electromagnetic or selsmic echo-ranging techniques. The experiments included tests of both concepts employing available hardware systems operating in shallow boreholes in surface granite rock. A Planar slot extending in the granite test medium service to simulate a fracture.

Five test boreholes were drilled as described earlier to provide different detection conditions for the electromagnetic and seismic borehole probing systems. The experiments were designed to provide a measure of the effects of borehole fluid conductivity and aspect angle of the fracture-simulating slot. Accordingly, the electromagnetic detection systems were operated in each borehole or borehole pair with the slot containing: (1) air; (2) a sheet metal reflector ( $8 \times 8$ feet); (3) fresh water; and (4) brine of at least two concentrations of salt ( $\mathrm{NaCl}$ ).

Two seismic echo-ranging experiments were performed; one with the slot dry and the second with the slot filled with water. Because there is essentially no change in the seismic reflection coefficient with variation in conductivity of water, only fresh water was used in the seismic tests.

\section{Radar Data Acquired}

Table IV presents a summary of the radar test conditions. The table identifies the borehole in which the radar was operated, the distance from the borehole to the target, the fluid in the slot, and the fluid surrounding the probe in the borehole.

\section{Hole-to-Hole Electromagnetic Data}

Table V presents a summary of the hole-to-hole electromagnetic test conditions. Borehole and target slot conditions for each of the test configurations are given. 
TABLE IV. SUMMARY OF RADAR TEST CONDITIONS

\begin{tabular}{|c|c|c|c|c|}
\hline Tape No. & Borehole & Range(m) & Target Conditions & $\begin{array}{l}\text { Borehole } \\
\text { Conditions }\end{array}$ \\
\hline 5 & 1 & 4 & $8^{\prime} \times 8^{\prime}$ Metal Sheet & Salt Water \\
\hline 5 & 1 & 4 & Salt water, $16 \Omega \mathrm{cm}$ & Salt Water \\
\hline 5 & 2 & 8 & Salt water, $152 \Omega \mathrm{cm}$ & Salt Water \\
\hline $1 \mathrm{C}$ & 2 & 8 & Salt water, $38 \Omega \mathrm{cm}$ & Salt Water \\
\hline $1 \mathrm{C}$ & 3 & 12 & Salt water, $38 \Omega \mathrm{cm}$ & Salt Water \\
\hline $1 C, 2 \mathrm{C}$ & 4 & 4 & Salt water, $177 \Omega \mathrm{cm}$ & Salt Water \\
\hline $2 \mathrm{C}$ & 5 & 8 & Salt water, $260 \Omega \mathrm{cm}$ & Salt Water \\
\hline 0 & 1 & 4 & Dry & Fresh Water \\
\hline 0 & 2 & 8 & Dry & Fresh Water \\
\hline 0 & 3 & 12 & Dry & Fresh Water \\
\hline 0 & 4 & 4 & Dry & Fresh Water \\
\hline 1 & 5 & 8 & Dry & Fresh Water \\
\hline 3 & 1 & 4 & Dry & Salt Water \\
\hline 3 & 1 & 4 & $400 \mathrm{Gal}$. Fresh Water & Salt Water \\
\hline 3 & 1 & 4 & $600 \mathrm{Gal}$. Fresh Water & Salt Water \\
\hline 3 & 1 & 4 & Salt Water, $10.1 \Omega \mathrm{cm}$ & Salt Water \\
\hline $3 / 4 a$ & 2 & 8 & Salt Water, $10.1 \Omega \mathrm{cm}$ & Salt Water \\
\hline
\end{tabular}


TABLE V. SUMMARY OF HOLE-TO-HOLE ELECTROMAGNETICTEST CONDITIONS

\begin{tabular}{cccll}
\hline Tape No. & \multicolumn{2}{c}{ Boreholes } & Target Conditions & Borehole Conditions \\
\cline { 2 - 4 } & Tr & Rec & Dry & Fresh Water \\
\hline 2 & 3 & 2 & Dry & Fresh Water \\
2 & 3 & 1 & Dry & Fresh Water \\
2 & 2 & 1 & Dry & Fresh Water \\
2 & 5 & 1 & Dry & Fresh Water \\
4 & 5 & 4 & 600 Gal. Fresh Water & Salt Water \\
6 & 3 & 1 & Salt Water, $260 \Omega \mathrm{cm}$ & Salt Water \\
6 & 4 & 5 & Salt Water, $260 \Omega \mathrm{cm}$ & Salt Water \\
6 & 1 & 2 & Salt Water, $260 \Omega \mathrm{cm}$ & Salt Water \\
6 & 1 & 3 & Salt Water, $260 \Omega \mathrm{cm}$ & Salt Water \\
\hline
\end{tabular}




\section{Seismic Reflection Data}

Seismic reflection data were recorded with the probes in three borehole pairs. Table VI summarizes the borehole seismic experiments. Because neither of the seismic probes were suitable for immersion in water, the boreholes were dry in all of the tests. 
TABLE VI. SUMMARY OF SEISMIC TEST CONDITIONS

\begin{tabular}{|c|c|c|c|c|c|c|}
\hline \multirow{2}{*}{$\begin{array}{c}\text { Cassette } \\
\text { No. }\end{array}$} & \multicolumn{2}{|c|}{ Boreholes } & \multicolumn{2}{|c|}{ Position(1) } & \multirow{2}{*}{$\begin{array}{l}\text { Type of } \\
\text { Scan }(2)\end{array}$} & \multirow[b]{2}{*}{ Comments } \\
\hline & Rec. & Xmtr & Rec. & Xmtr & & \\
\hline 1 & 1 & 2 & $180^{\circ}$ & $0^{\circ}$ & CD & Rotation experiments and common \\
\hline 2 & 1 & 2 & $180^{\circ}$ & $0^{\circ}$ & CD & $\begin{array}{l}\text { depth scans. Loose probe } \\
\text { attachment, data questioanble. }\end{array}$ \\
\hline 3 & 1 & 2 & $180^{\circ}$ & $0^{\circ}$ & CD & \\
\hline 4 & 1 & 2 & $180^{\circ}$ & $0^{\circ}$ & CD & \\
\hline $5-6$ & 1 & 2 & $180^{\circ}$ & $0^{\circ}$ & CD & Repeat tapes $1,2,3$, slot dry. \\
\hline $6-7$ & 1 & 2 & $180^{\circ}$ & $\mathbf{0}^{\circ}$ & Offset & Rec. at $6.0 \mathrm{~m}$ \\
\hline $7-8$ & 2 & 3 & $180^{\circ}$ & $0^{\circ}$ & CD & slot dry \\
\hline $8-9$ & 2 & 3 & $0^{\circ}$ & $0^{\circ}$ & CD & slot dry \\
\hline $9-10$ & 2 & 3 & $180^{\circ}$ & $0^{\circ}$ & Offset & Rec at $6.0 \mathrm{~m}$ \\
\hline 11 & 4 & 5 & $180^{\circ}$ & $0^{\circ}$ & CD & Scan start at $5 \mathrm{~m}$ slot dry \\
\hline 12 & 4 & 5 & $0^{\circ}$ & $0^{\circ}$ & CD & Slot dry \\
\hline 13 & 4 & 5 & $0^{\circ}$ & $0^{\circ}$ & Offset & Rec. at $5 \mathrm{~m}$, slot dry \\
\hline $14-15$ & 1 & 2 & $180^{\circ}$ & $0^{\circ}$ & CD & Water in slot \\
\hline $15-16$ & 1 & 2 & $180^{\circ}$ & $0^{\circ}$ & Offset & Rec. at $6 \mathrm{~m}$ water in slot \\
\hline $16-17$ & 2 & 3 & $180^{\circ}$ & $0^{\circ}$ & CD & Water in slot \\
\hline $17-18$ & 2 & 3 & $180^{\circ}$ & $0^{\circ}$ & Offset & Rec at $6 \mathrm{~m}$ water in slot \\
\hline 19 & 1 & 2 & Various & - & CD & Rotation tests \\
\hline 20 & 1 & 2 & $270^{\circ}$ & $270^{\circ}$ & CD & Water in slot \\
\hline
\end{tabular}

(1) Position of transducers relative to plane of target slot, clockwise viewed from above, $0^{\circ}=$ direction from borehole to target.

(2) CD Scan is a comon depth scan, probes hoisted in unison. Offset scan - the receiver probe fixed at the lowest position in borehole, the transmitter hoisted to each of the data interval positions. 


\section{TEST RESULTS}

\section{A. Directional Radar Experiments}

The results of the borehole radar tests are organized according to the factors which control the radar reflection coefficient of the target, 1.e. the material filling the slot. The target conditions are identifled as: (1) air filled; (2) metal reflector inserted; and (3) water of varlous conductivities.

\section{Air-Filled Target slot Tests}

The test plan called for recording radar reflection data in each of five boreholes for each of the target conditions. This plan was implemented to the greatest extent possible. In some instances, the raw data appeared to be adequate; however, when data processing was applied, it was found that the $\pm 10 \mathrm{~cm}$ ambiguity of the cable odometer produced some probe position errors.

The most effective reflection signal enhancement technique applied was one which removed the static system-related signals in the radar video waveforms.

The directional radar can be operated in either of two scan modes. In one mode, the probe is held stationary at each depth interval while the antenna is rotated through eight angular positions. Radar waveforms are recorded at each 45-degree increment. This procedure is repeated at each depth station until the vertical depth interval of interest is logged. This type of borehole scan assures that each of the azimuthal position recordings are made at the same level in the borehole; however, this procedure is very slow. The alternate procedure consists of eight constant-angle vertical scans with the antenne oriented at each of the efght angular positions. This is a much faster scanning technique and is usually satisfactory. Data were recorded during the tests using both techniques. It was found later that during some of the constant-angle scans, the depth position of the probe varied as much as 10 centimeters for each data station from scan to scan.

In the signal enhancement process, video waveforms taken at complimentary angles are subtracted. The residual waveform is free of signals which are independent of antenna position such as internal feedover and vertical reflection signals from the hole collar and hole bottom. Reflection 8 ignals and noise remain in the four video waveforms with a 180-degree ambiguity as to the direction of the reflecting interface. If necessary, this ambiguity could be removed by additional processing.

If the interfering signals vary significantly with vertical position, the subtraction process will not be effective if the complimentary angle signals are not recorded at precisely the, same elevation. This incomplete removal of stationary signals is demonstrated in some of the waveforms shown later and accounts for some loss of the final data quality. 
Figure 15 shows nested radar signal waveforms corresponding to the difference of signals received from directions of 45 degrees and 225 degrees. Figure $15(a)$ displays 250 nanoseconds of radar time window for the depth range of 8.0 meters to 2.6 meters. The incomplete removal of surface (hole collar) reflections is shown by the signals tending diagonally upward to the left. Figure 15(b) shows the first 100 nanoseconds of the display with the signal amplitude increased by a factor of 2.5. Electromagentic parameter measurements indicate that the reflections from the air-filled slot should be received at approximately 62.5 nanoseconds after transmit time. A group of weak reflection signals occurring at that time can be detected.

Figure 16 shows the subtracted radar waveforms wth the probe positioned in Borehole No. 2. The subtraction process was almost completely ineffective in this case because of the depth offset error between the 45 degree and the 225 degree waveforms. Reflections from the target slot cannot be seen in this data.

Figure 17 shows the subtracted radar data for 45 degrees (225 degrees) with the probe in Borehole 3. No clear target reflections are visible in these data.

No reflections from the air-filled slot were detected in data from Borehole 4 or Borehole 5 . Vertical depth errors in the scans seriously reduced the effectiveness of the reverse-angle subtraction processing.

\section{Metal Reflector Tests}

A square metal reflector eight feet on a side was fabricated using 24-gauge galvanized steel sheet attached to two $4 \times 8$-foot sheets of plywood. This reflector was lowered to the bottom of the slot with the metal facing Borehole No. 1.

With the radar probe in Borehole No. 1, constant depth-azimuthal scans from 8.2 meters to 4.0 meters depth were performed. Figure 18 shows eight nested raw data waveforms. Very little reflection signal is detectable in the raw data; however, when reverse-angle subtraction processing is applied, the large reflection signal shown in Figure 19 is obtained. In Figure 19(a) the broadband output is shown. A $100 \mathrm{MHz}$ low-pass filter was applied to the data to yield the waveforms shown in Figure 19(b). The directivity of the radar antenna is demonstrated in Figure 20. Figure 20(a) shows the 90 (270) degree response and Figure 20(b) shows the 135 (315) degree response.

From the azimuthal responses shown in Figures 19 and 20 , the true target direction is very near 45 degrees magnetic bearing from the borehole. Cancellation of the reflection signal is almost complete in the measurements at 135 (315) degrees. 


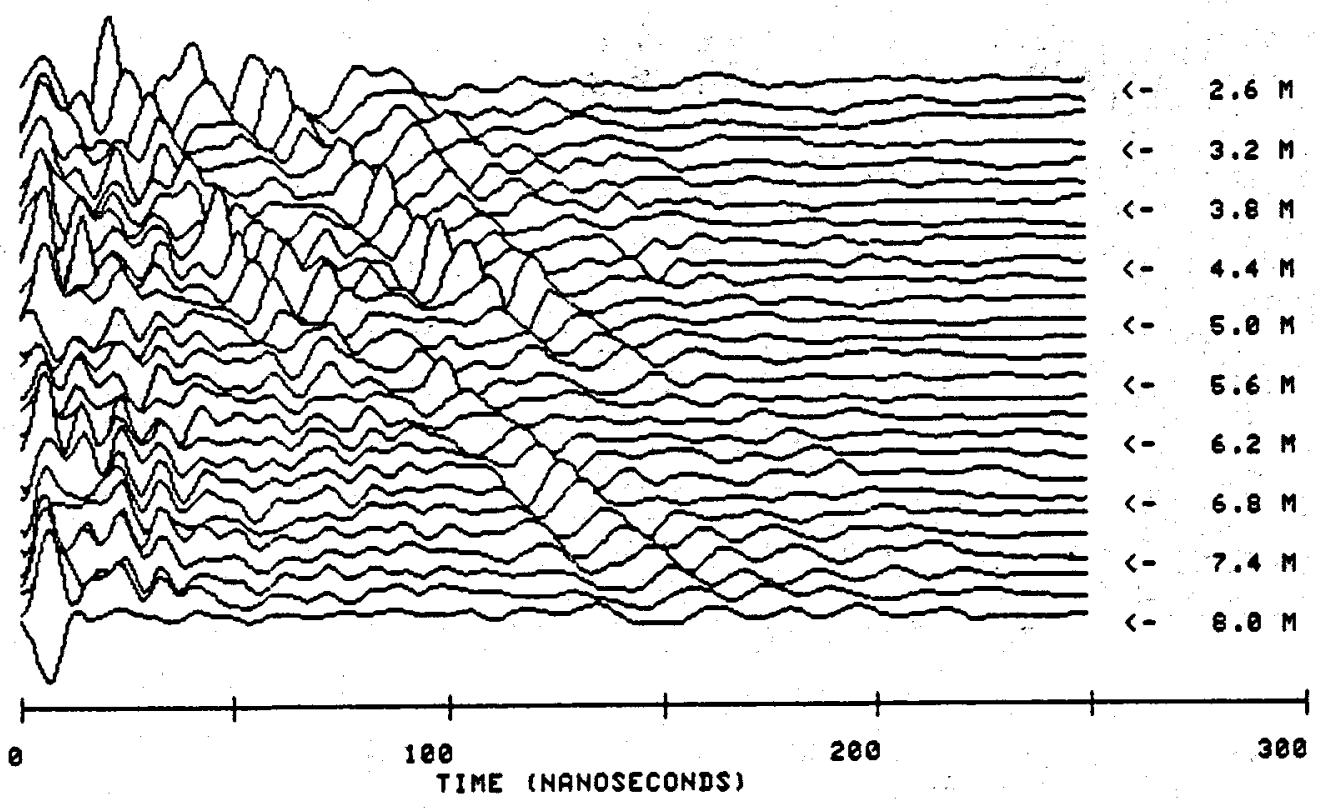

(a) 250 Nanosecond Time Window

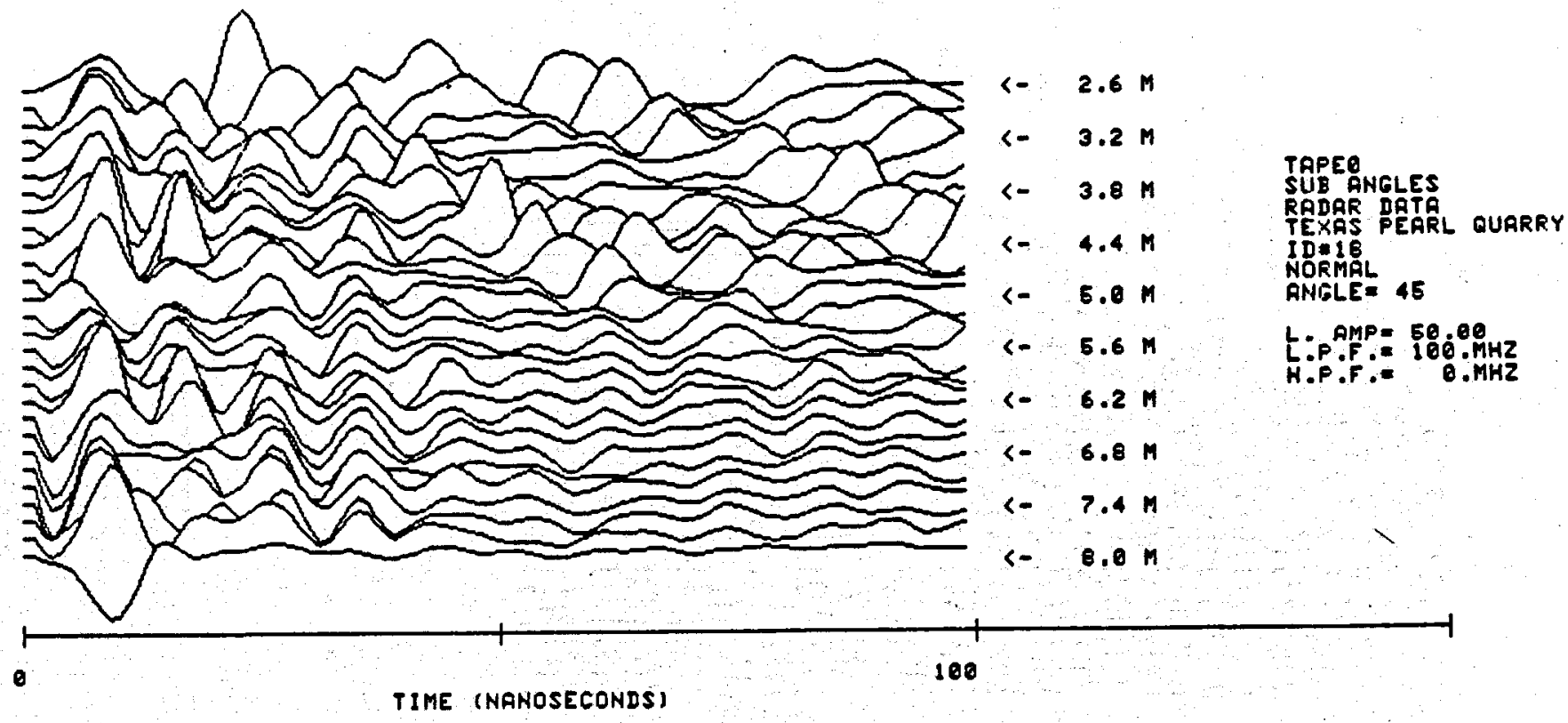

(b) 100 nanosecond Time Window, Amplified Signal

FIGURE 15. $45^{\circ}\left(225^{\circ}\right)$ ANTENNA POSITION RADAR RESPONSE FROM BOREHOLE NO. 1 , AIR FILLED TARGET SLOT 


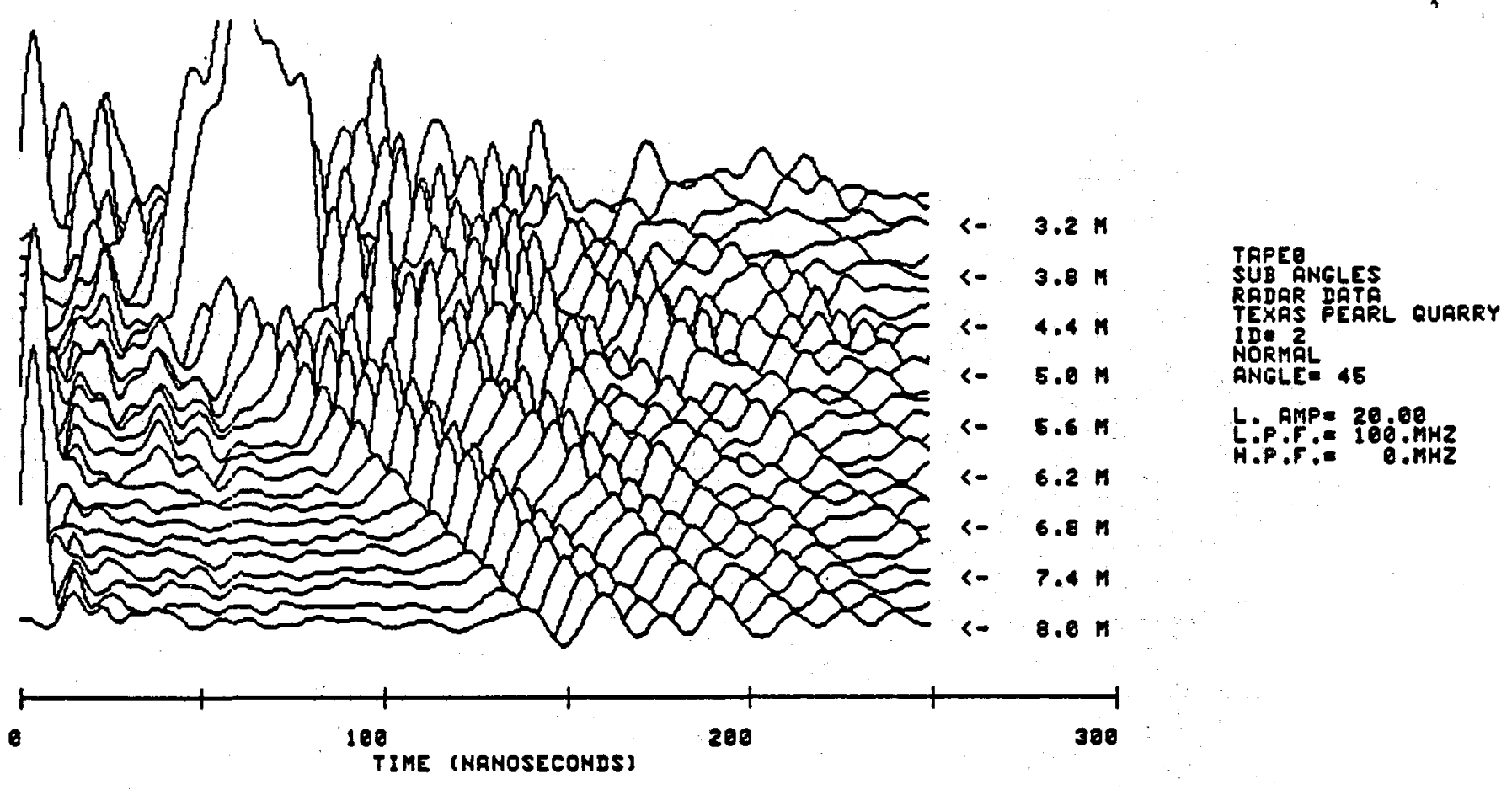

FIGURE 16. RADAR SIGNALS WITH PROBE IN BOREHOLE 2, TARGET SLOT DRY
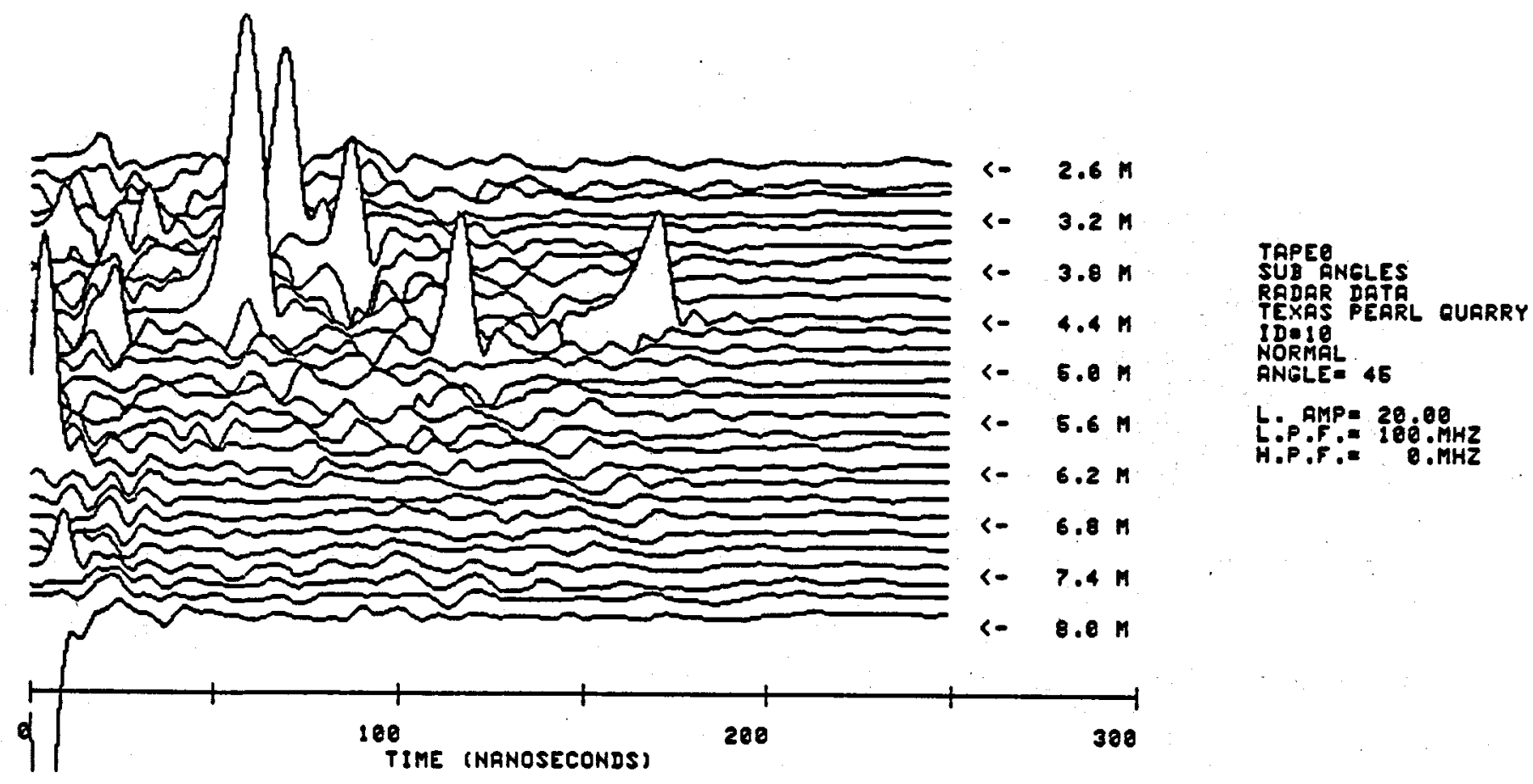

FIGURE 17. RADAR SIGNALS WITH PROBE IN BOREHOLE 3, TARGET SLOT DRY 

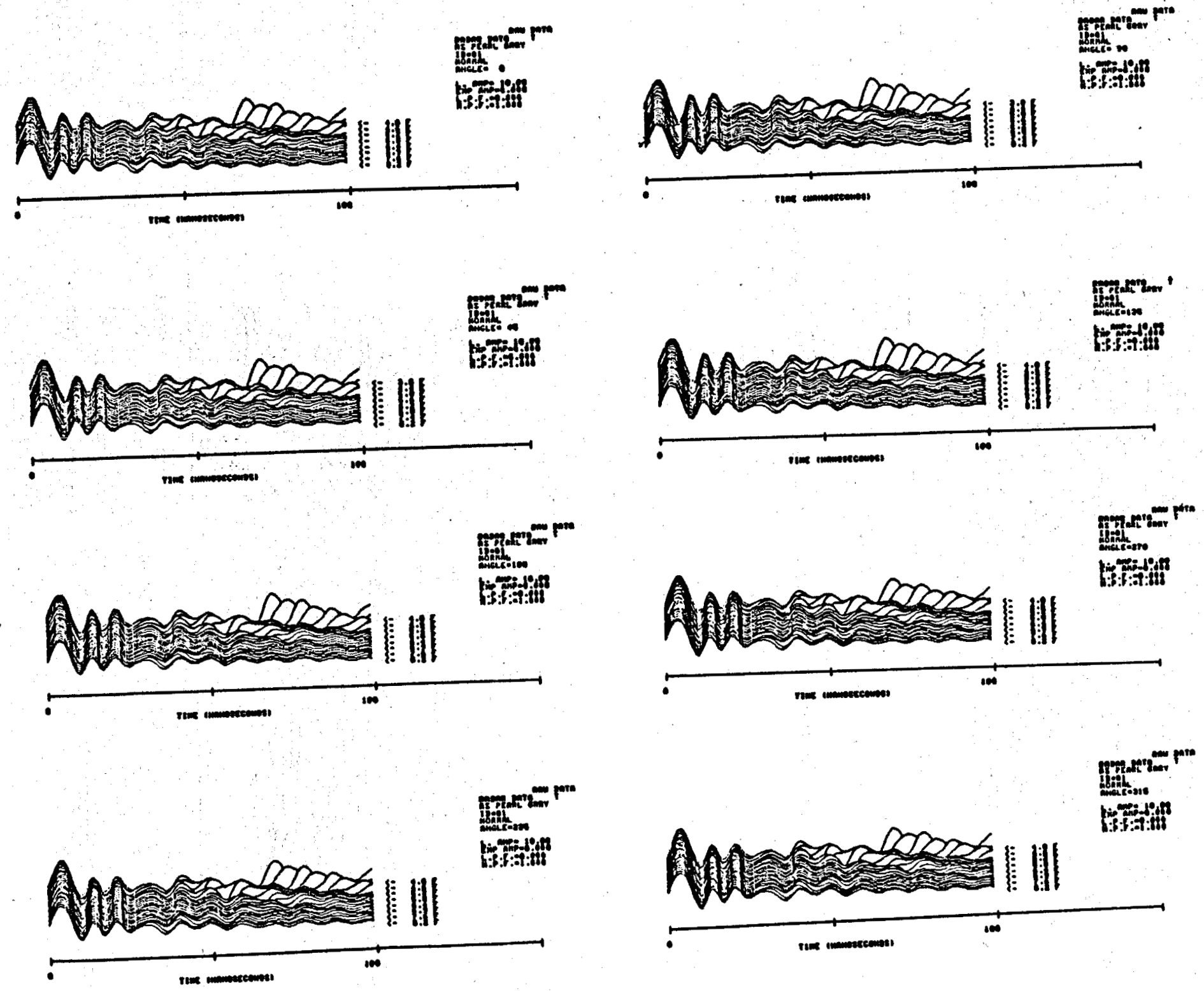

FIGURE 18. RAW DATA WAVEFORMS WITH PROBE IN BOREHOLE 1, METAL REFLECTOR IN TARGET SLOT 


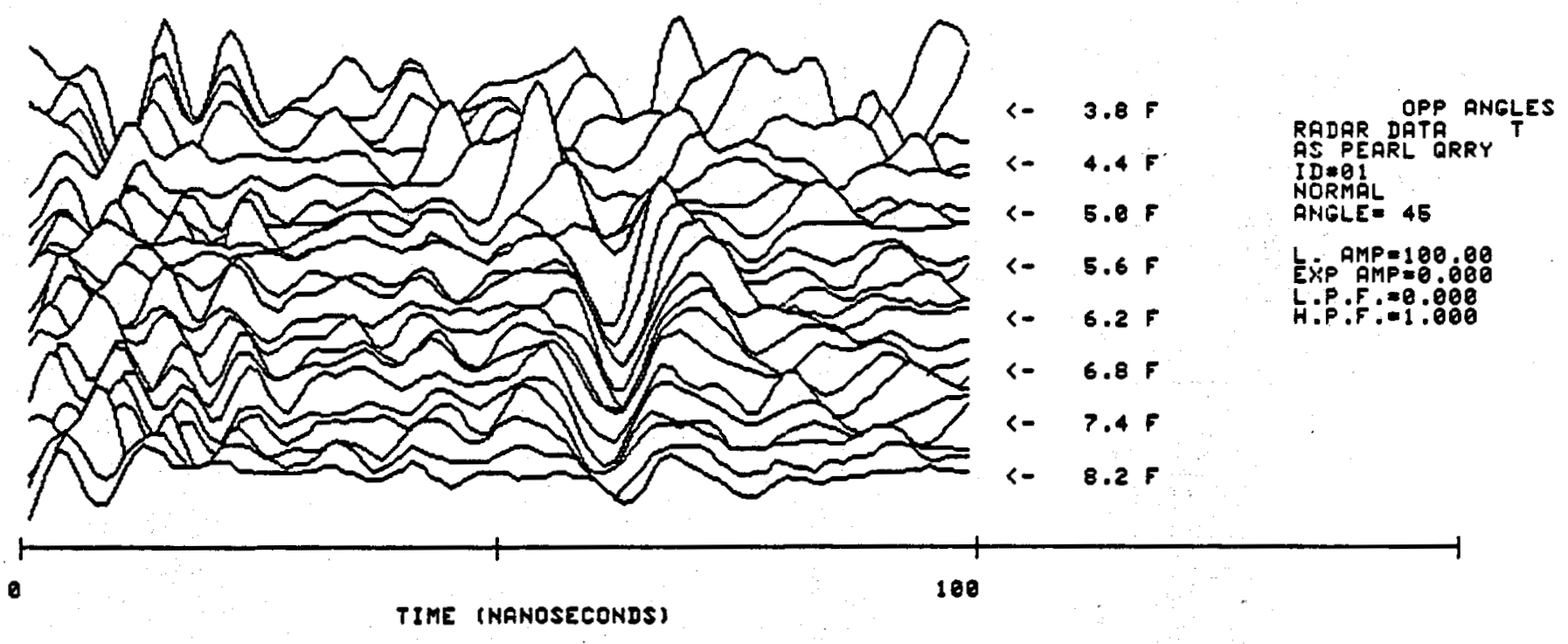

(a) Broadband Response, Returns from $45^{\circ}$ and $225^{\circ}$ Subtracted

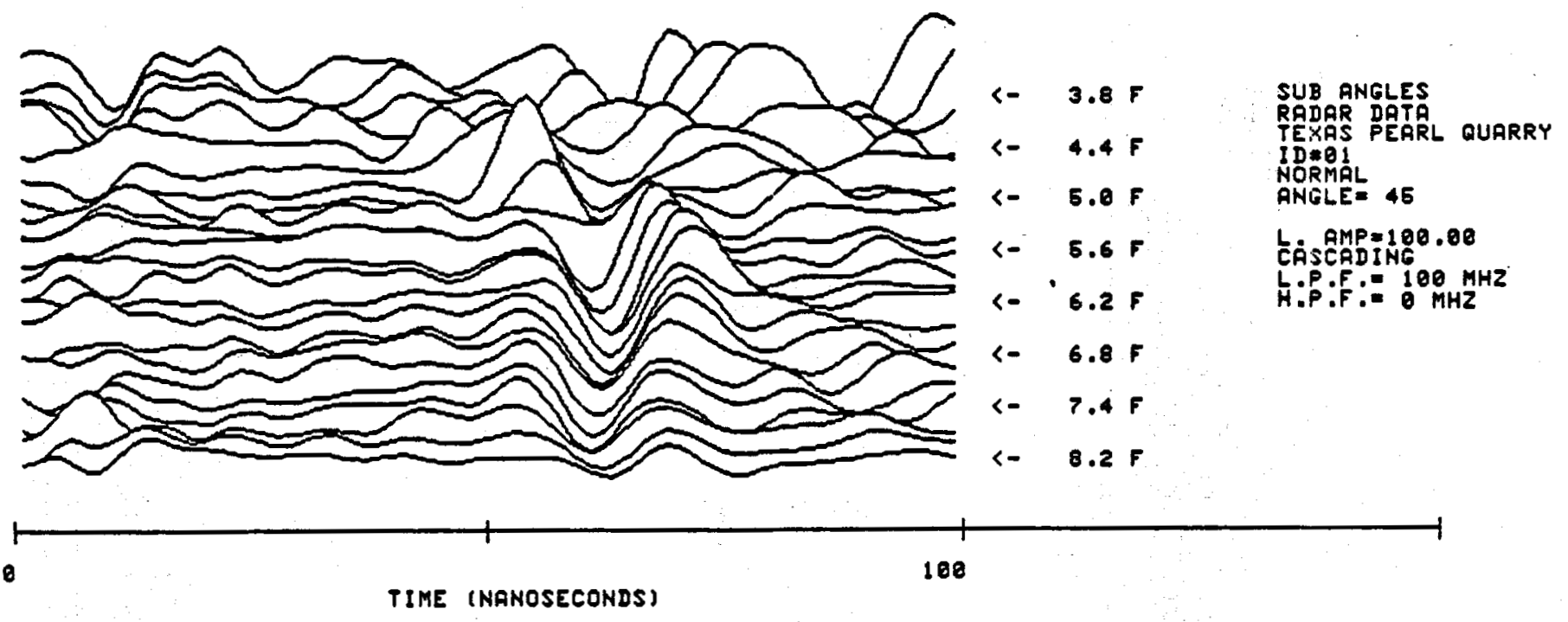

(b) $100 \mathrm{MHz}$ Low Pass Filter Response, Returns from $45^{\circ}$ and $225^{\circ}$ Subtracted

FIGURE 19. RADAR SIGNALS WITH PROBE IN BOREHOLE 1, METAL REFLECTOR IN TARGET SLOT 


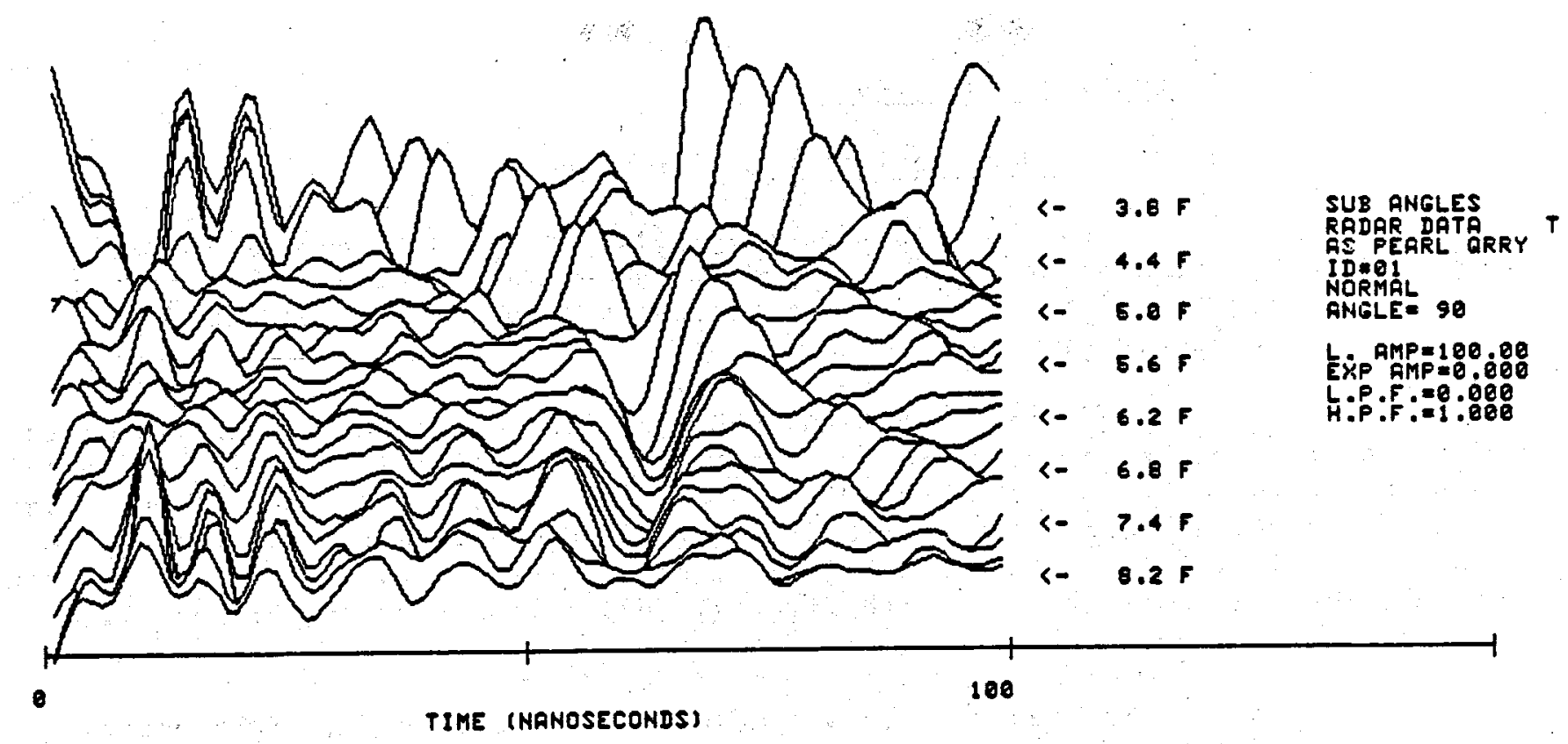

(a) Difference of Signals from $90^{\circ}$ and $270^{\circ}$

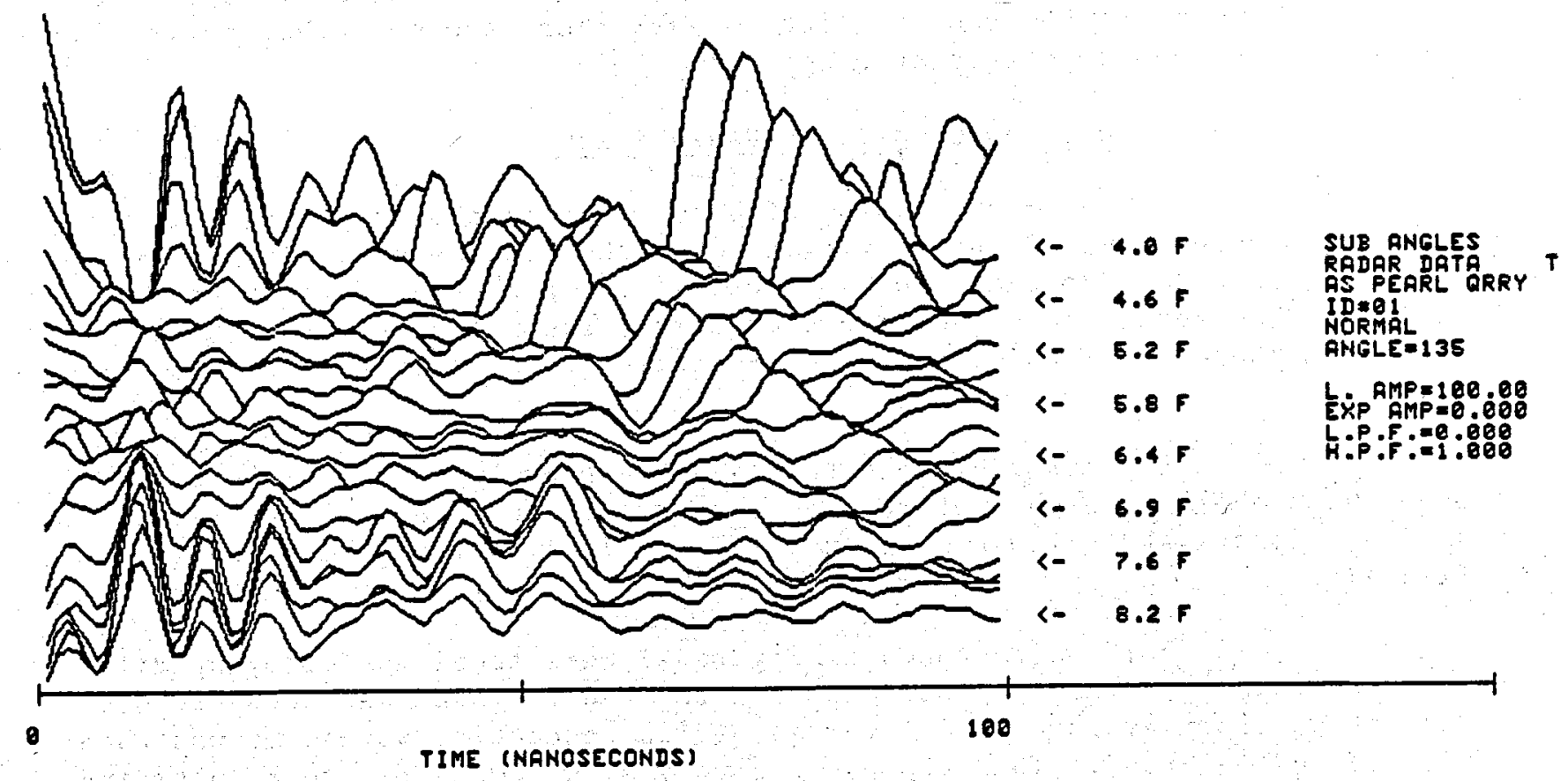

(b) Difference of Signals from $135^{\circ}$ and $315^{\circ}$

FIGURE 20. RADAR SIGNALS WITH PROBE IN BOREHOLE 1, METAL REFLECTOR IN TARGET SLOT 


\section{Conductive Fluid Tests}

\section{a. $\quad 10.1 \mathrm{Ohm}$-Centimeter Resistivity}

A sodium chloride brine solution was prepared by mixing rock salt with fresh water in 55-gallon drums shown in Figure 9. The water was poured into the slot, allowed to stabilize in temperature, and then sampled for conductivity measurements.

The radar waveforms shown in Figures 21 and 22 were recorded with the radar probe in Borehole No. 1 with a salt solution in the slot which later measured to be 10.1 ohm-centimeter resistivity. The two types of borehole scans described earlier were performed; Figure 21 shows data recorded using the constant-angle vertical scans and Figure 22 shows data recorded using the constantdepth azimuthal scan data. In both figures, reflections from the brine-filled s lot are very clear.

The radar probe was moved to Borehole No. 2, eight meters away from the slot, and the two scans were repeated. Figure 23 shows the results of the constant-angle scans. Figure 24 shows the results of the constant depth scans. The plots indicate almost identical data with the slot reflections appearing at approximately 160 nanoseconds. Although this is 35 nanoseconds later than expected, a time base shift of that magnitude has obviously occurred either in the processing or in the recording of the data. The reflections are concluded to be from the slot target; there are no other reflecting surfaces in the granite near that range.

\section{b. $16.0 \mathrm{Ohm}$-Centimeter Resistivity}

The concentration of salt water in the target slot was reduced to produce a fluid resistivity of 16.0 ohm-centimeters. The radar probe was operated in Borehole No. 1 to obtain the processed data shown in Figure 25. The reflections from the slot target are not significantly different from those obtained with 10.1 ohm-centimeter resistivity fluid in the slot.

Figure 26 shows the radar response with the probe positioned in Borehole 2, eight meters from the target slot. A weak but clear signal at approximately 160 nanoseconds is a reflection from the brinefilled slot.

The data shown in Figure 27 were acquired employing different recording equipment. The output of the radar system was connected to a Nicolet waveform averager. An average of 128 sequential waveforms was then digitized and recorded. This process was very slow; however, the results indicate that with appropriate signal enhancement the slot is detectable by the radar at a distance of 12 meters away (Borehole 3 ). 


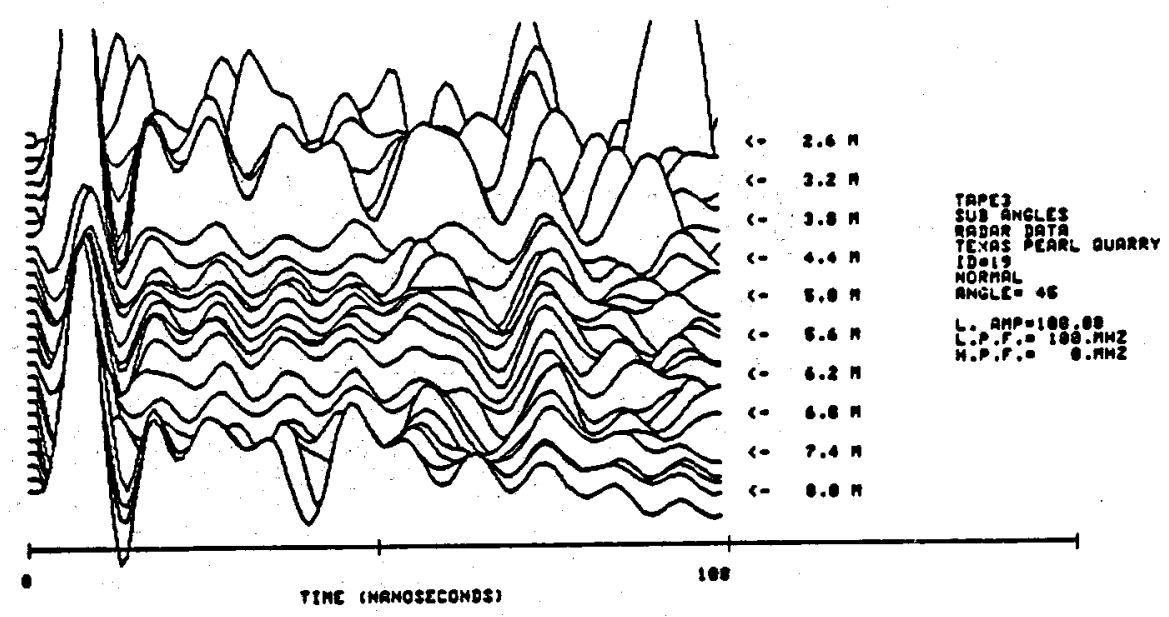

(a) $100 \mathrm{MHz}$ Low Pass Filtered Data

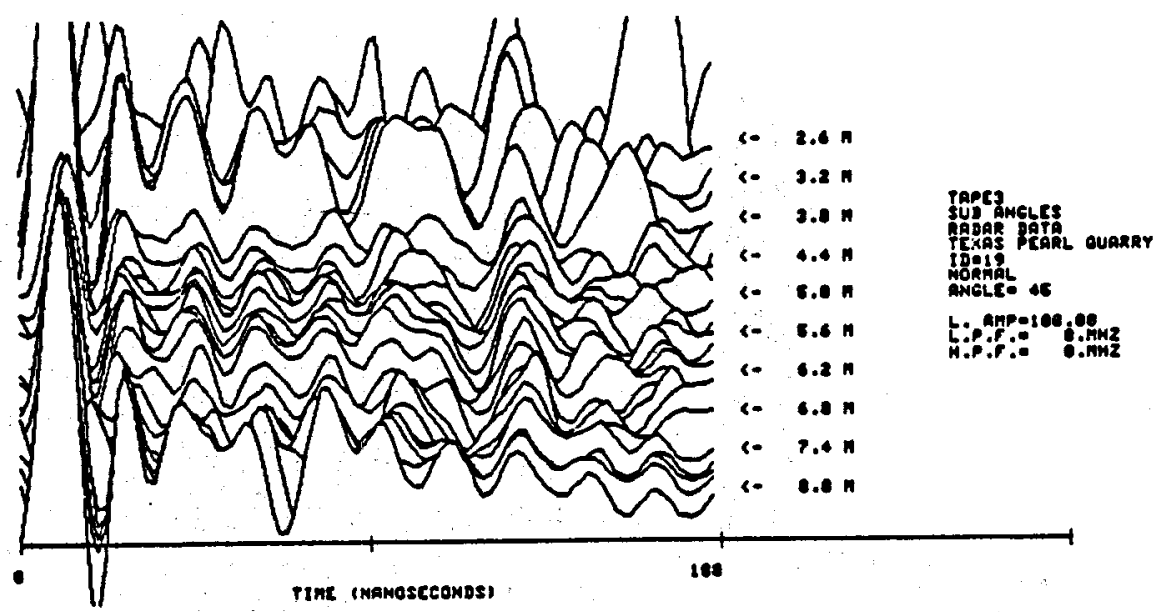

(b) Broadband Data

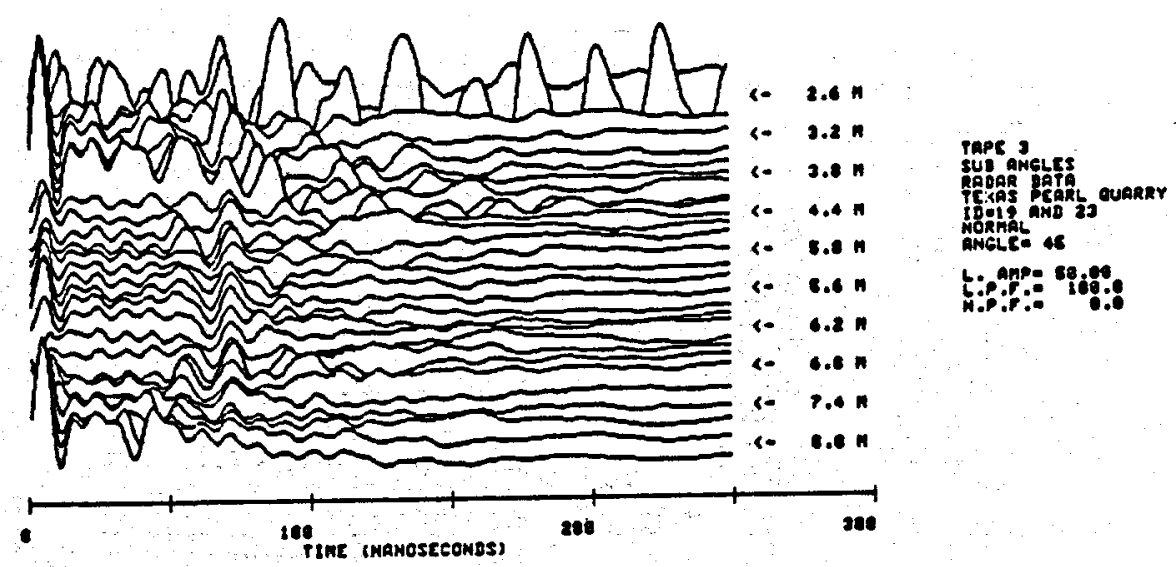

(c) 50 MHz Low Pass Filtered Data, 250 ns Window

FIGURE 21. CONSTANT ANGLE SCANS OF BOREHOLE 1 WITH 10.1 OHM CENTIMETER BRINE IN TARGET SLOT 

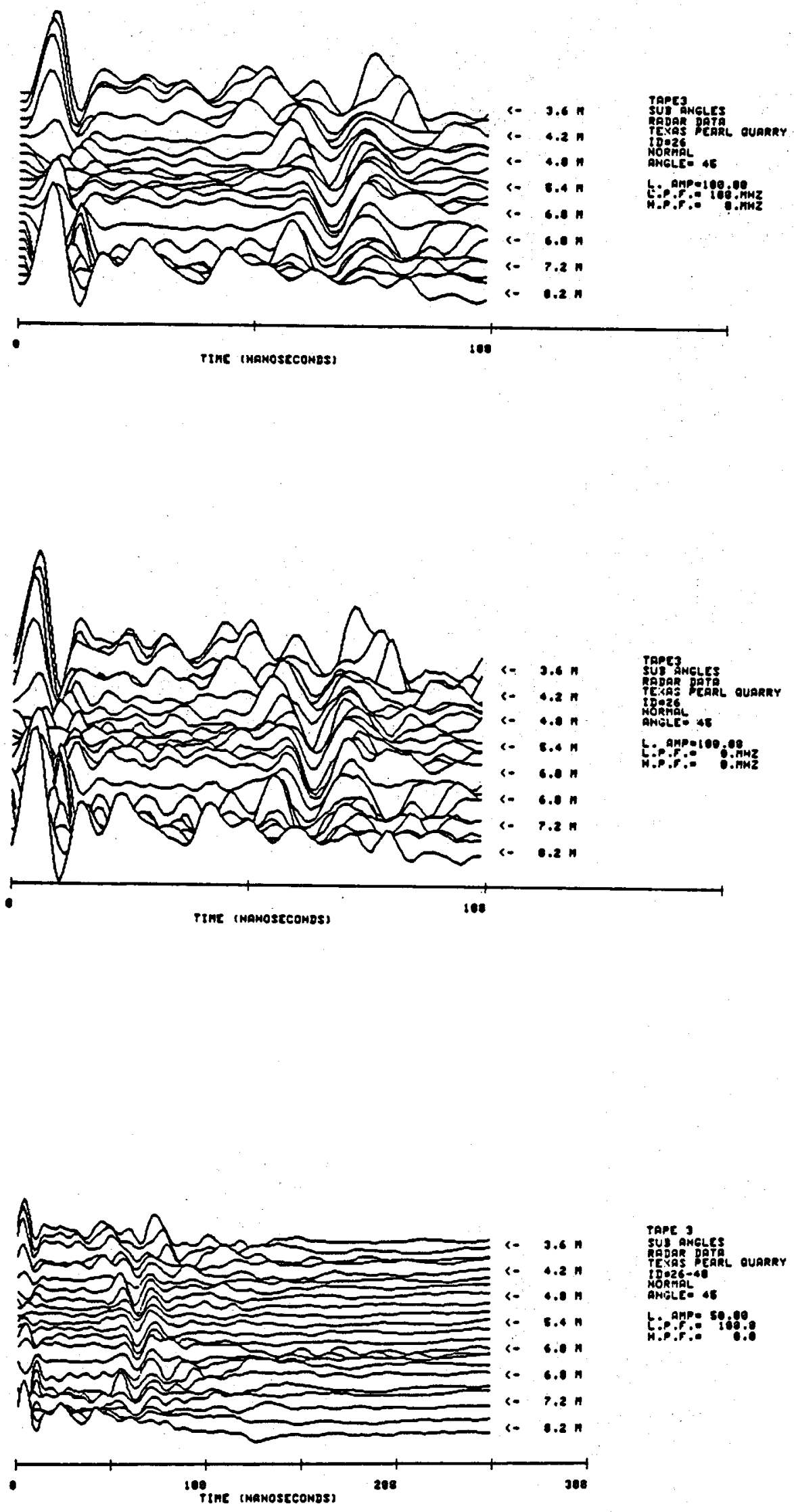

FIGURE 22. CONSTANT DEPTH SCANS OF BOREHOLE 1 10.1 OHM CENTIMETER BRINE IN TARGET SLOT 

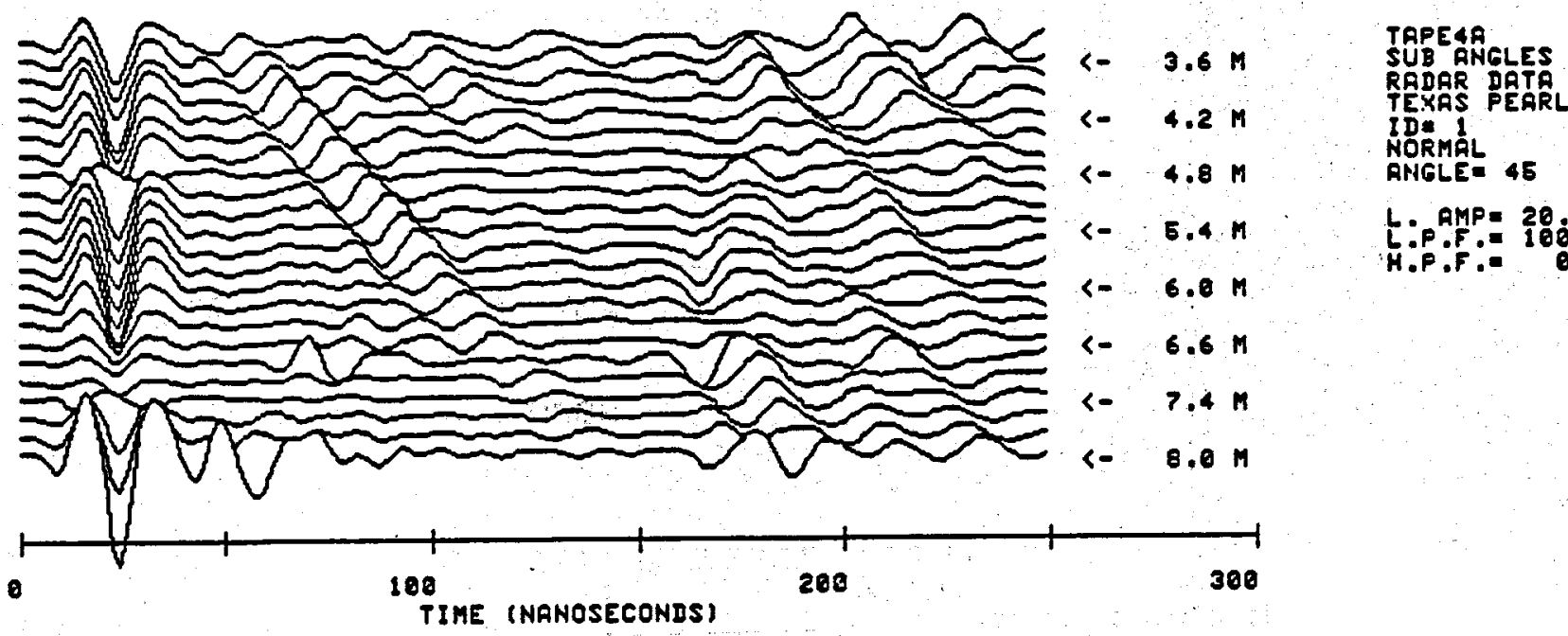

RADAR DATR

IDE 1

NORMAL

ANGLE 45

L.P AMP $=20.08$

H.P.F.: IOQ.MHZ

FIGURE 23. RADAR PROBE IN BOREHOLE 2, CONSTANT ANGLE SCAN,

10.1 OHM CENTIMETER RESISTIVITY BRINE IN TARGET SLOT 


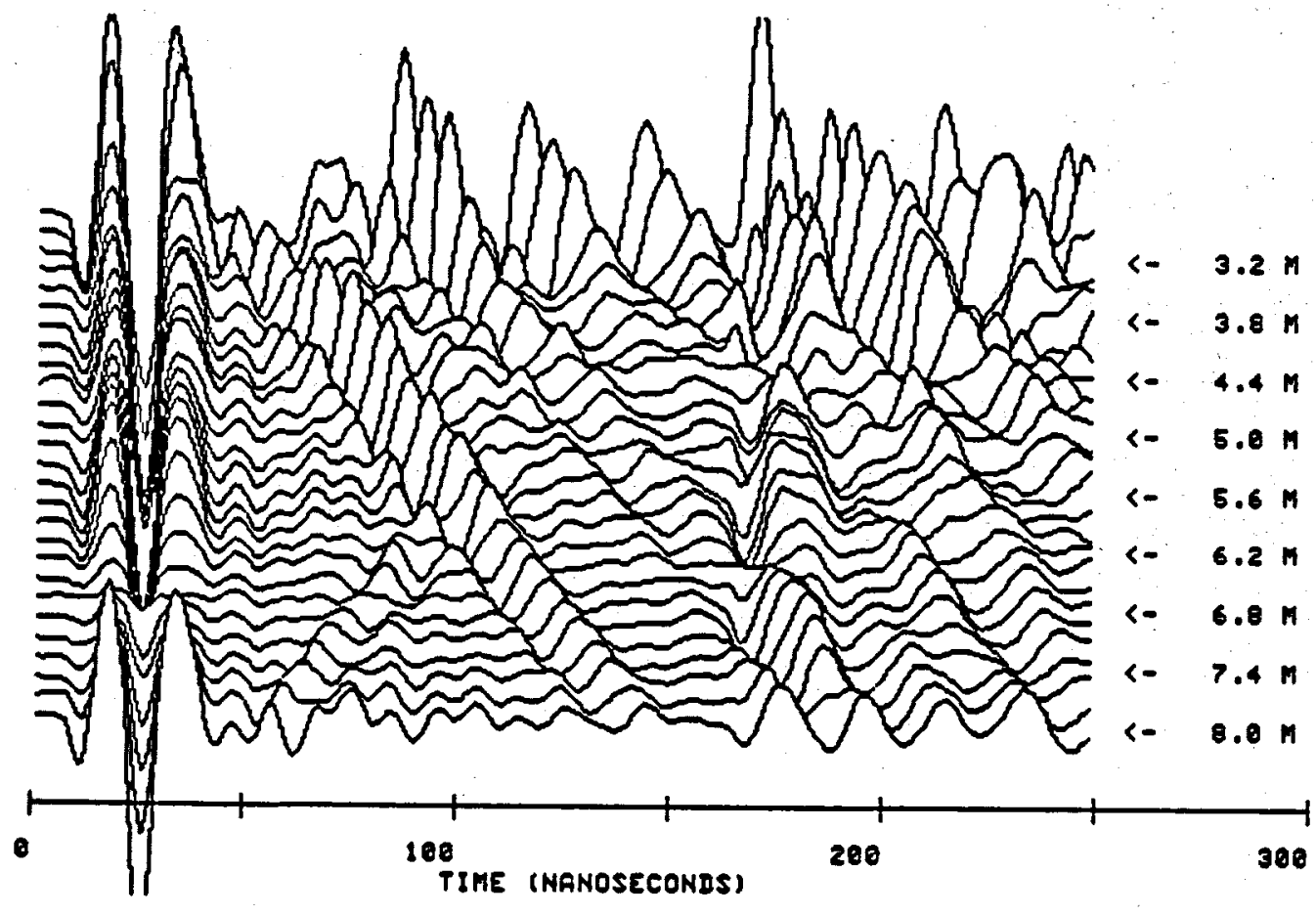

TAPE 3

SUB ANGLES

RADAR DATA OUARRY

TEXAS PEARL

NORMAL

ANGLE $=45$

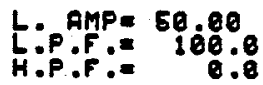

FIGURE 24. RADAR PROBE IN BOREHOLE 2, CONSTANT DEPTH SCAN, 10.1 OHM CENTIMETER RESISTIVITY BRINE IN TARGET SLOT 


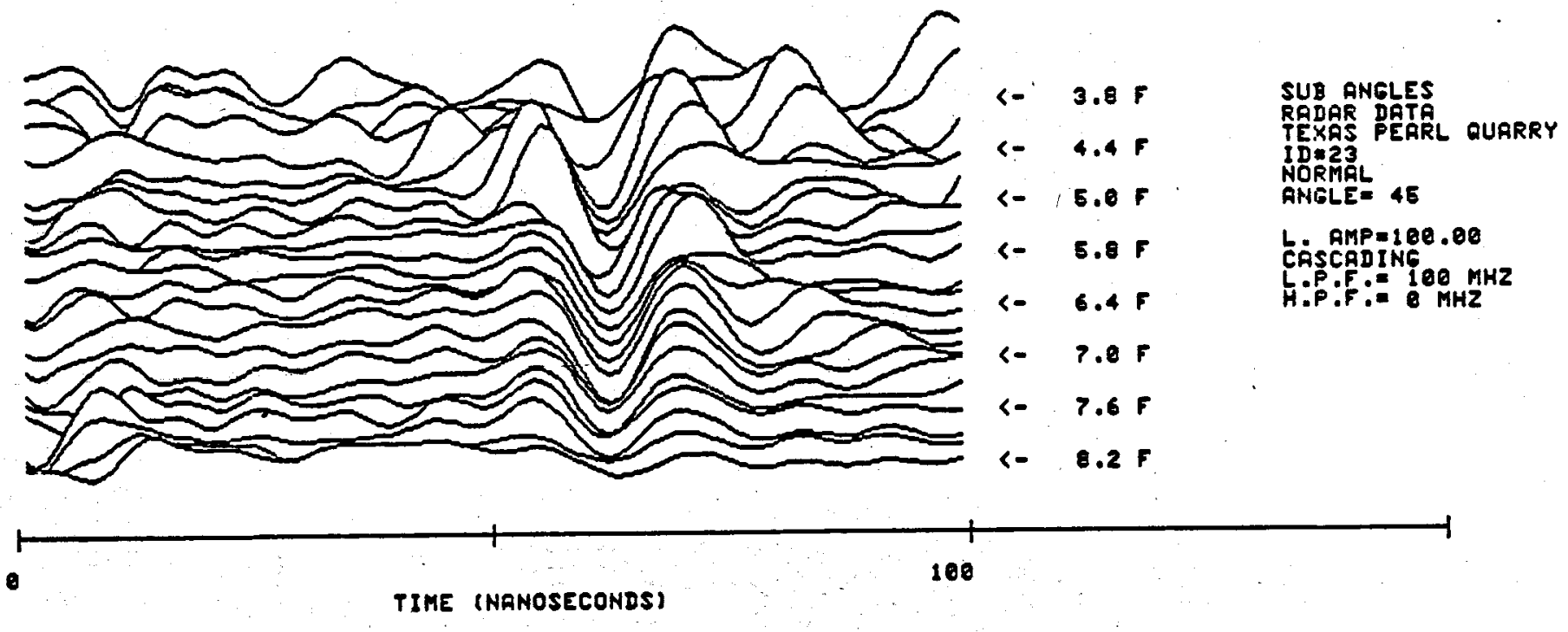

FIGURE 25. RADAR PROBE IN BOREHOLE $1,16.0$ OHM CENTIMETER RESISTIVITY BRINE IN TARGET SLOT

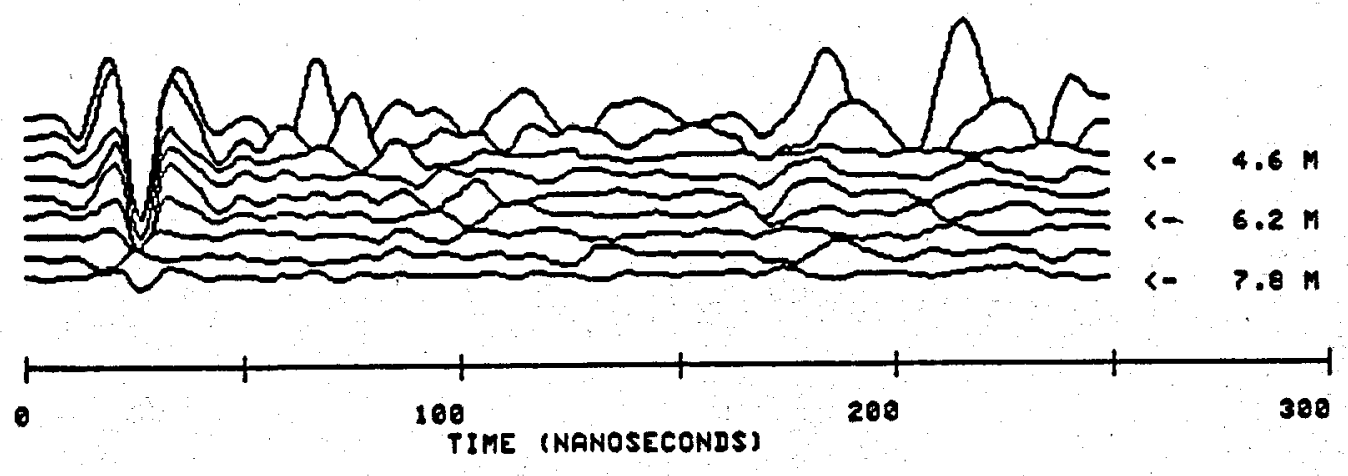
TAPEWOB
RADAR DATA
TEXAS PEARL QUARRY $1 D * 47$
NORMAL
AHGLE= 45

L:PMP=280.08

FIGURE 26. RADAR PROBE IN BOREHOLE 2, 16.0 OHM CENTIMETER RESISTIVITY BRINE IN TARGET SLOT 


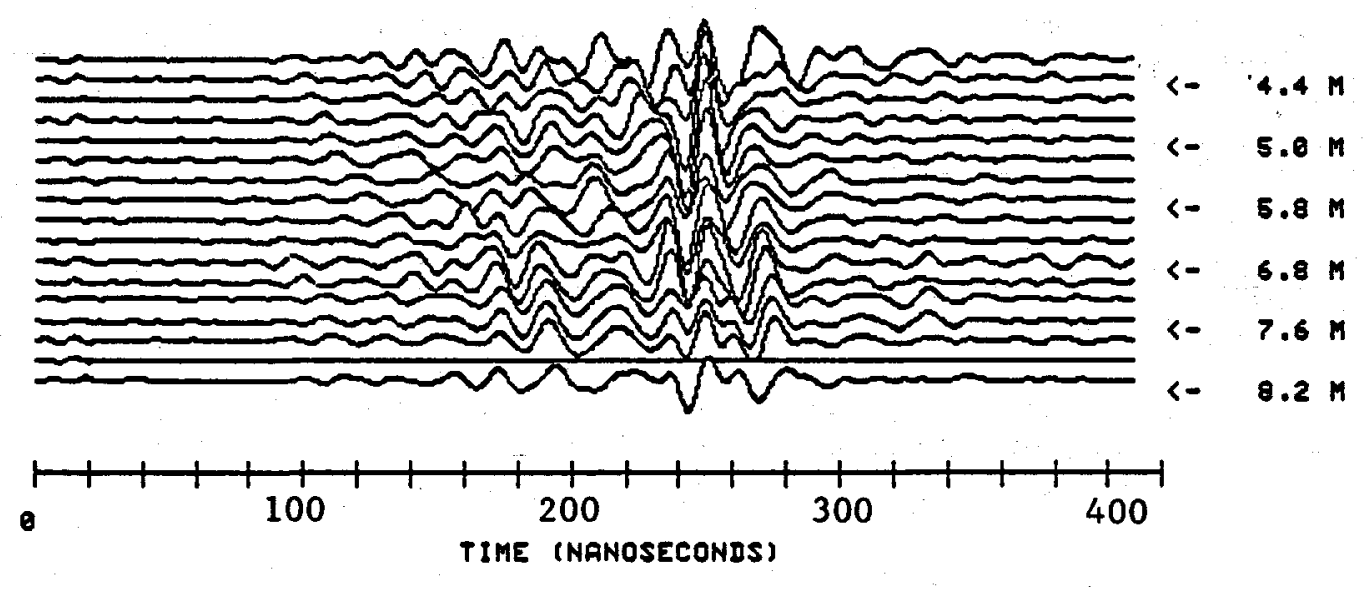

FIGURE 27. RADAR PROBE IN BOREHOLE $3,16.0$ OHM CENTIMETER
RESISTIVITY BRINE IN TARGET SLOT

FIGURE 27. RADAR PROBE IN BOREHOLE $3,16.0$ OHM CENTIMETER
RESISTIVITY BRINE IN TARGET SLOT
SUB ANGLES

GUMINES RARR

BOREHOLE : 3

MORMAL

ANGLE= 45

L. AMP $=5 \dot{B}^{25}$

L.P.F.: 5 Q.MHZ 


\section{B. Hole-to-Hole Electromagnetic Reflection Tests}

The hole-to-hole electromagnetic system was operated as a bistatic radar probe in pairs of holes with the expectation that in addition to the direct arrival of the electromagnetic pulse from transmitter to receiver, there would also be received pulse signals reflected from the target slot. Tests were conducted with air and with two conductivities of water in the slot.

\section{Dry Target Slot Experiments}

\section{a. Transmitter in Borehole 2 - Receiver in Borehole 3}

In the data shown in Figure 28 , the transmitter probe was held fixed at 6.5 meters depth in Borehole No. 2 while the receiver probe was scanned up Borehole No. 3. The direct arrival signal is quite strong and the associated travel time increases with range precisely as expected. Waves reflected from the slot should arrive at the receiver at the times indicated by the line labeled REFL. There are not distinct arrival signals corresponding to this predicted travel time presumably because of scattering and interface losses.

\section{b. Recelver in Borehole 1 - Transmitter in Borehole 3}

The two-way pulse reflection distance was shortened by four meters by locating the receiver in Borehole 1 and the transmitter in Borehole 3. Refelctions from the slot should appear along the line marked REFL in Figure 29. The signal peaks which trend toward time zero at zero depth are the result of pulse energy propagating on the wireline cables. These undesirable signals tend to mask reflection signals when the probes are operated within a few meters of the surface. Nevertheless, there are no obvious signals indicating reflections from the dry target slot.

\section{c. Receiver in Borehole 4 - Transmitter in Borehole 5}

Figure 30 shows the results of a common depth hole-to-hole scan in Boreholes 4 and 5 as shown in Figure 7. There is a line of signal peaks at the proper time for a reflection from the edge of the target slot. However, the direct signal to the receiver is very strong and there is the possibility of overloading and delayed recovery in the receiver. An examination of Figure 31 in which the transmitter is held fixed at the bottom of Borehole 5 and the receiver scanned up Borehole 4 shows that apparent reflection follows the same time delay pattern as the direct arrival signal, indicating that the signals are the result of receiver saturation and not a reflection. No other indications of reflections are seen in the data display.

\section{Target Slot Filled with Conductive Fluid}

\section{a. Transmitter in Borehole 1 - Receiver in Borehole 2}

The data displayed in Figure 32 was recorded with the receiver fixed at 6.0 meters depth in Borehole 1 and the transmitter scanned up 


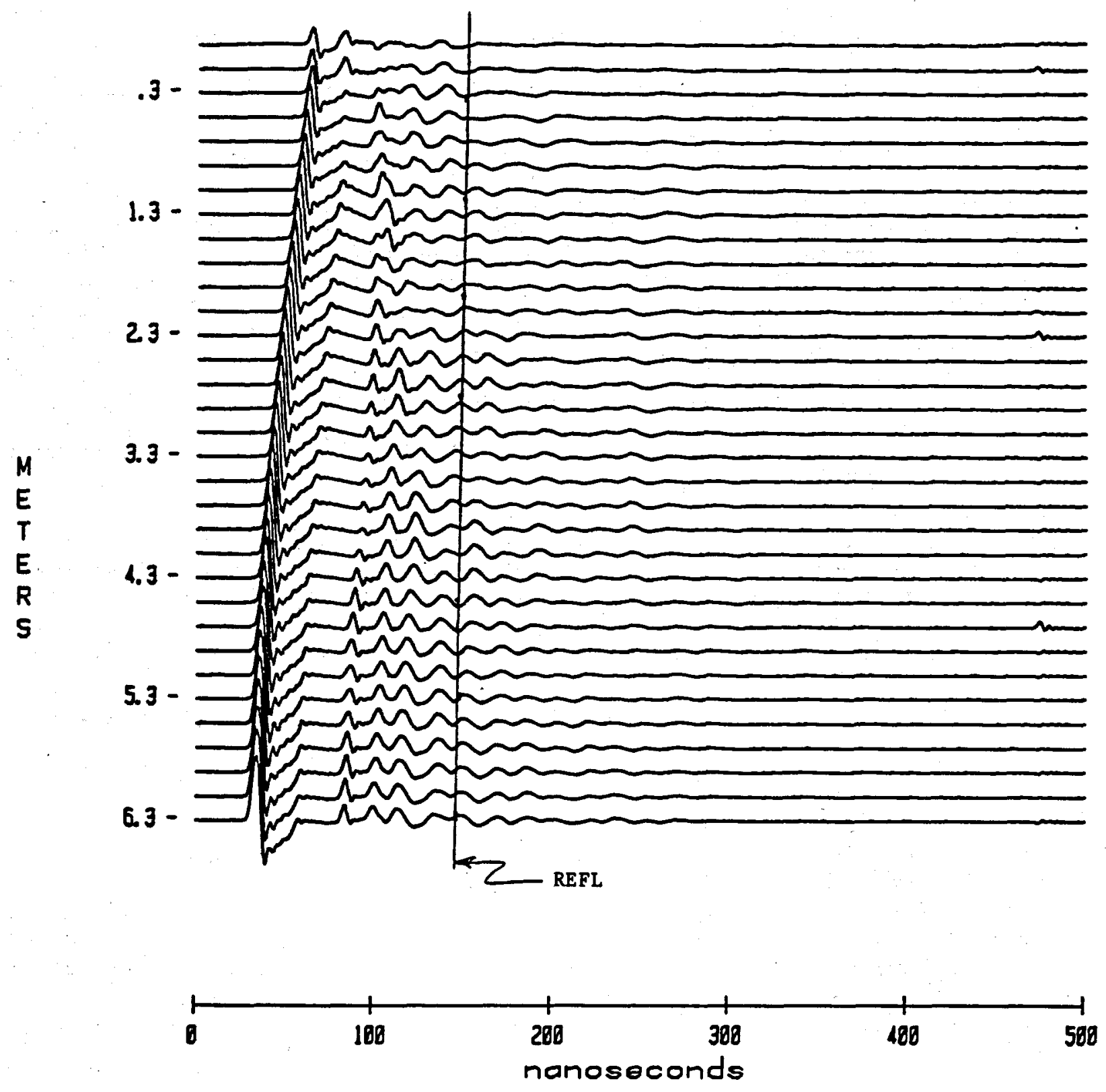

FIGURE 28. HOLE TO HOLE ELECTROMAGNETIC TESTS, RECEIVER IN BOREHOLE 2 TRANSMITTER IN BOREHOLE 3, TARGET SLOT DRY 


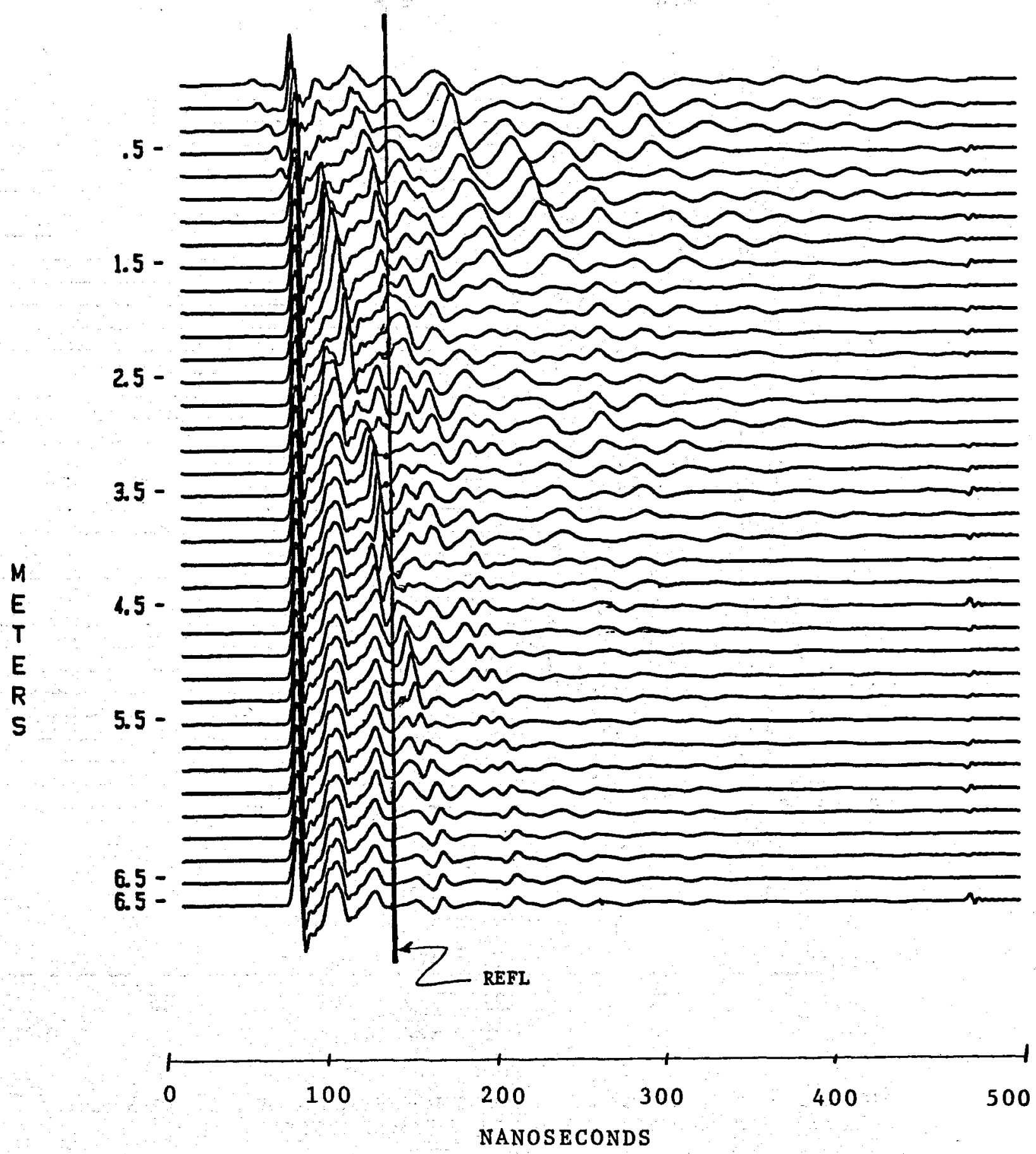

FIGURE 29. HOLE TO HOLE ELECTROMAGNETIC TESTS, RECEIVER IN BOREHOLE 1, TRANSMITTER IN BOREHOLE 3, TARGET SLOT DRY 


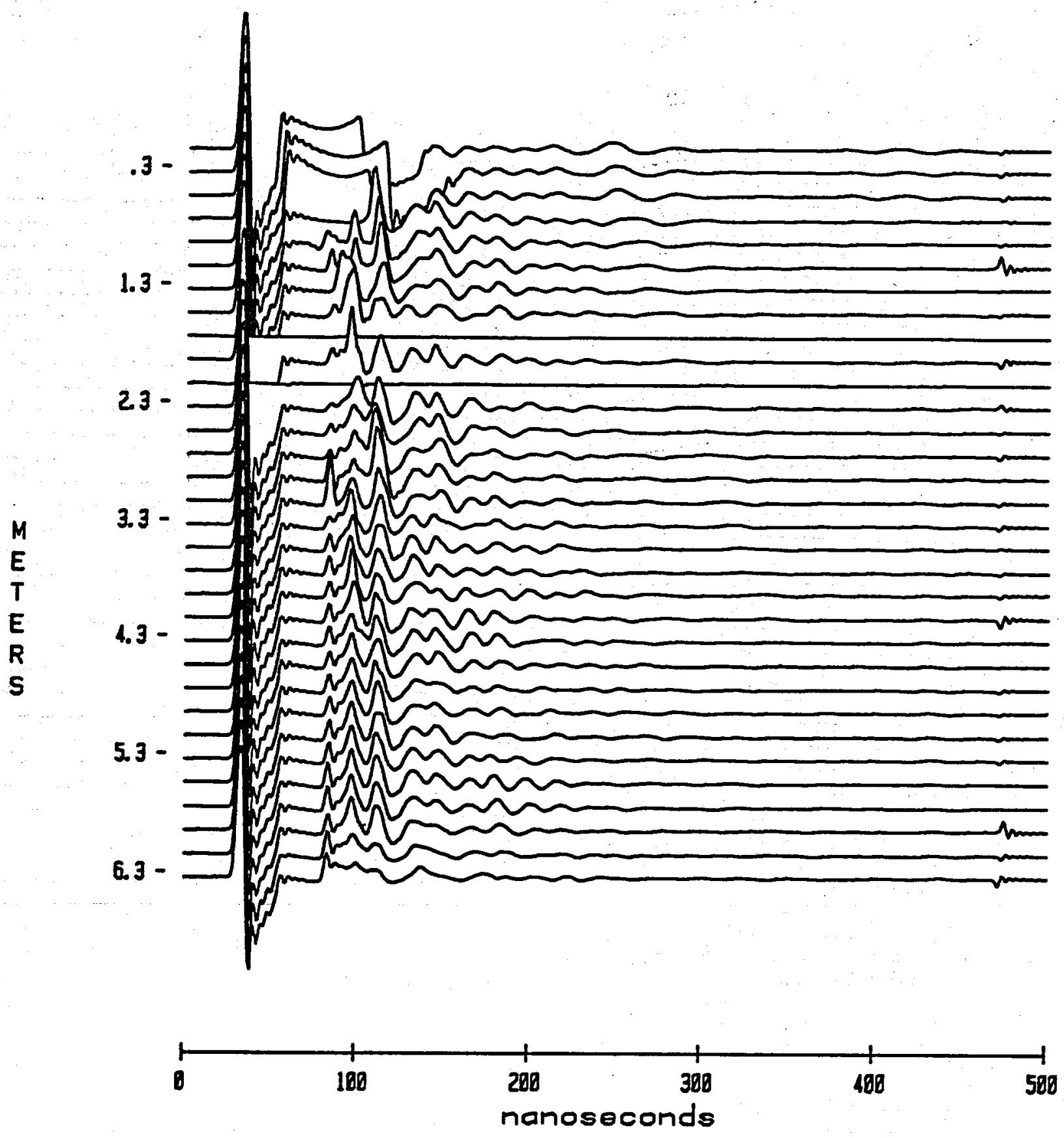

FIGURE 30. HOLE TO HOLE ELECTROMAGNETIC TESTS, RECEIVER IN BOREHOLE 4, TRANSMITTER IN BOREHOLE 5, TARGET SLOT DRY 


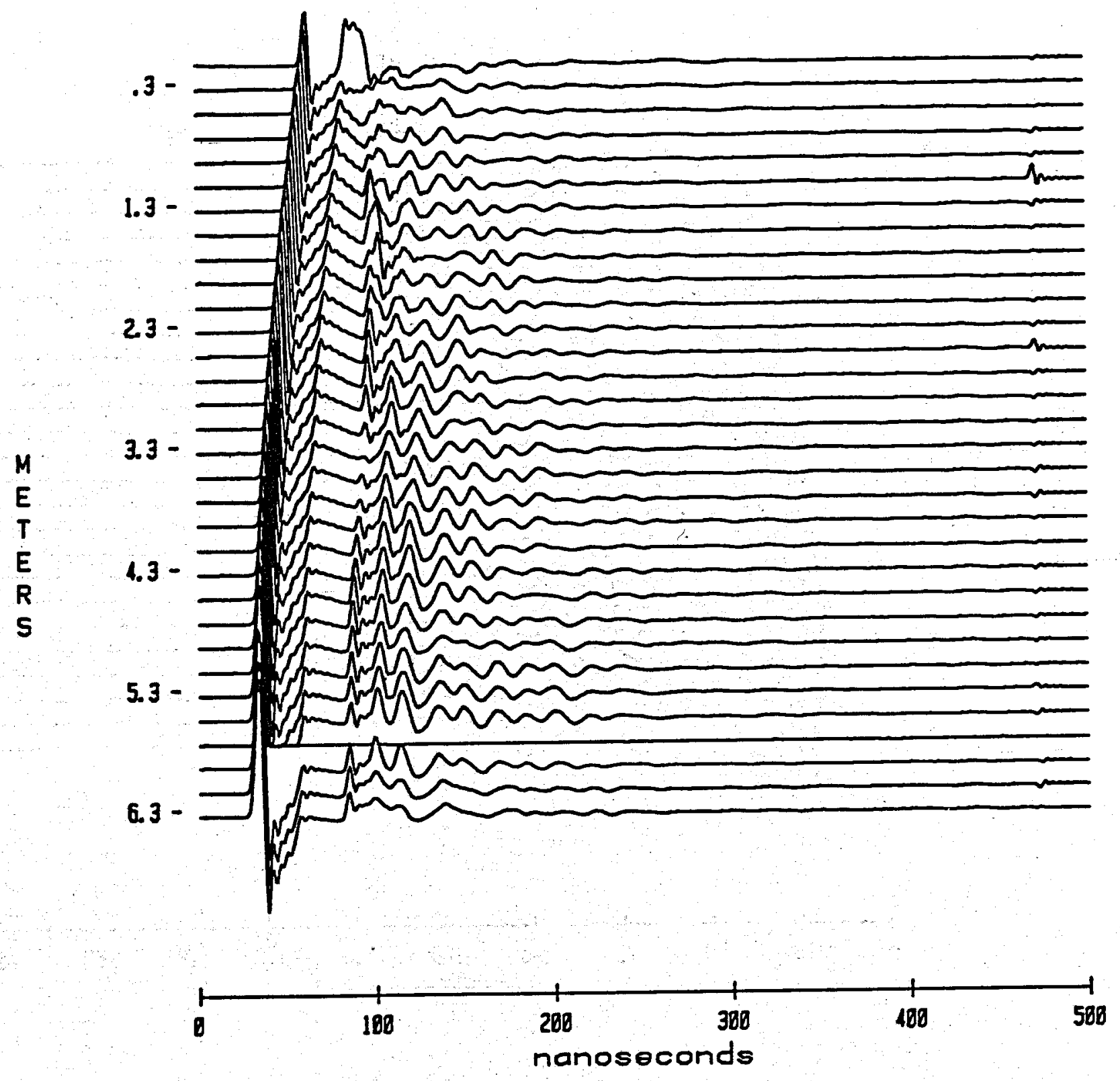

FIGURE 31. HOLE TO HOLE ELECTROMAGNETIC TESTS, RECEIVER IN BOREHOLE 4, TRANSMITTER FIXED IN BOREHOLE 5, TARGET SLOT DRY 

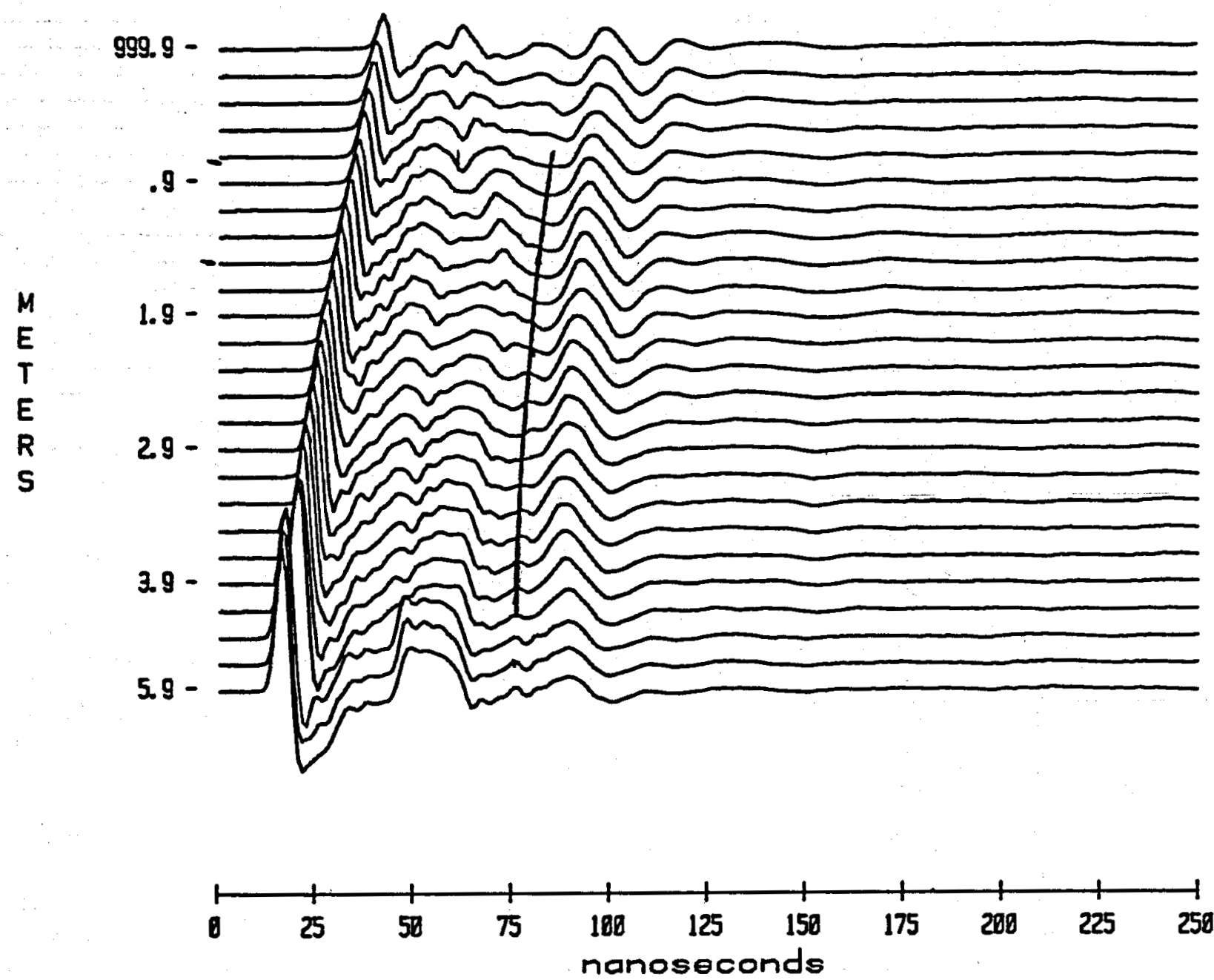

FIGURE 32. HOLE TO HOLE ELECTROMAGNETIC TESTS, RECEIVER FIXED IN BOREHOLE 2, TRANSMITTER IN BOREHOLE 1, 260 OHM CENTIMETER BRINE IN TARGET SLOT 
Borehole 2 to the surface. Reflections from a vertical face would follow a move-out curve (shown on the display) which is different from the direct arrival move-out. Although the time of arrival appears to be late by approximately five nanoseconds, the strong signals starting at about 80 nanoseconds at 4.9 meters depth appear to be reflections from the fluid-filled target slot. A sample of the fluid was measured to have a resistivity of $260 \mathrm{ohm}$-centimeters. A $20 \mathrm{~dB}$ attenuator was installed in the receiver to minimize saturation effects of the direct arrival.

\section{b. Transmitter in Borehole 1 - Receiver in Borehole 3}

Figure 33 indicates signals which are appropriate in time and move-out for reflections from the target slot. The reflections are shaded to highlight their position on the display. The amplitude of these signals is 12 to $15 \mathrm{~dB}$ less than the reflections shown in Figure 32. This is approximately the expected attenuation loss caused by the additional path length.

\section{Seismic Experiments}

The initial seismic data acquisition experiments were terminated prematurely when the transmitter probe became lodged in Borehole No. 2 . The probe was recovered slightly damaged and it was necessary to perform repairs. The probes were repaired and modified for controlled-orientation operation and a second field trip was organized to acquire seismic data only. Two groups of experiments were performed, one with the slot dry and the second with the slot filled with fresh water. In addition, several experiments were performed to determine the effects of transducer rotational position on received signal polarity and amplitude.

\section{Probe Orientation Experiments}

In the initial seismic experiments, the transmitter and receiver probes were simply lowered into the boreholes by the hydraulic lines and the electrical cables. The orientation position of the transducers was random. The relative orientation of the transducers was determined to have a significant effect on the polarity and amplitude of the first arriving components of each sesimic wave type. It was also shown that coherence of signals from station to station in the boreholes was dependent upon the probe being clamped in the borehole in a repeatable fashion.

Accordingly, the centralizers were improved to hold the probe modules very nearly centered in the borehole while the pistons were extended to clamp the probes in the borehole. To control the orientation at the probes as they were lowered or hoisted in the boreholes, five-foot sections of PVC pipe were fabricated with rigid couplings on one end. Holes were drilled through the couplings with mating holes through the opposite end of each pipe section. As the pipes sections are assembled, bolts are placed through the holes to form a rotationally rigid length of pipe. Fixtures for attaching the pipe to the probes were fabricated. With the pipes attached, the probes could be lowered to a depth of 30 feet in the boreholes while maintaining accurate control of the azimuthal orientation of the probes from the surface. This method of probe orientation control was used throughout the remainder of the seismic experiments. 


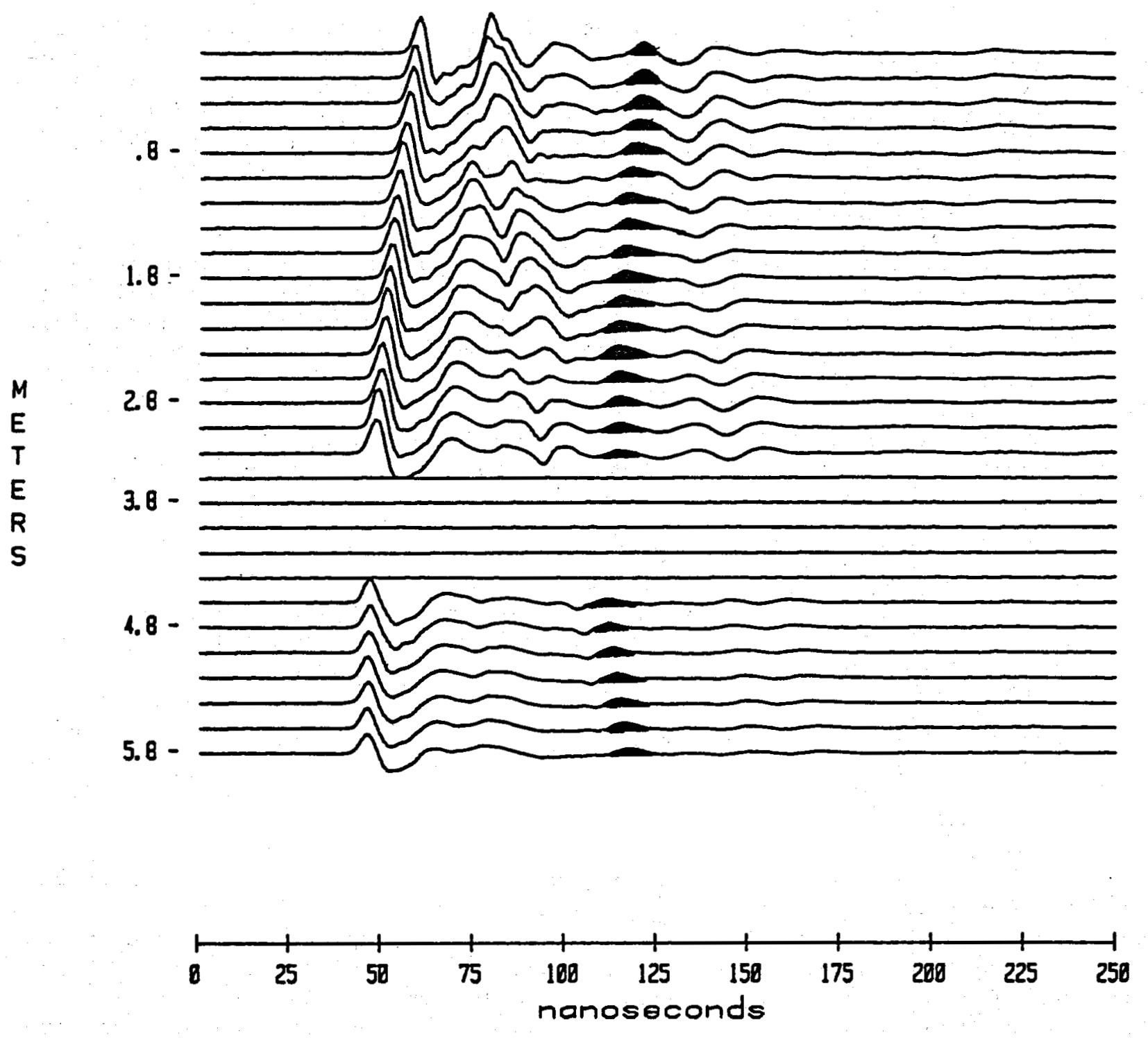

FIGURE 33. HOLE TO HOLE ELECTROMAGNETIC TESTS, TRANSMITTER FIXED IN BOREHOLE 1, RECEIVER IN BOREHOLE 3, 250 OHM CENTIMETER BRINE IN TARGET SLOT 
Figures 34,35 , and 36 show the results of the probe rotation experiments. Figure 34 shows the output of receiver channel no. 1 for four orientations of the transmitter and receiver transducers. The rotational positions of the transducers are shown to the right of each waveform. the features of interest in each waveform are the amplitude and polarity of the first arriving compressional wave and shear wave signals.

When both transducers are positioned along the line joining the two boreholes and pointing in the same direction ( $\operatorname{Rec} 0^{\circ} / \mathrm{Xmtr} 0^{\circ}$ ), the compressional wave first arrival is positive and approximately $6.6 \mathrm{millimeters} \mathrm{amplitude}$ in the displayed waveform. In the second waveform, the receiving transducer was rotated 90 degrees $\left(\operatorname{Rec} 90^{\circ} / \mathrm{Xmtr} 0^{\circ}\right.$ ) whereby the compressional wave signal is reduced to approximately $1.2 \mathrm{millimeters} \mathrm{while} \mathrm{the} \mathrm{shear} \mathrm{wave} \mathrm{first} \mathrm{motion}$ remains positive at about the same amplitude observed in the first orientation condition.

In the third waveform of Figure 34, the compressional wave first motion is negative when the transducers are pointing at one another $\left(\operatorname{Rec} 180^{\circ} / \mathrm{Xmtr} 0^{\circ}\right)$. The shear wave amplitude is reduced to less than one half of the previous two waveforms while the first motion polarity remains positive.

The last waveform in Figure 34 was taken with the receiver transducer rotated by another 90-degree angular increment ( $\operatorname{Rec} 270^{\circ} / \mathrm{Xmtr} 0^{\circ}$ ). The compressional wave is diminished and the shear wave signal, although approximately the same amplitude as in the second waveform, is reversed in polarity.

Figure 35 illustrates the effect of rotating the transmitter. In the first waveform, the receiver and transmitter transducers are at 90 degrees and 270 degrees, respectively; i.e. the transducers are pointing in opposite directions perpendicular to the line between the boreholes. In the second waveform, the transmitter position was rotated 180 degrees. As anticipated, the direct shear wave signal reversed polarity as did the reflection signal at $S$. The compressional wave signal is small compared with the shear wave for this orientation of the transducers. With-careful positioning of the probes it should be possible to completely null either the compressional wave or the shear wave direct arrival. Figure 36 illustrates the estimated shear and compressional wave sensitivity patterns of the seismic transducers.

One of the principle reasons for operating the seismic system in a bistatic mode with the transmitter and receiver modules in separate adjacent boreholes was to reduce or eliminate the interference with echo reception of interface waves associated with the borehole walls and air column. Even with this separation of source and receiver, there were significant interface waves introduced into the seismic receiver signals. The amplitude of these signals was frequently as large as the direct body wave signals and an order of magnitude greater than the reflection signals. The highest frequency of these interferring signals (approximately $750 \mathrm{~Hz}$ ) was two to three octaves below the frequency of the direct and reflected seismic signals $(4.5$ to $6 \mathrm{KHz})$. Because 

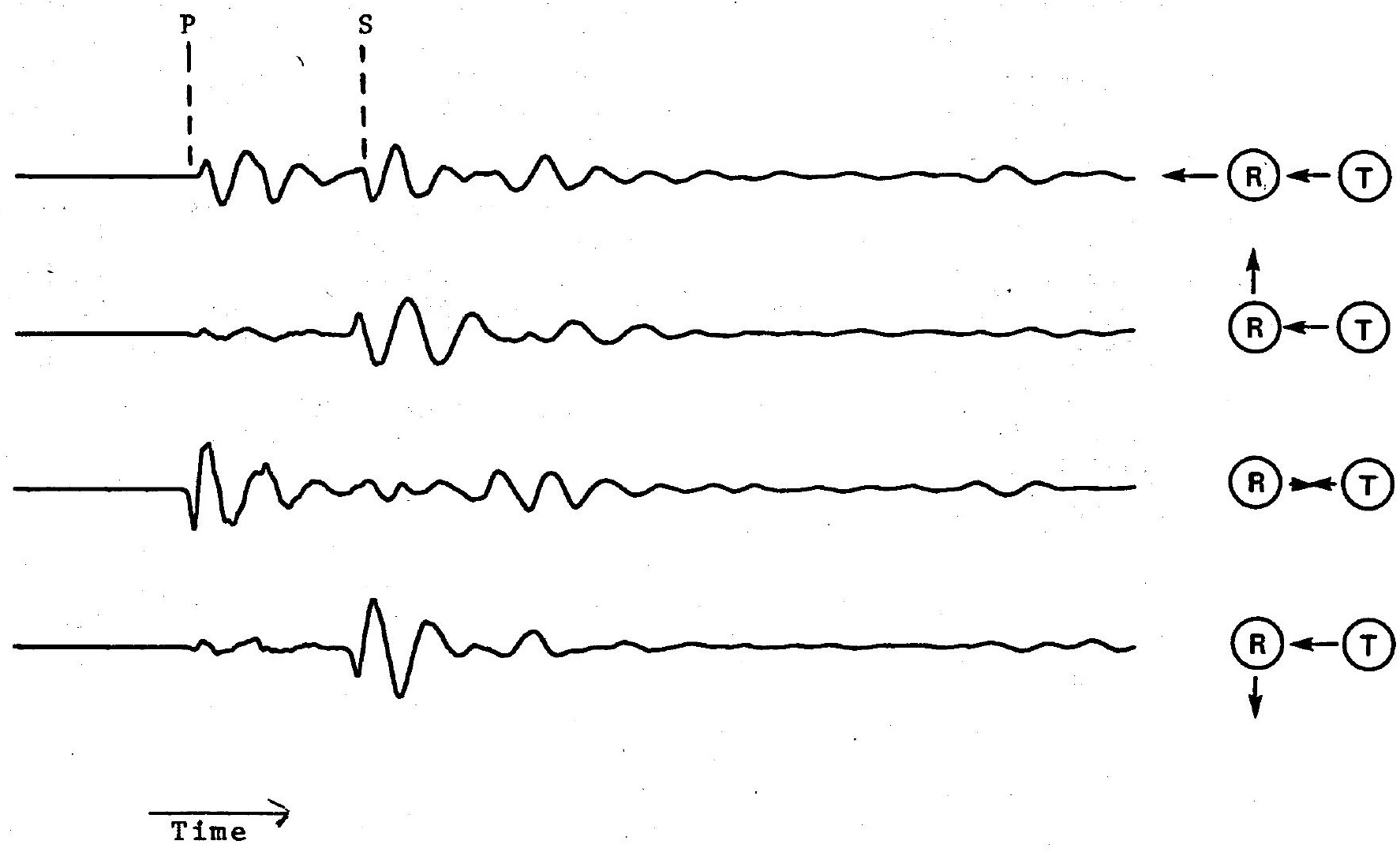

FIGURE 34. BOREHOLE SEISMIC SYSTEM OUTPUT SIGNALS FOR FOUR ROTATIONAL POSITIONS OF THE RECEIVER, HOLE-TO-HOLE OPERATION 

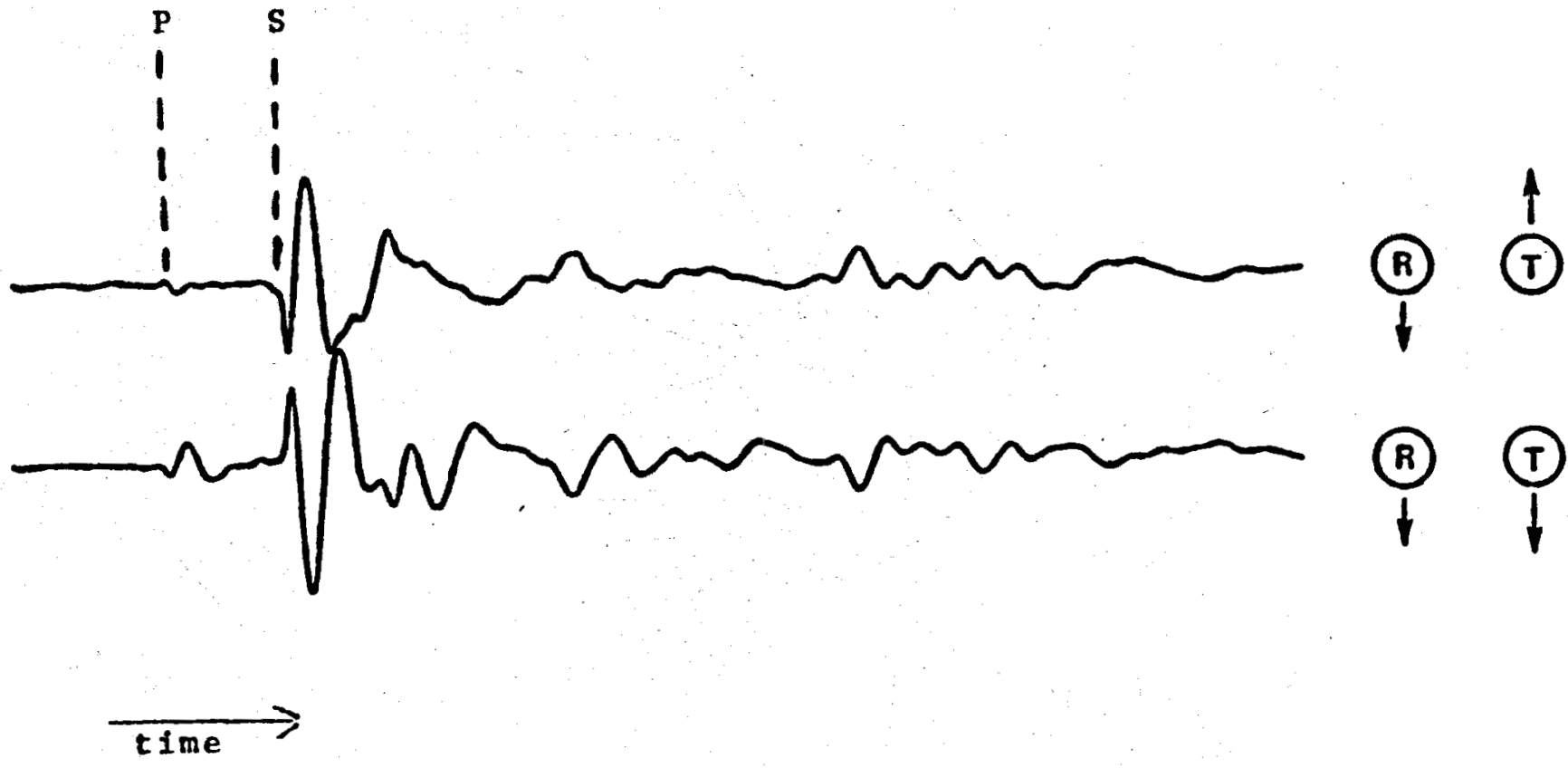

FIGURE 35. BOREHOLE SEISMIC SYSTEM OUTPUT SIGNALS WITH PROBES ORIENTED FOR MAXIMUM SHEAR WAVE RECEPTION 


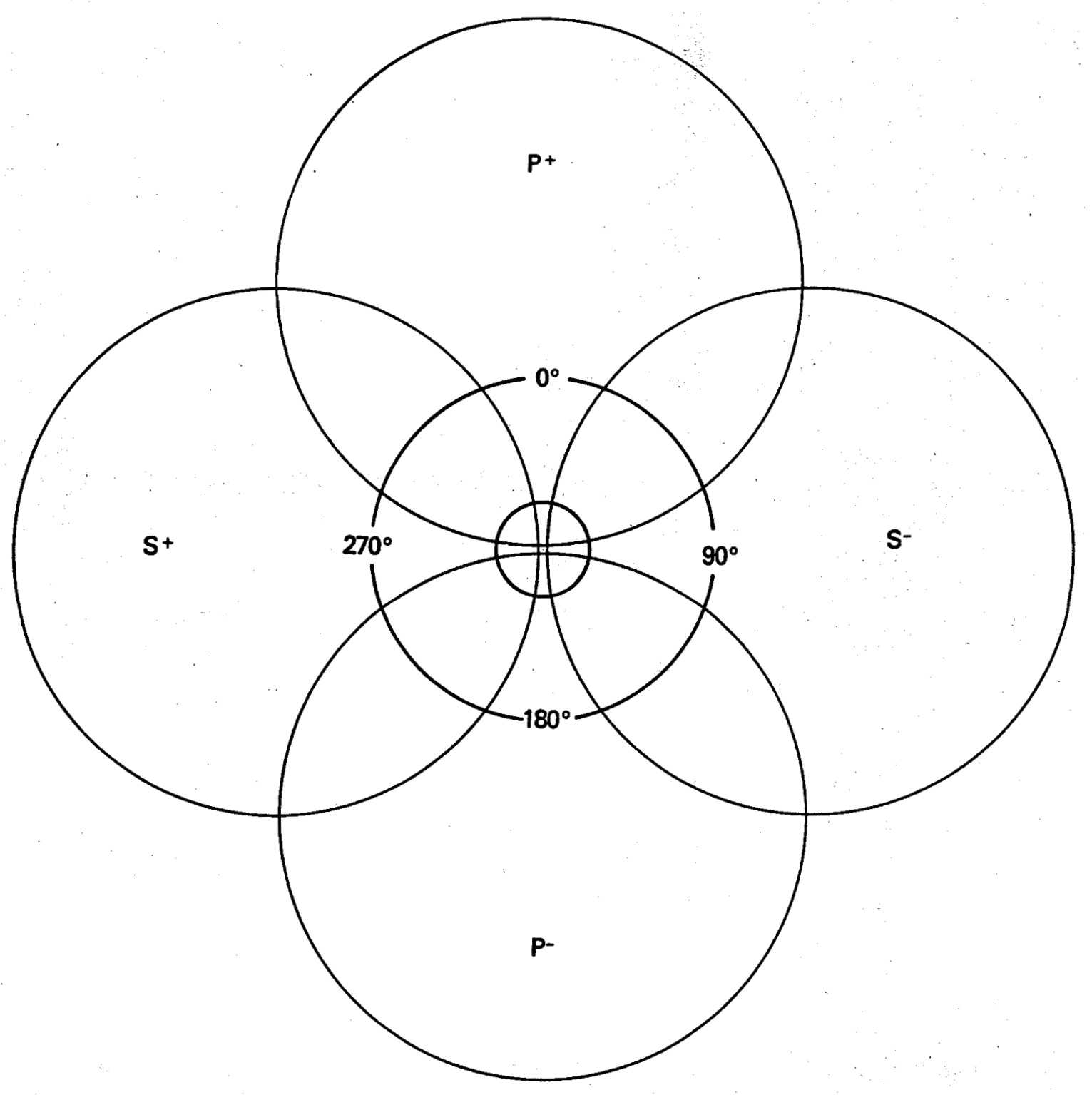

FIGURE 36. TRANSMITTING AND RECEIVING SENSITIVITY PATTERN OF BOREHOLE SEISMIC MODULES 
all of the data was recorded below system saturation levels, it was possible to remove the interface waves from the displayed data by the use of a high-pass digital filter in the play-back system. A low-pass filter was also employed to reduce random high frequency signals above $10 \mathrm{KHz}$ occurring in the data apparently the result of mechanical resonances in one or both of the probe attachment structures. The seismic waveforms shown in Figure 34 through 44 were plotted with these filters in the playback program.

\section{Reflection Tests Without Water in Target Slot}

The first reflection tests were performed with the target slot. dry and with the receiver in Borehole No. 1 and transmitter in Borehole No. 2 at 4.0 and 8.0 meters from the target, respectively. A common depth scan was performed with the transmitter and receiver probes being hoisted in unison from 6.0 meters depth to 1.0 meter in 25 -centimeter increments. The receiver transducer was at the 180-degree position pointing toward the transmitter. The transmitting transducer was at zero degrees pointed in the direction of the target slot.

Figure 37 displays the receiver output for each depth interval with the waveforms nested closely together to emphasize the coherent elements in the data. To highlight the more outstanding reflection signals, the positive peaks of the signals in successive waveforms have been shaded. Figure 37 , shows four reflections in addition to the compressional and shear wave direct arrivals. Reflections from the slot target should form a vertical line because the plane of the target is vertical and parallel to the boreholes and the time of arrival for a compressional or shear wave reflection should be three times the travel time for the four-meter hole-to-hole distance. There are no clear reflections meeting these requirements in Figure 37 . The reflections which tend toward zero depth are related to surface reflections. Two reflection trends which appear to be from an interface below the bottom of the boreholes and are clearly shear wave reflections as indicated by the moveout slope of the wavefronts. The velocities of compressional waves and shear waves as derived from these tests are $6.22 \mathrm{~km} / \mathrm{sec}$ and $3.2 \mathrm{~km} / \mathrm{sec}$, respectively.

Data displayed in Figure 38 were taken with the receiver probe fixed at 6.0 meters depth in Borehole 1 while the transmitter probe was hoisted to one meter depth in 25-centimeter increments. This offset scan was employed to develop distinguishing move-out features required to positively identify vertical planar target reflections. The hyperbolic shape of the direct compressional and shear wave arrivals are clearly seen in the display. Two of the reflections detected in the previous common depth scan are highlighted. No evidence of target slot reflections are present.

The probes were next deployed with the receiver in Borehole 2 and the transmitter in Borehole 3. Data resulting from a common depth scan is shown in Figure 39 in which the wavefront arrivals from two surface reflections are highlighted. No target reflections are present at four times the four meter hole-to-hole travel time delay. 


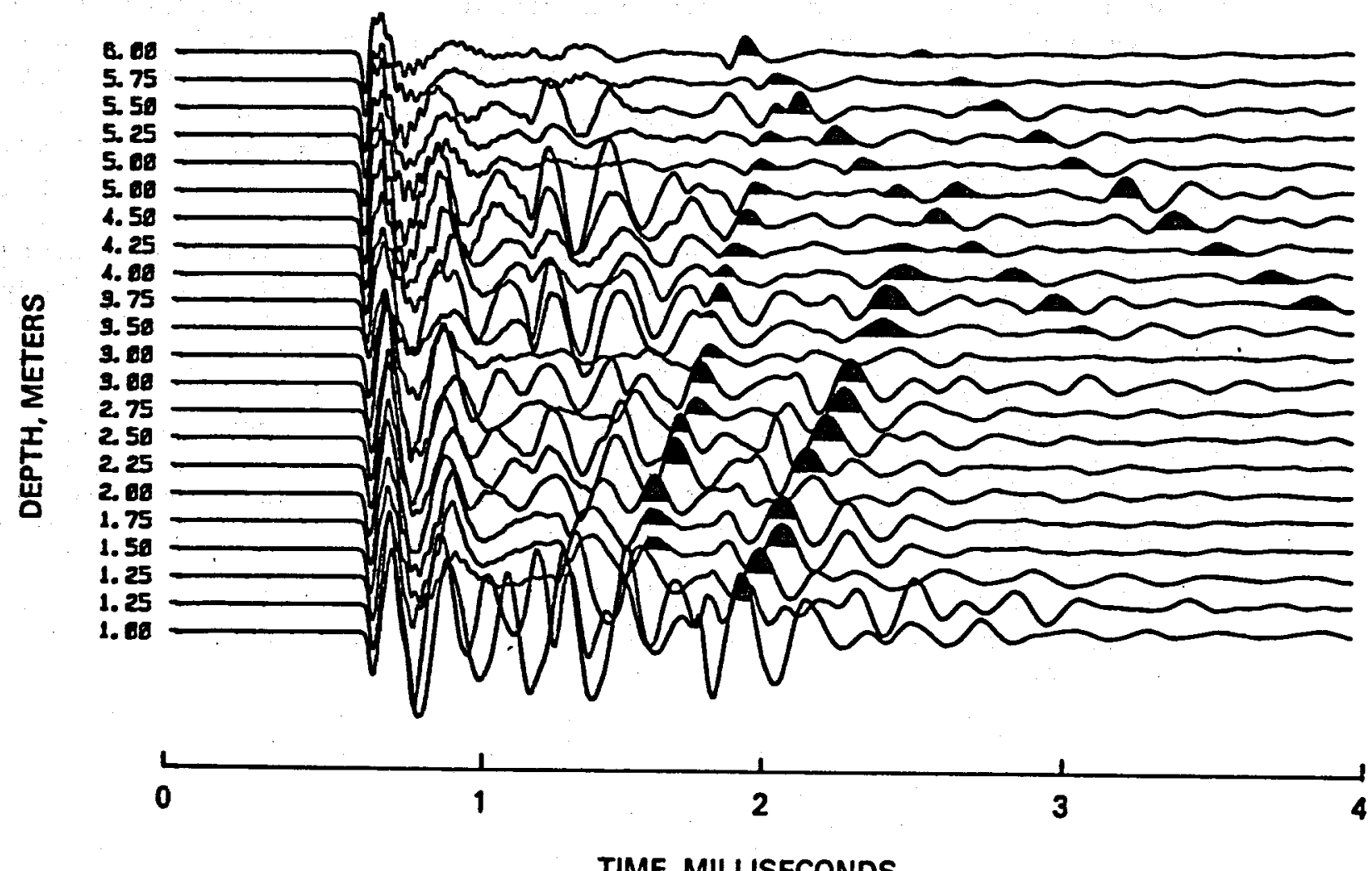

TIME, MILLISECONDS

FIGURE 37. BOREHOLE SEISMIC COMMON DEPTH SCAN, RECEIVER IN BOREHOLE 1, TRANSMITTER IN BOREHOLE 2, TRANSDUCER ORIENTATION - R/180 T $/ 0^{\circ}$, TARGET SLOT DRY 


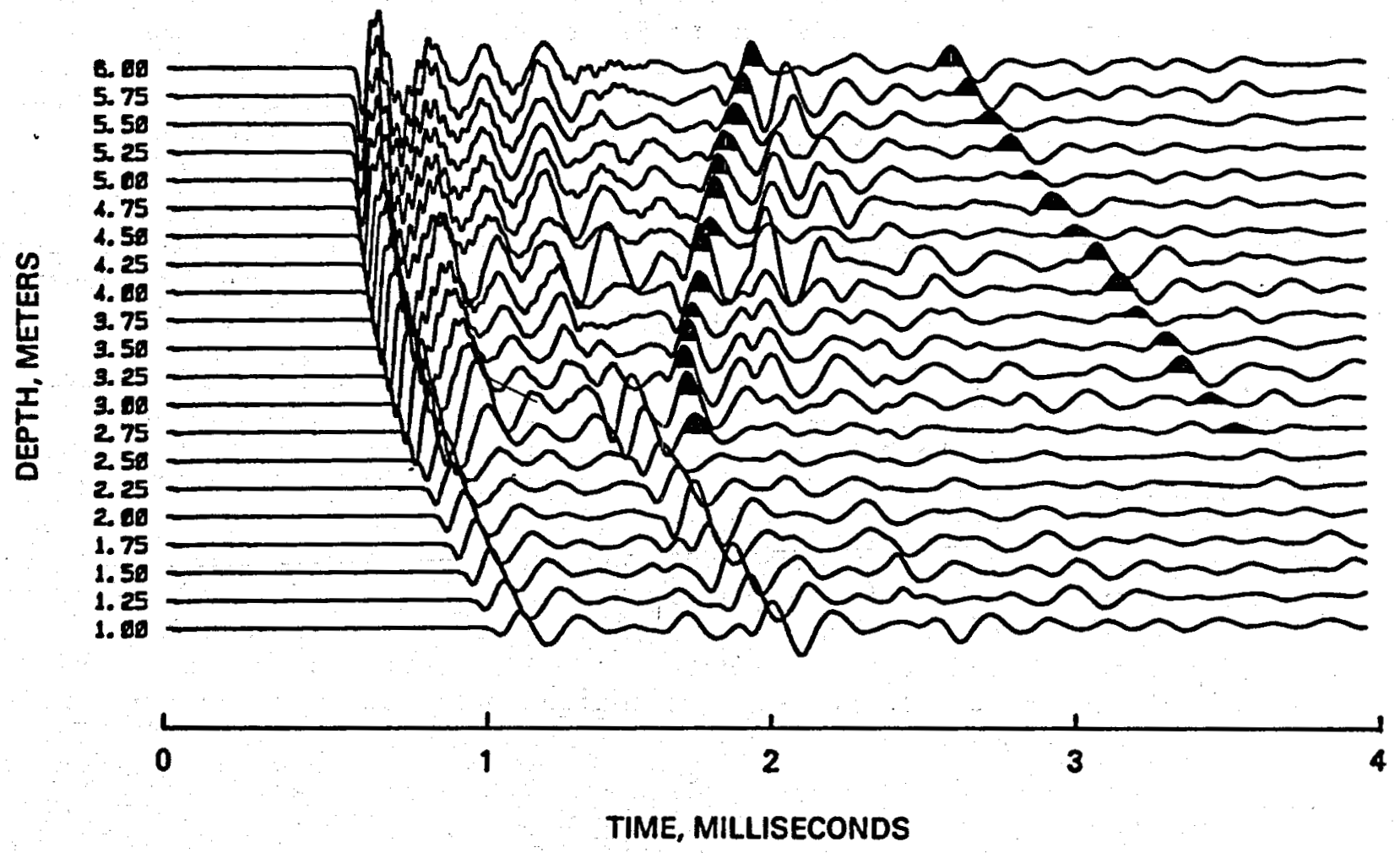

FIGURE 38. BOREHOLE SEISMIC OFFSET SCAN, RECEIVER FIXED AT 6 METERS IN BOREHOLE 1, TRANSMITTER IN BOREHOLE 2, TRANSDUCER ORIENTATION $\mathrm{R} / 180^{\circ}, \mathrm{T} / 0^{\circ}$, TARGET SLOT DRY 
Figure 40 shows the results obtained with the receiver probe rotated 180 degrees from that used for Figure 39 . Reversed polarity surface reflections were obtained and are highlighted in Figure 40 . No reflections are evident from the dry target.

The seismic probes were next operated in Boreholes 4 and 5 with the receiver located four meters and the transmitter eight meters from the slot. Data recorded in this experiment are shown in Figure 41; however, no reflections are evident in this edge view of the slot. A shear wave surface reflection has been highlighted.

\section{Reflection Tests with Water in the Target Slot}

The target slot was filled with fresh water and the preceding experiments were repeated. With the receiver and transmitter in Boreholes 1 and 2 , respectively, the data shown in Figure 42 were obtained. The transducers were oriented in the same positions as those used in Figure 37 (Rec $180^{\circ}$ \% Xmtr $0^{\circ}$ ). Several reflections have been highlighted in the waveforms shown in Figure 42, however none of these are associated with the target slot.

Figure 43 shows the seismic waveforms acquired with the receiver probe in Borehole 2 and the transmitter probe in Borehole 3. Reflections from a greater depth than the boreholes and from the surface are evident, however, no reflections from the target slot were obtained.

The final seismic experiment was performed with the probes in Boreholes 1 and 2 . The transmitting and receiving transducers were positioned at 90 degrees with respect to the line joining the boreholes ( Rec $270^{\circ} / \mathrm{Xmtr} 270^{\circ}$ ); that is, parallel to the slot. Data acquired in this experiment are shown in Figure 44. Three reflection trends are highlighted in the figure, one reflection starting at about 3.5 meters depth and extending to 1.75 meter depth in the boreholes occurs at the appropriate time for shear wave reflections from the slot. This reflection, obtained with the transducers oriented for shear wave illumination of the target and shear wave detection of reflections from the target, is the only clearly detectable target slot reflection obtained in the seismic reflection tests. 


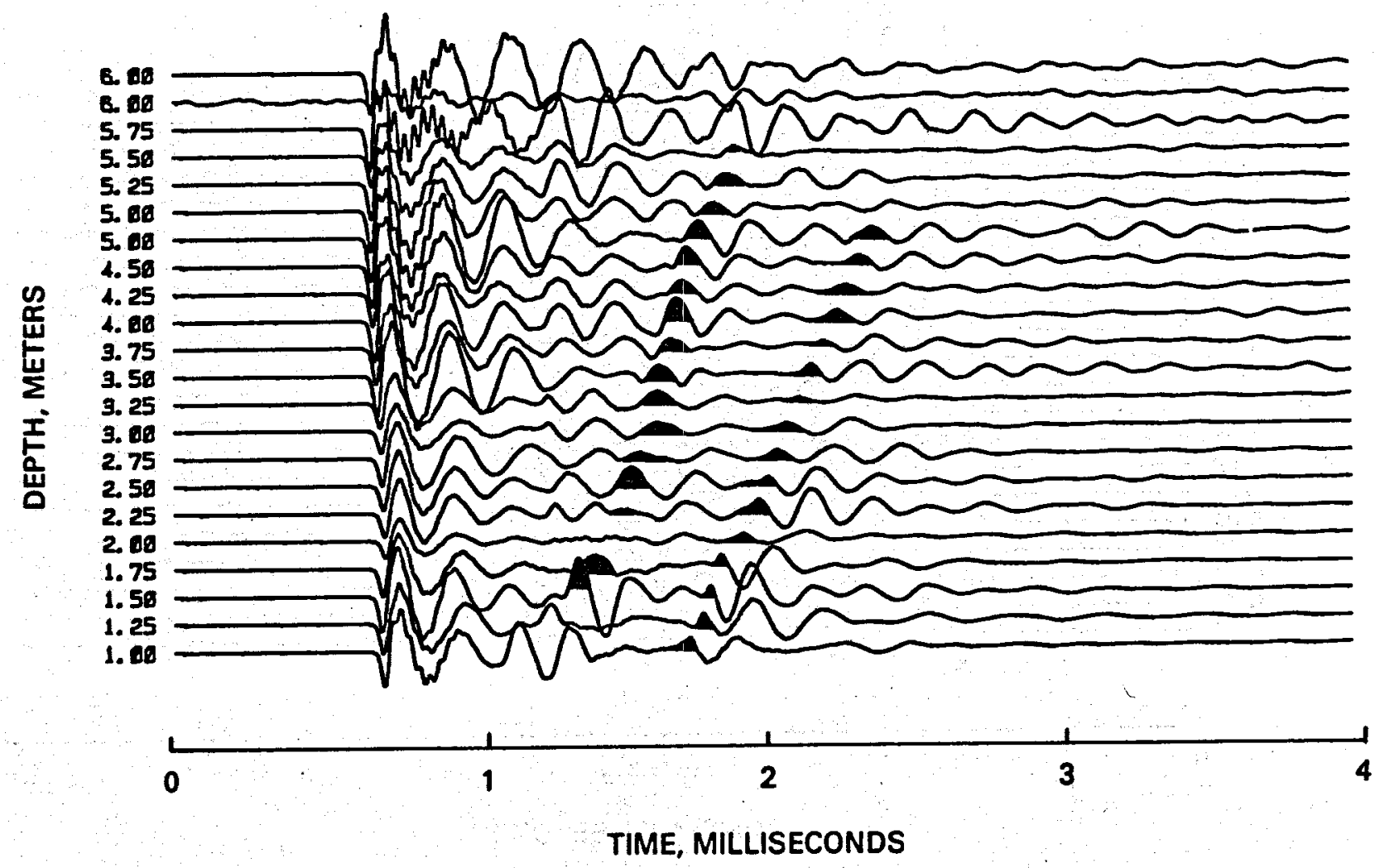

FIGURE 39. BOREHOLE SEISMIC COMMON DEPTH SCAN, RECEIVER IN BOREHOLE 2 , TRANSMITTER IN BOREHOLE 3 , TRANSDUCER ORIENTATION R/180 T $/ 0^{\circ}$, TARGET SLOT DRY 


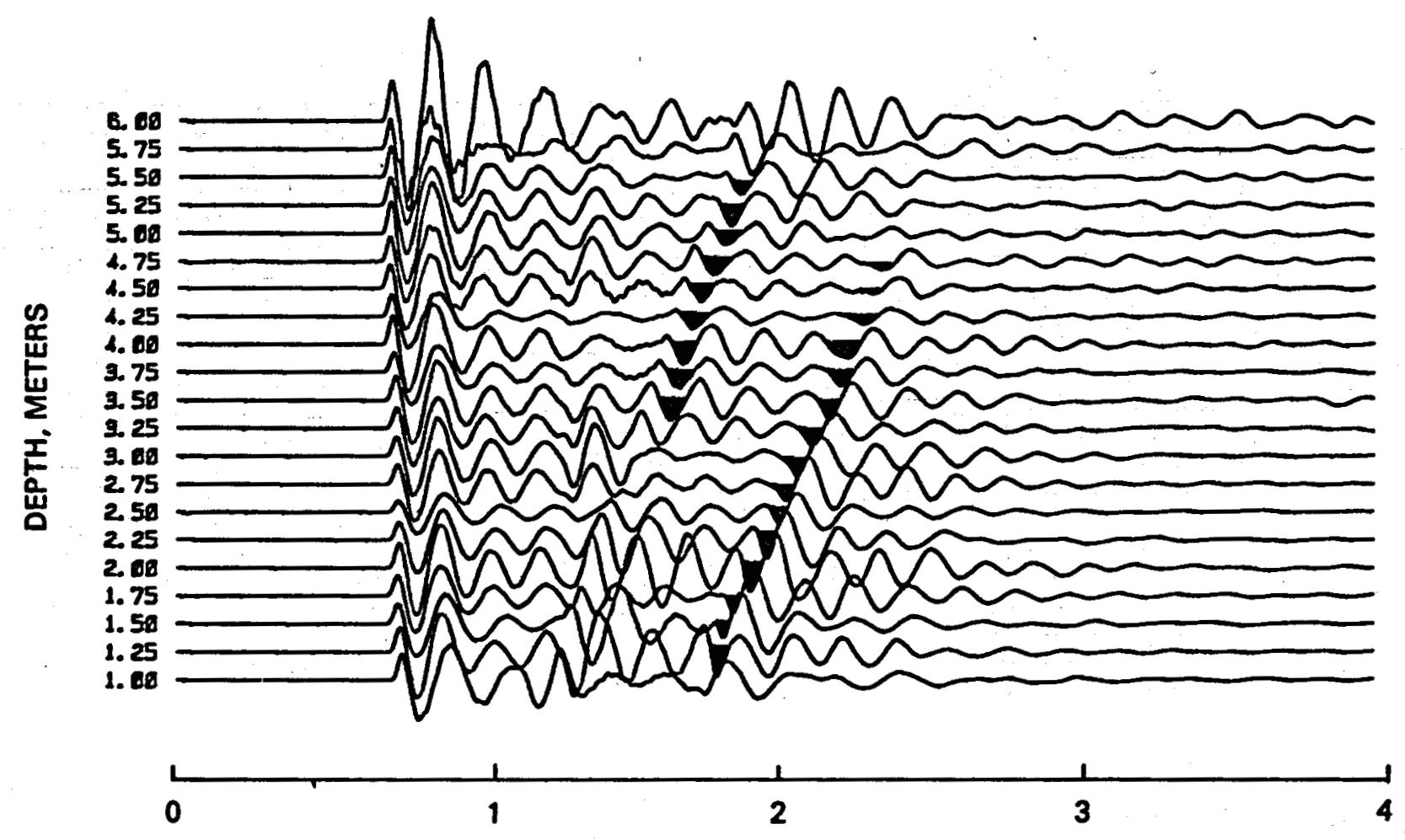

TIME, MILLISECONDS

FIGURE 40. BOREHOLE SEISMIC COMMON DEPTH SCAN, RECEIVER IN BOREHOLE 2, TRANSMITTER IN BOREHOLE 3, TRANSMITTER ORIENTATION - R/ $0^{\circ}$, T $/ 0^{\circ}$, TARGET SLOT DRY 


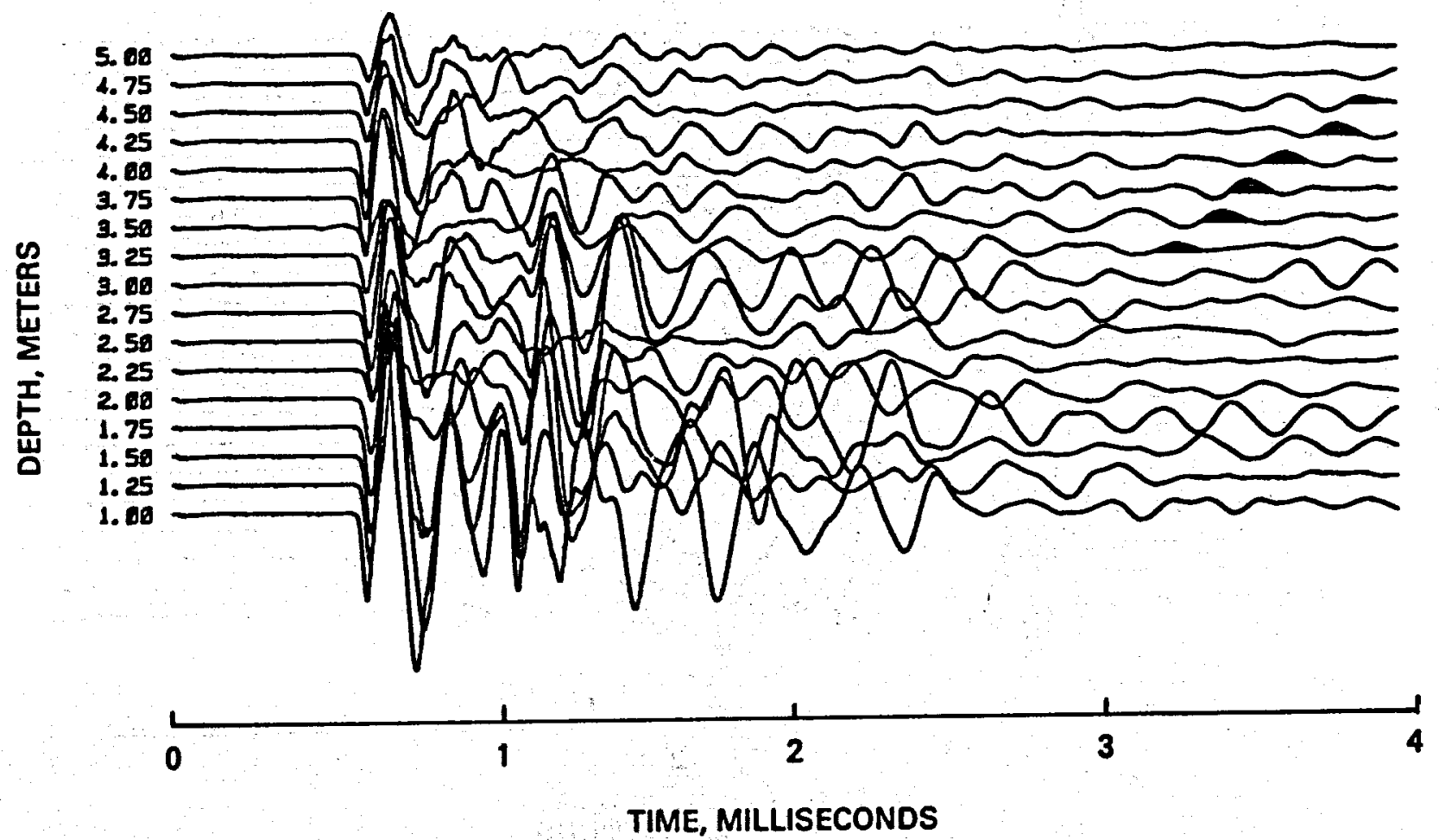

FIGURE 41. BOREHOLE SEISMIC COMMON DEPTH SCAN, RECEIVER IN BOREHOLE 4, TRANSMITTER IN BOREHOLE 5, TRANSDUCER ORIENTATION - R/180 , T/ $0^{\circ}$, TARGET SLOT DRY 


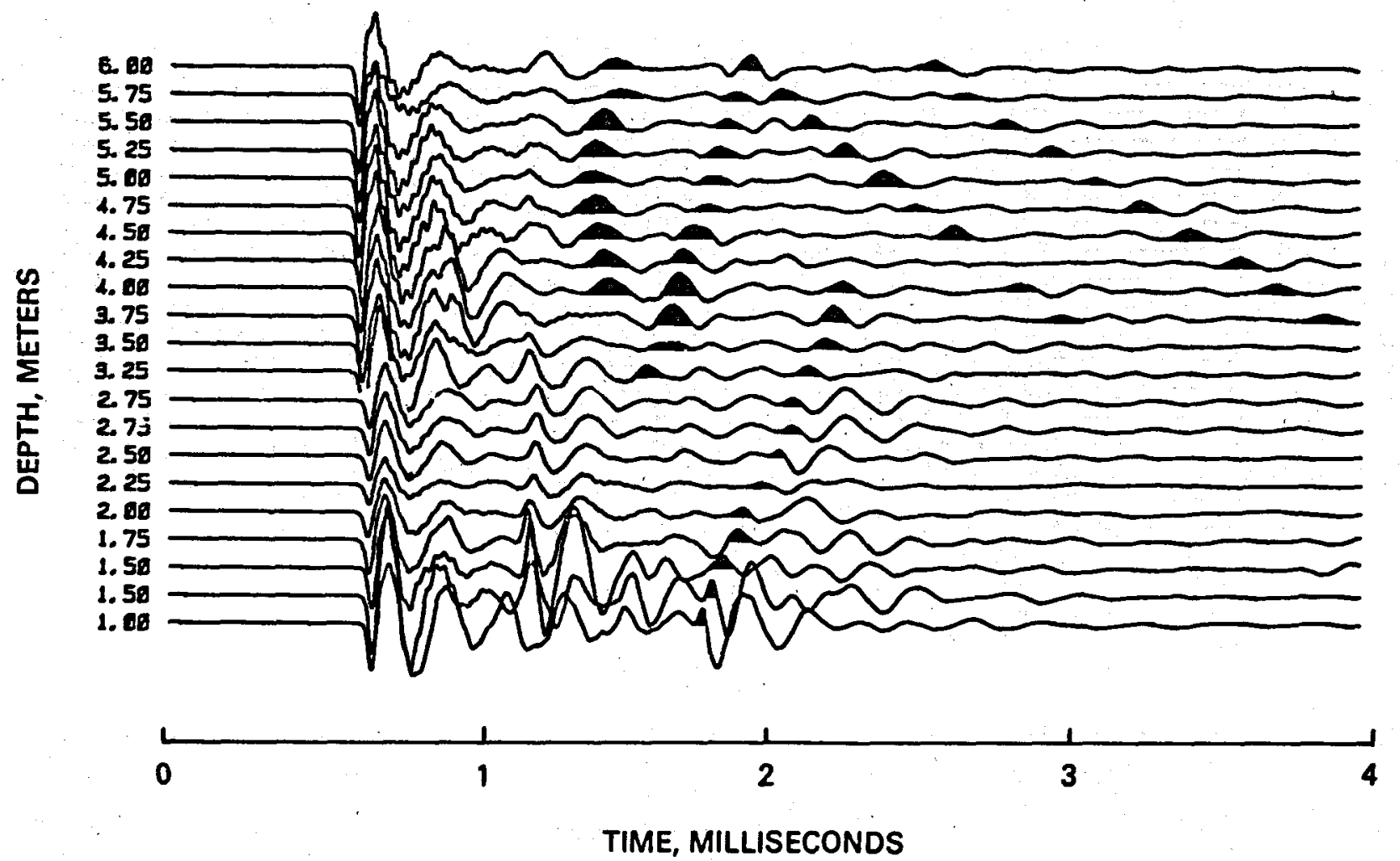

FIGURE 42. BOREHOLE SEISMIC COMMON DEPTH SCAN RECEIVER IN BOREHOLE 1, TRANSMITTER IN BOREHOLE 2, TRANSDUCER ORIENTATION - R/180 , $\mathrm{T} / 0^{\circ}$, TARGET SLOT WATER FILLED 


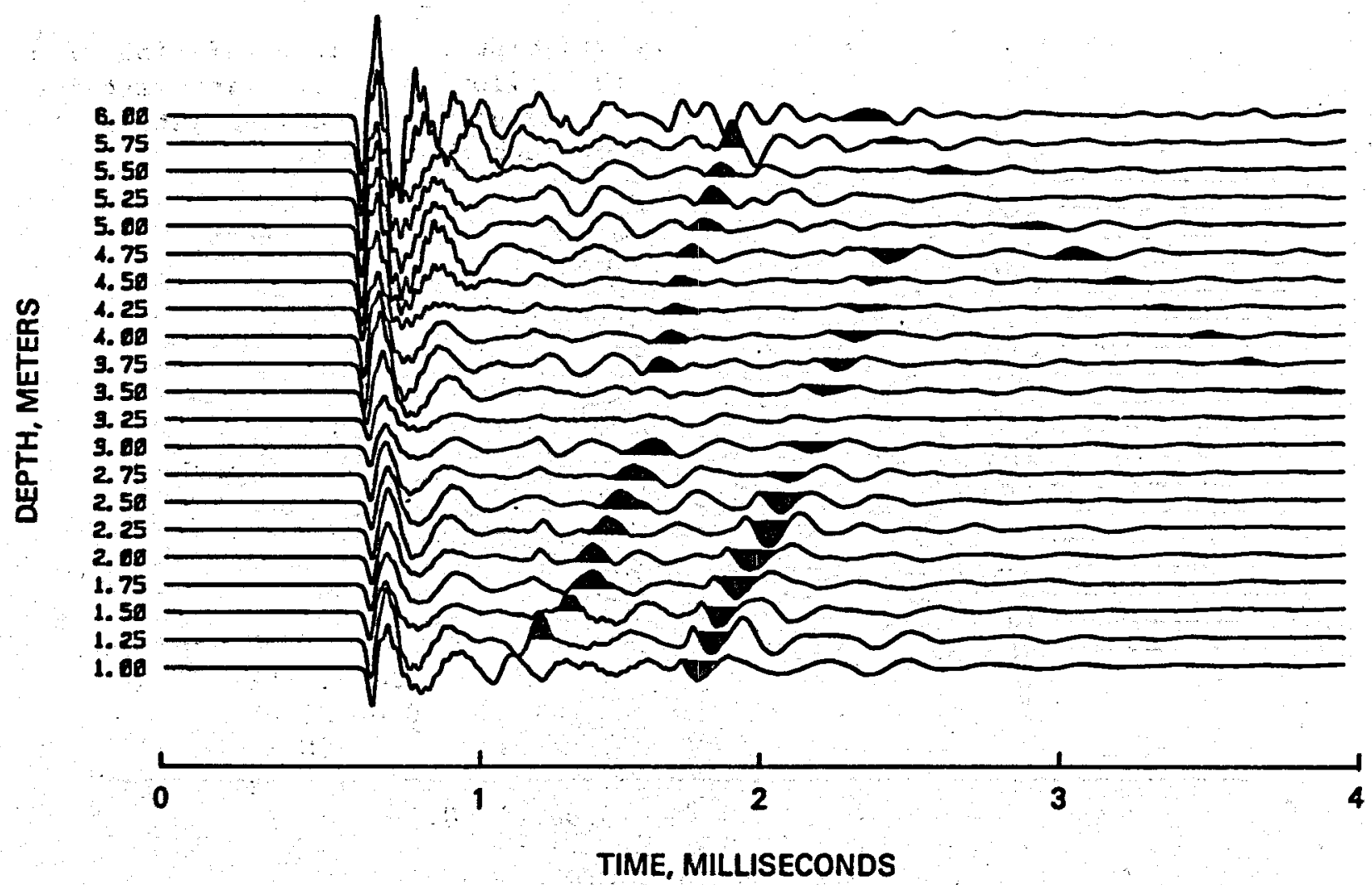

FIGURE 43. BOREHOLE SEISMIC COMMON DEPTH SCAN, RECEIVER IN BOREHOLE 2, TRANSMITTER IN BOREHOLE 3, TRANSDUCER ORIENTATION $-R / 180^{\circ}, \mathrm{T} / 0^{\circ}$, TARGET SLOT WATER FILLED 


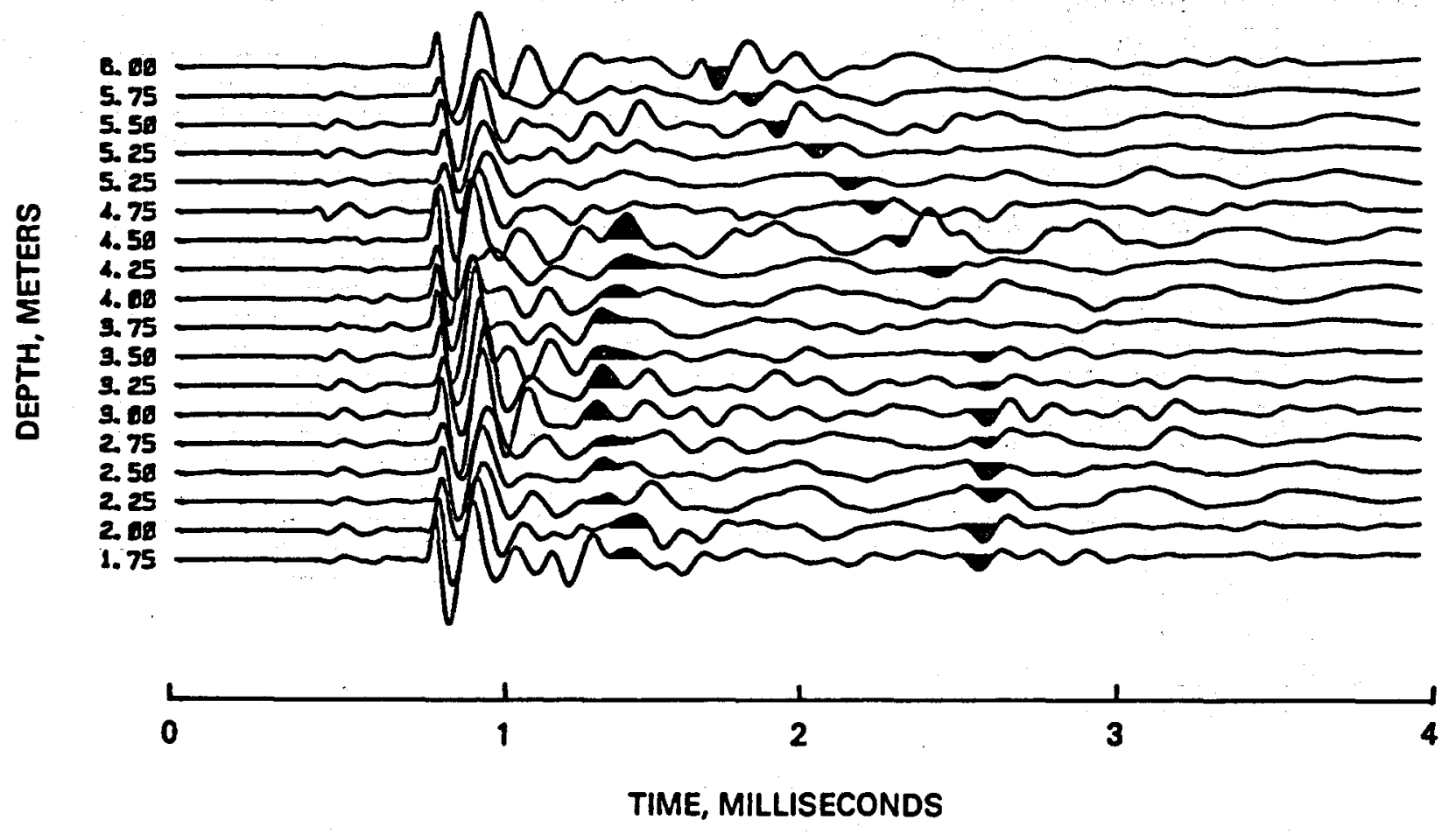

FIGURE 44: BOREHOLE SEISMIC COMMON DEPTH SCAN, RECEIVER IN BOREHOLE 1, TRANSMITTER IN BOREHOLE 2, TRANSDUCER ORIENTATION $-\mathrm{R} / 270^{\circ}, \mathrm{T} / 270^{\circ}$, TARGET SLOT WATER FILLED 


\title{
VI. CONCLUSIONS AND RECOMRENDATIONS
}

Two pulse-echo probing techniques were evaluated as potential geothermal well fracture zone detection methods. One of these techniques employs an electromagnetic pulse transmitter which emits 10 nanosecond wide video pulses from a controlled directional antenna. Reflections are detected by a broadband ( 30 to $300 \mathrm{MHz}$ ) receiver operating in the same radar probe. Electromagnetic tests were also conducted with a bistatic radar system which consists of separate omnidirectional transmitter and receiver modules. These probes are operated in adjacent parallel boreholes.

The second probing method evaluated was a bistatic seismic pulse-echo system. The system consists of separate transmitting and receiving probes employing hydraulic pressure to clamp the transducers firmly against the boreholes wails. These seismic probes were operated in borehole pairs using borehole scanning methods similar to the bistatic radar.

Auxiliary tests were also performed at the granite quarry test site to measure the electromagnetic and seismic characteristics of the rock. These tests to determine the suitability of the test site yielded the following average velocity and attenuation values:

\author{
Electromagnetic Velocity - 0.128 meter/nanosecond \\ Electromagnetic Attenuation - $1.36 \mathrm{~dB} /$ meter ( 30 to $300 \mathrm{MHz}$ baud) \\ Seismic Compressional Wave Velocity - $5.89 \mathrm{kilometer/second}$ \\ Seismic Shear Wave Velocity - $3.05 \mathrm{kilometer} / \mathrm{second}$ \\ Compressional Wave Attenuation (approx.) $-0.3 \mathrm{~dB} / \mathrm{meter}$ \\ Shear Wave Attenuation (approx.) - $1.0 \mathrm{~dB} / \mathrm{meter}$
}

The fracture simulating target for the tests was a flame-cut slot in the granite seven to eight centimeters wide; 6.1 meters deep by 21.3 meters long. A section of the slot 3.1 meters long was sealed to contain liquid. Reflection tests were performed with the test section air filled and liquid filled.

The radar was operated in each of the five boreholes shown in Figure 7 . With air in the target slot, reflection signals were detected only when the radar probe was operated in Borehole No. 1 four meters from the slot with a broadside view. As shown in Figure 15, the reflection signals at 62 nanosconds time delay are about an order of magnitude smaller than the surface reflection even in this processed data.

In the second group of radar tests, the radar was operated in Borehole No. 1 with an elght foot square metal reflector lowered to the bottom of the slot. The processed radar signals shown in Figure 19 and 20 clearly indicate a strong reflection where the antenna is directed at the target. The amplitude of these reflection signals is approximately 10 to $12 \mathrm{~dB}$ above non-target related signals for depths of the probe below about five meters. 
The metal reflector was replaced with a brine solution of $10.1 \mathrm{ohm}$ centimeter resistivity. With the radar operating in Borehole No. 1 , reflection signals approximately 6 to $10 \mathrm{~dB}$ above non-target related signals were obtained. When the radar was operated in Borehole No. 2, eight meters from the slot, the slot reflection amplitude diminished significantly to yield a signal to noise ratio near unity. As shown in Figure 24 , the reflection is readily distinguished from noise by the persistant reflection signal timing in succeeding waveform traces.

The brine solution was diluted to $16.0 \mathrm{ohm}$-centimeter resistivity and the preceeding tests were repeated. There was a slight increase ( 1 to $2 \mathrm{~dB})$ in the reflection signal to noise ratio when the radar probe was operated in Borehole No. 1 and 2. The slot was detected from Borehole No. 3 at

12 meter distance, however it was necessary to average 128 waveforms at each position of the radar antenna to obtain a display signal to noise ratio greater than unity.

The target slot was not detected in any radar tests with the probe operating in Boreholes No. 4 or 5 .

The bistatic pulsed electromagnetic system was operated in several borehole pair combinations with the expectation that in addition to the direct transmitter to receiver signals there would also be reflections from the target slot. Figures 32 and 33 show the target reflection obtained with the probes operating in Borehole pairs 1-2 and 1-3 respectively. For these tests, the slot was filled with 260 ohm-centimeter resistivity brine. No reflections were detected for any hole pair combination with air in the slot.

Results of early seismic reflection tests indicated a strong preferential orientation of the seismic transmitter and receiver probes. The probes were modified to allow control from the surface of the transducer orientation for all of the subsequent tests.

Seismic reflection tests were performed with the probes in three borehole pair combinations; 1-2, 2-3, and 4-5. Repeatability of the signals from station to station in the boreholes was such that the waveforms could be nested closely. This type of display enhances the recognition of reflection trends in the complete data $\mathrm{log}$. In each of the borehole-pair scans there were several indications of reflections from geologic structure. However, these were shown to be compressional and shear wave reflections from the surface and from a horizontal planar discontinuity approximately 9.6 meters below the surface.

The seismic reflection tests were performed with various orientation of the transducers and with the slot air filled and water filled. In no case were reflections detected with the transducers oriented for maximum compressional wave transmission and reception. When the transducers were oriented parallel to each other and perpendicular to the line between the boreholes, shear wave reflections were received from the water filled target slot. The amplitude of these reflection signals is approximately $13 \mathrm{~dB}$ below the 
level of the shear wave propagating directly between source and receiver modules. This difference in signal amplitude is consistent with the estimated shear wave attenuation, spreading loss and reflection loss caused by the estimated shear wave attenuation, spreading loss and reflection loss caused by the additional eight meter two-way path length from Borehole No. 1 to the slot.

If a direct comparison of the detection results of the two methods is made, the electromagnetic probing method appears to be somewhat superior to the seismic method. These results are based however on a comparison of two systems of different levels of development. The success of the radar is due almost entirely to the directional radiation pattern of the transmitting antenna. If this capability were improved and the transmitter power increased, the radar sensitivity to conducting fluid filled fractures and fracture zones would be greatly enhanced.

If the level of sophistication of the seismic probe were advanced to provide the same degree of signal repeatability and radiation directionality, the seismic method could show a similar fracture detection capability. In highly conductive fluid saturated rock, radar propagation range may be limited whereas seismic propagation would not be affected.

If a single method must be recommended for further development, the radar is the obvious choice. Improvements in the radiation pattern directivity increased transmitter power, improved receiver protection from direct signal feedover, and data acquisition system improvements should receive first attention. 


\section{Bibliography}

1. "Fracture Detection from Well Logs," Suau, J. and J. Gartner, The Log Analyst, March-April 1980.

2. "Identifying Fractures with Conventional We11 Logs," McCoy, R. L., R. M. Kumar, and R. W. Pease, World Oil, December 1980.

3. "An Approach to Evaluating Fractured Reservoirs," Nelson, R. A., Journal of Petroleum Technology, September 1982.

4. "Acoustic Emissions as a Tool for Hydraulic Fracture Location: Experience at the Fenton Hill Hot Dry Rock Site," Albright, J. N. and C. F. Pearson, Society of Petroleum Engineers Journa1, August 1982.

5. "The Geometry of a Large-Scale Nitrogen Gas Hydraulic Fracture Formed in Devonion Shale: An Example of Fracture Mapping with Tiltmeters," Evans, K., G. Holzhausen and D. M. Wood, Society of Petroleum Engineers Journal, October 1982 .

6. "Results from Using the CSAMT Geophysical Technique to Map 0i1 Recovery Processes," Barte1, L. C. and J. R. Wayland, Technical Conference of the Society of Petroleum Engineers of AIME, October 5-7, 1981, San Antonio, Texas.

7. "Controlied-Source Audiomagnetotellurics in Geothermal Exploration," Sandberg, S. K. and G. W. Hohmann, Geophysics, January 1982 .

8. "Geophysica1 Applications in Coal Exploration and Mine Planning: Electromagnetics," Barte1, L. C. and T. L. Dobecki, SME-AIME Annual Meeting, February 14-18, 1982, Dallas, Texas.

9. "Advances in Well Logging," Timur, A., Journal of Petroleum Technology, June 1982 .

10. "Ultrasonic Characteristics of a Rock Mass," McKenzie, C. K., G. P. Stacey and M. T. Gladwin, Int. J. Rock Mech. Min. Sci. \& Geomech. Abstr. 1982 .

11. "Using Compressional and Shear Acoustic Amplitudes for the Location of Fractures," Morris, R. L., D. R. Grine and T. E. Arkfeld, Journal of Petroleum Technology, June 1964.

12. "Fracture Detection by Circumferential Propagation of Acoustic Energy," Setser, G. G., Technical Conference of the Society of Petroleum Engineers of AIME, October 5-7, 1981, San Antonio, Texas. 
Bibliography cont.

13. "Acoustic Modes of Propagation in the Borehole and Their Relationship to Rock Properties," Paillet, F. L. and J. E. White, Geophysics, August 1982 .

14. "Topical Report on Subsurface Fracture Mapping from Geothermal Wellbores," Hartenbaum, B. A. and G. Rawson, U. S. Department of Energy Report DOE/ET/27013-T1, September 1980.

15. "Cross-Borehole Fracture Mapping Using Electromagnetic Geotomography," Ramirez, A. L., F. J. Deadrick, and R. J. Lytle, Lawrence Livermore National Laboratory Report UCRL-53255, May 1982 .

16. "Cross-Hole, Short-Pulse Radar Experiments Using a Transponder," Wright, D. L. and R. D. Watts, International Geoscience and Remote Sensing Symposium, August-September 1983.

17. "Cross-Hole Seismic Surveys: Applications for studying Subsurface Fracture Systems at a Hot Dry Rock Geothermal site", Fehler M. and C. Pearson, Geophysics Vo1. 49, No. 1, January, 1984 . 
Ton Anderson

Drilling Fluid Consultants 17726 S.W. Overlook Ln. Lake Oswego, OR 97034

Ed Bingman

Shell 0il Company

Two Shell Plaza

P.0. Box 2099

Houston, TX 77001

Larry Diamond

Dyna-Drill

P.0. Box C-19576

Irvine, CA 92713

Tom Turner

Phillips Petroleum Company

Geothermal Operations

655 East 4500 South

Salt Lake City, UT 84107

Jim Kingsolver

Geothermal Operations

Simith Tool

P.0. Box C-19511

Irvine, CA 92713

John C. Rowley

Los Alamos National Labs

Mail Stop D-461

Los Alamos, NM 87545

Ed Martin

Superior 0il

Eastern Division

P.0. Box 51108 OCS

Lafayette, LA 70505

B. J. Livesay

2616 Angell Ave.

San Diego, CA 92122

Ben Bradford

Dowell

P.0. Box 2710

Tulsa, OK 74102
Gene Polk

NL Baroid

P.0. Box 280

Sandia Park, NM 87047

James W. Langford

Security Division

Dresser Industries, Inc.

P.0. Box 24647

Dallas, TX 75224

John E. Fontenot

NL, MND

P.0. Box 60070

Houston, TX 77205

Del E. Pyle

Union Geothermal Division

Union cil Co. of California

Union 0il Center

Los Angeles, CA 90017

William D. Rumbaugh

Research \& Development

Otis

P.0. Box 34380

Dallas, TX 75234

Dwight Smith

Halliburton

Drawer 1431

Duncan, OK 73533

Tom Warren

Amoco Production Company

Research Center

P.0. Box 591

Tulsa, OK 74102

H. E. Mallory

P.0. Box 54696

Tulsa, OK 74144

Jim Combs

Geothermal Resources Int'1. Inc. 545 Middlefield Rd., Suite 200 Menlo Park, CA 94025 
Dr. Melvin Friedman

Center for Tectonophysics and Dept. of Geology

Texas A\&M University

College Station, TX 77843

EGGG Instruments

6612 Renee Ave. N.W.

A1buquerque, NM 87109

William (Chris) Allen

Science \& Technology Division Union $0 i 1$

P.0. Box 76

Brea, CA 92621

S.A. Suhler

T.E. Owen

Dept. of Geosciences

Southwest Research Institute

San Antonio, TX 78284

U.S. Department of Energy (3)

Geothermal Hydropower

Technologies Division

Forrestal B1dg., CE 324

1000 Indpendence Ave. S.W.

Washington, D.C. 20585

Attn: J. Bresee
R. Toms
D. Allen

W. P. Grace, DOE/ALO

Nuclear \& Geosciences Division

1540 W.C. Luth

1541 H.C. Hardee

1541 L.C. Bartel

1542 B.M. Butcher

3141 L.J. Erickson (5)

3151 W. L. Garner (3)

2344 J.T. Cordaro

2345 M.W. Callahan

6200 V.L. Dugan

6220 D.G. Schueler

6240 R.K. Traeger

6241 J.R. Ke1sey (10)

.6241 H.T. Chang (10)

6241 F.M. Wolfenbarger

6246 B. Granoff

6247 P.J. Hommert

HU.8. GOVERNMENT PRINTING OFFICE:1084-776-027 I 1287
Mr. Ken Granzow

Dikewood Corporation

1613 University B1vd., N.E.

Albuquerque, NM 87106

Mr. Anthony Veneruso

Gearhart Industries, Inc.

P.O. Box 1936

Fort Worth, TX 76101

Mr. Larry Scott

Mission Research Corporation

1720. Randolph Rd., S.E.

Albuquerque, NM $\mathbf{8 7 1 0 6}$

A. Aduci

U.S. Department of Energy

San Francisco Operations office

1333 Broadway

We11s Fargo Building

Oakland, CA 94612

Rama Rau

Gearhart Industries, Inc.

P. 0. Box 34456

9190 Telephone $\mathrm{Rd}$.

Houston, TX 77034

6250 B.W. Marsha11

6252 H.M. Dodd

6253 J.F. Anderman

6253 D.A. Northrop

6256 D. Engi

6256 C.M. Hart

6256 J.R. Wayland

6257 J.K. Linn

6257 C.A. Sear1s

6300 R.W. Lynch

6320 R.M. Jefferson

6330 W. D. Weart

7110 J.D. P1impton

7116 C.W. Cook

7553 R.L. Parker

7553 G.A. Seely

8214 M.A. Pound 